\title{
Stroke survivors with aphasia and their social participation
}

Citation for published version (APA):

Dalemans, R. J. P. (2010). Stroke survivors with aphasia and their social participation. [Doctoral Thesis, Maastricht University]. Datawyse / Universitaire Pers Maastricht. https://doi.org/10.26481/dis.20100312rd

Document status and date:

Published: 01/01/2010

DOI:

10.26481/dis.20100312rd

Document Version:

Publisher's PDF, also known as Version of record

\section{Please check the document version of this publication:}

- A submitted manuscript is the version of the article upon submission and before peer-review. There can be important differences between the submitted version and the official published version of record.

People interested in the research are advised to contact the author for the final version of the publication, or visit the DOI to the publisher's website.

- The final author version and the galley proof are versions of the publication after peer review.

- The final published version features the final layout of the paper including the volume, issue and page numbers.

Link to publication

\footnotetext{
General rights rights.

- You may freely distribute the URL identifying the publication in the public portal. please follow below link for the End User Agreement:

www.umlib.nl/taverne-license

Take down policy

If you believe that this document breaches copyright please contact us at:

repository@maastrichtuniversity.nl

providing details and we will investigate your claim.
}

Copyright and moral rights for the publications made accessible in the public portal are retained by the authors and/or other copyright owners and it is a condition of accessing publications that users recognise and abide by the legal requirements associated with these

- Users may download and print one copy of any publication from the public portal for the purpose of private study or research.

- You may not further distribute the material or use it for any profit-making activity or commercial gain

If the publication is distributed under the terms of Article $25 \mathrm{fa}$ of the Dutch Copyright Act, indicated by the "Taverne" license above, 
Stroke survivors with aphasia and their social participation 
The publication of this thesis was financially supported by Hogeschool Zuyd, Stichting Afasie Nederland

ISBN 9789052789194

(C) Copyright R.J.P. Dalemans, Maastricht 2010

Cover illustration by Ruth Dalemans

Printing: Datawyse / Universitaire Pers Maastricht 


\title{
Stroke survivors with aphasia and their social participation
}

\author{
DISSERTATION \\ to obtain the degree of Doctor at the Maastricht University, \\ on the authority of the Rector Magnificus Prof. dr. G.P.M.F. Mols, \\ in accordance with the decision of the Board of Deans, \\ to be defended in public on Friday 12 March 2010, at 12.00 hours \\ by
}

Ruth J.P. Dalemans

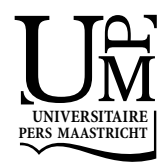




\section{Supervisors}

Prof. dr. Luc P. de Witte

Prof. Wim J.A. van den Heuvel

Prof. dr. Derick T. Wade

\section{Assessment Committee}

Prof. dr. Martien Limburg (chairman)

Dr. Hans van Balkom, Radboud Universiteit Nijmegen

Dr. Caroline van Heugten

Prof. Dr. Erik Manders, Katholieke Universiteit Leuven

Prof. dr. Rob Smeets 


\section{Contents}

Chapter 1: General Introduction ....................................................................

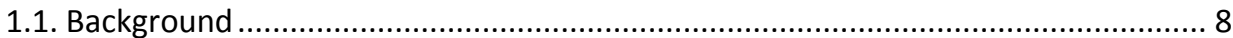

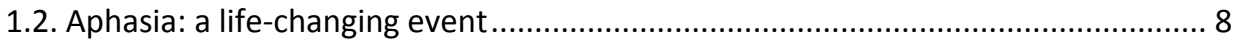

1.3. Aphasia and Social participation: developments in policy and health .................. 10

1.4. Aims of the study and outline of the thesis .................................................. 12

Chapter 2: Social participation in working age people with aphasia:

A review of the literature .......................................................... 17

Chapter 3: Measures for rating social participation in people with aphasia ........ 41

Chapter 4: Psychometric properties of the Community Integration Questionnaire adjusted for people with aphasia............................................... 59

Chapter 5: Social participation through the eyes of people with aphasia ........................................................................................ 73

Chapter 6: Social participation of people with aphasia and related factors ......... 95

Chapter 7: Facilitating the participation of people with aphasia in research ..... 111

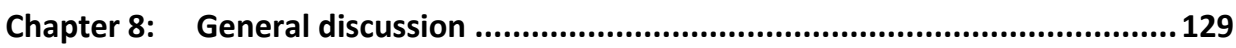

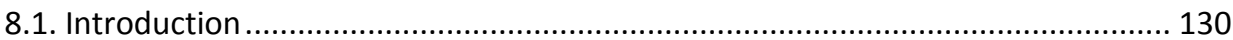

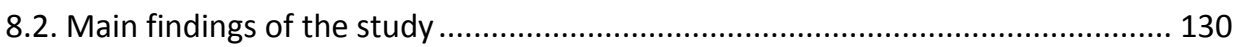

8.3. Social participation in people with aphasia: where do we stand? ...................... 133

8.4. Social participation in people with aphasia: where should we go? ....................... 137

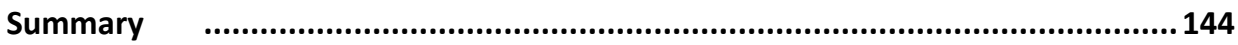

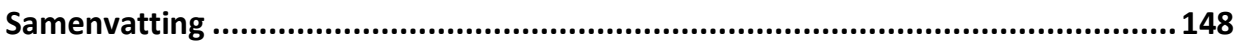

Appendix Community Integration Questionnaire adjusted for people with aphasia ................................................................................... 153

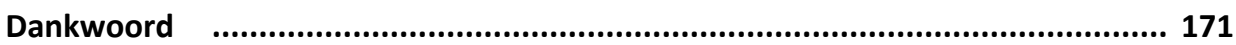

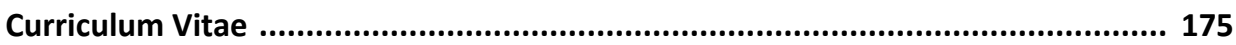



Chapter 1:

General Introduction 


\subsection{Background}

Through communication we connect with the world and give meaning to our lives. We build relationships and social interactions using words, gestures, signs, pictures, and symbols. Language is required in almost every social activity, from talking to your child to giving a presentation for your work, from voting in a club to writing a letter to your lover, from laughing at a joke to understanding an education program, from reading a short message on your telephone to learning from a book. Humans are social animals, dependent upon communication. Aphasia, the loss of language skills and the consequential difficulty in communicating, profoundly affects the lives of people with aphasia and those surrounding them. Aphasia is a neurological disorder caused by damage to the portions of the brain that are responsible for language. Primary signs of the disorder include difficulty in expressing oneself when speaking, trouble understanding speech, and difficulty with reading and writing (1).

The most frequent cause of aphasia is a stroke (2). Stroke is the third most common cause (7.5\%) of DALY's (Disability Adjusted Life Years) in the Netherlands $(3,4)$. Each year, in the Netherlands, 41,000 people suffer a stroke for the first time(5), leading to about 7500 new patients with aphasia each year (6). The number of people with aphasia will increase in the future: stroke incidence doubles with each decade of life after the age of 55. At the same time, emergency response times for stroke are decreasing and acute intervention procedures are improving, resulting in improved survival rates. Furthermore, new medications and maintenance regimens are extending the life span of stroke survivors (7). The proportion of people with aphasia changes during the rehabilitation process. Of patients with acute stroke, approximately $25 \%$ have aphasia $(8,9)$. At 6 months post onset of stroke at least $20 \%$ still have aphasia, evenly divided among severe and mild cases. The change is in part due to recovery from the loss and in part to an increased mortality among those with aphasia.

Aphasia after stroke alters and limits communication (10). Communication is required to interact with the environment and to participate in life. Aphasia therefore may alter social participation and role performance (11). Although the prevalence of aphasia as a consequence of stroke is relatively high, little is known about the social participation of people with aphasia and the factors related to it. This thesis investigates the social participation of people with aphasia and the factors that are related.

\subsection{Aphasia: a life-changing event}

Aphasia is a life-changing event because of its impact on communication abilities. People are confronted with a loss of language, isolating them from their social world, often without the ability to understand the environment and without the ability to express their own thoughts, feelings, and questions about what is happening to them. But many people with aphasia recover and communication abilities change during the process of rehabilitation. A series of distinct phases of recovery emerges and each phase seems to demand a different balance in care (12). 


\section{Aphasia in the acute phase}

In the first days and weeks following a stroke some people may recover their ability to communicate very quickly. For others recovery is a long and winding road with different twists and turns (13).

Improvement from aphasia can initially take place because of changes at the neural level and later because of changes at the behavioral level, whether spontaneous or therapy-induced (14). Decrease of the functional damage usually takes place in the first 1 or 2 months.

The sudden and usually unexpected nature of a stroke usually leads to a wide range of profound physical, social, behavioral, emotional and financial problems. People with aphasia show a great variation of emotional reactions in the acute phase from fear, anger, indifference, sadness, alienation to happiness. Some people with aphasia and their families seek care, others remain alone with their problems $(15,16)$.

The emphasis in care in the acute phase is mostly on diagnosing the aphasia and on providing information to people in the direct environment concerning the stroke and aphasia. However information provision for patients who have suffered a stroke and their families is often insufficient(17). Information currently available is often difficult for patients with aphasia to understand. Traditionally, the primary focus in this stage is focused on repairing impaired language, based on the assumption that linguistic treatment will interact with the neural recovery and reorganization(10). The assumption is unproven(18) and runs the risk of overlooking and undermining the importance of conversational interactions (19).

\section{Aphasia in the rehabilitation phase}

Three months after onset, the clinical picture best corresponds to the anatomical damage. Further recovery takes place in the majority of patients (14). Comprehension is the verbal behavior that usually recovers first and recovers in the largest number of patients.

People with aphasia try to find a way out of their isolation by learning to manage feelings, developing functional one-liners to make it possible to communicate, and organizing things (20).

Clinicians mostly continue to focus on linguistic therapy until a plateau in linguistic functioning is reached. After a linguistic plateau is achieved, treatment becomes more functionally oriented to further improve the patients' communicative skills.

Rehabilitation may assist the natural recovery and facilitate adaptation to the new condition. However, we may be overlooking the patients' needs in terms of their social interaction and communication in the different phases. The relevance of knee-to-knee individual sessions of drills on word retrieval and phonologic precision ("Name the picture. Point to your head. Point to your feet.") may soon be outdated for all but a few process-oriented conditions. International conferences on treatment approaches for aphasia are increasingly imbued with elements of social context and interaction needs of communicators (21). It seems self-evident that a condition that strikes at the very heart of personhood, the ability to communicate, calls for an intervention model that accounts for everything we know about humans: personality, human nature, emo- 
tions, adjustment factors. A bio-psychosocial model with focus on the long term is required (19) to fully understand the consequences of aphasia.

\section{Aphasia in the chronic phase}

A father in a wheelchair may have trouble getting up to his son's graduation in a building because there are stairs, but once he gets in, he can socialize and interact with other parents and teachers. Another father with aphasia may be able to walk up the steps but not be able to communicate with others because of his communication disorder, making it difficult to participate, although he is surrounded by other people. The invisible nature of aphasia makes it difficult to cope with it (19). The effect of aphasia on social participation permeate through all people closely associated with the injury.

Several aspects of living with aphasia remain mysterious: adaptation, accommodation, and adjustment to chronicity. Not all aphasia goes away. Few people with the disability return to premorbid baselines of function or of life participation (22). Living with aphasia is a process of transition and transformation. In the chronic phase, about six months post onset, people with aphasia and their families mostly seek a new focus in life, adapting to the new situation (23). During the early phase following stroke, people with aphasia and their families are involved in the rehabilitation program with professional support. Later, in the chronic phase after discharge, families generally receive no (professional) support and many problems may arise or become more acute, provoking disturbances in this family system (24). How does one accept a radically altered life? How does a family adjust to a life that may be ten times more challenging than life before the stroke? Is it possible to deal with chronicity and a prodigiously changed existence? Is there a precedent for dealing with the illness experience? How does one cope with chronicity? How does one live with aphasia?

Perhaps the greatest toll that aphasia takes on individuals with stroke and their families lies in the area of family relationships and socialization (25). People with aphasia experience social exclusion at infrastructural, interpersonal, and personal levels(26). When people with aphasia return to their homes after a period of rehabilitation, the social consequences of their disorder becomes obvious $(27,28)$.

\subsection{Aphasia and Social participation: developments in policy and health}

In recognition of the significance of the issue of inclusion, governments and accreditation bodies around the world have developed guidelines, mandates and laws to foster equal access for people with disabilities. In the Netherlands, The Ministry of Health, Welfare and Sport encourages people with disabilities to be as independent as possible. The current policy is not to shut chronically ill people away in institutions, but to give them a place in the community. In 2002, the parliament unanimously approved a bill on the equal treatment of disabled and chronically ill people, prohibiting discrimination against them in the field of employment, training and transport. This law, the Equal Treatment on the Grounds of Disability or Chronic Illness Act, came into force in December 2003. This important legislative tool should enable disabled and chronically ill people to legally enforce their equal rights (29). All physical, mental and psychologi- 
cal limitations are covered by this law. Equal treatment in everyday life is the basis for participating in society - but people themselves must actually make this happen (29). The availability of specific collective services for people with aphasia remains a gap (30). Vulnerable citizens with complex disabilities, such as people living with the consequences of a stroke, need to address different services and communities for each specific disability. Successful navigation of the system takes enormous energy, razorsharp advocacy and considerable health literacy(31). For people with aphasia this is very difficult because they cannot negotiate or communicate their specific needs. Further, their needs are often invisible because their impairment is invisible, making it very difficult for the environment to understand and accept their living situation. There are few experienced professionals and comprehensive services available.

A law is not enough to facilitate adaptation in society for people with aphasia. It is important to recognize and understand the consequences of aphasia. Therefore, a good conceptual framework might help to improve communication between researchers, health care professionals and policy makers. The International Classification of Functioning, Disability and Health (ICF) provides a conceptual framework and common language for describing human functioning and disability (World Health Organization, 2001)(32). The ICF provides direction for comprehensive rehabilitation by classifying individual functioning at the levels of (a) body functions and structures and (b) activities and participation. The ICF has moved from being a consequence of disease classification to become a components of health classification. It puts the notions of 'health' and 'disability' in a new light. It acknowledges that every human being can experience a decrement in health and thereby experience some degree of disability (33). Disability is not something that only happens to a minority of humanity. Within this model, functioning and disability ("body functions and structures," "activities," and "participation") are seen as a dynamic interaction between the "health condition" ("disorder/disease"), such as a stroke and his or her contextual factors ("personal factors" and "environmental factors").

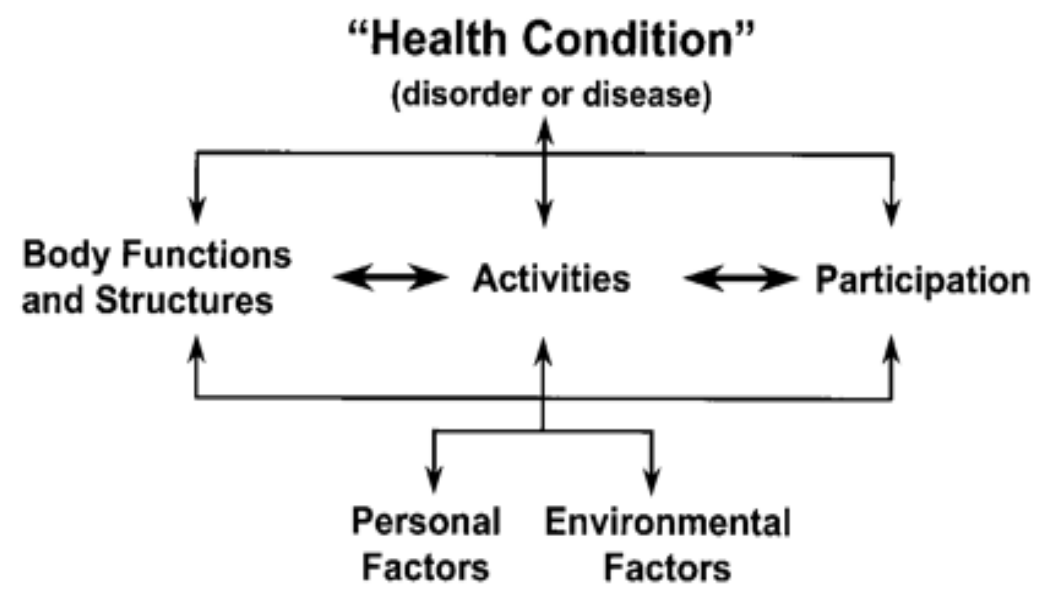

Figure 1: International Classification of Functioning, disability and health (WHO, 2001) 
The International Classification of Functioning, disability and health (ICF) (33) defines participation as involvement in a life situation. It shifts the focus to social life, how people live with their health conditions, and how these health conditions can be improved to achieve a productive, and fulfilling life in the context in which they live. Both personal factors and environmental factors can have an important impact on the participation in life of people with aphasia (34). The ICF has succeeded in expanding the realm of health and health care; social participation and environmental influences are now considered important elements in understanding the consequences of disease (35). However, it remains difficult to capture the important outcomes that focus on the everyday experience of individuals with aphasia and their families (35).

The developments in policy and classification models play a part in changing societal attitudes toward stroke and aphasia, and more broadly, to chronic disease and human potential. The extensive consequences of aphasia transcend the physical aspects of life and that affect the social aspects of life of all involved parties(36). Given the pervasiveness of the social consequences from aphasia, it is surprising that there has been relatively little focus on this issue. It is a challenge to capture and document the real-life meaningful changes in individuals affected by aphasia in order to organise outcome evaluation, and aid in designing advocacy efforts and research regarding the effectiveness of interventions.

This thesis investigates the social participation of people with aphasia and the related personal and environmental factors.

\subsection{Aims of the study and outline of the thesis}

The primary aim of this thesis is to investigate social participation of stroke survivors with aphasia and the related personal and environmental factors. It attempts to answer the following questions:

- What is already known about the social participation of people with aphasia?

- How can we measure social participation in people with aphasia?

- How do people with aphasia perceive their social participation?

- How do people with aphasia participate and which factors are related to their social participation?

We started with a systematic review of the literature concerning the social participation of working age people with aphasia (Chapter two). Communication impairments following stroke impact social interactions and life experience. Knowledge about social participation of people with aphasia is necessary to look beyond body functions and activities into actual performance in life. This study aimed to describe what is known from the literature about social participation in working age people with aphasia after stroke, and to assess the quality of these studies.

We conducted a second systematic review to identify and describe measures of social participation that may be specifically useful when measuring social participation in people with aphasia (Chapter three). This was essential because we wished to measure social integration in a large sample of people with aphasia after stroke. The Community Integration Questionnaire was identified as the most suitable measure for 
our study. The Community Integration Questionnaire (CIQ) was adjusted and tested with 150 people for feasibility in measuring social participation of people with aphasia. Chapter four reports the psychometric properties of the adjusted CIQ for this population (internal consistency, factor analysis, test-retest reliability, and convergent validity).

The Community Integration Questionnaire is a quantitative measure, but little is known about the way people with aphasia actually perceive their social participation and its influencing factors. We explored this through a qualitative study on how stroke survivors with aphasia perceive participation in society and what factors they thought influenced it (Chapter five).

Chapter 6 reports the central part of this investigation, a study of 150 stroke survivors from the Southern Netherlands. We investigated the extent of social participation of people with aphasia and factors associated with the extent of social participation.

An important inclusion in this thesis is the description of strategies and techniques for facilitating the participation of people with aphasia in research (chapter seven). These insights were gained through experience in undertaking research in people with aphasia. This is important because people with aphasia are often excluded from research because researchers assume that it is difficult to measure anything when the question is language based. Thus there is a pattern of recruiting only those individuals who have the competence to express their perspective, or to express verbally with a reflective and clear style (37).

Chapter 8 completes this thesis by discussing the main findings and providing methodological reflections and recommendations for future research and outlining the important clinical implications. 


\section{References}

1. Kirshner HS. Language and Speech Disorders: Aphasia. In: Bradley W, Darof RB, Fenichel GM, Jankovic J, editors. Neurology in Clinical Practice: Principles of Diagnosis and Managment. fourth ed: Butterworth Heinemann; 2004. p. 141-61.

2. Laska AC, Hellblom A, Murray V, Kahan T. Aphasia in acute stroke and relation to outcome. Journal of Internal Medicine. 2001;249:413-22.

3. Hoeymans N, Gommer AM, Poos MJJC. Wat is de ziektelast in Nederland? Gezondheid en ziekte: Sterfte, levensverwachting en DALY's. Bilthoven: RIVM; 2006 [updated 2006 Nationaal Kompas Volksgezondheid, versie 3.18, 25 juni 2009 (C) RIVM, Bilthoven / Disclaimer; cited]; Available from: http://www.nationaalkompas.nl.

4. Yu EH, Lungu C, Kanner RM, Libman RB. The use of diagnostic tests in patients with acute ischemic stroke. Journal of Stroke and Cerebrovasculair diseases. 2009;18(3):178-84.

5. Bots ML, Berger-van Sijl M, Jager-Geurts MH, Bos M, Reitsma JB, Breteler MMB, et al. Incidentie van cerebrovasculaire ziekte in Nederland in 2000. In: Jager-Geurts MH, Peters RJG, van DS, M.L. B, editors. Hart- en vaatziekten in Nederland 2006 Cijfers over leefstijl- en risicofactoren, ziekte en sterfte. Den Haag: Nederlandse Hartstichting; 2006. p. 35-56.

6. Stichting Afasie Nederland. Afasie, feiten en getallen. Arnhem; 2009 [updated 2009; cited]; Available from: http://www.afasie.nl/new/?cat=home.

7. Lingraphica. Aphasia statistics. 2009 [updated 2009; cited]; Available from: http://www.aphasia.com/wordpdf/1.BasicStatistics.pdf.

8. Van Heugten $C$, editor. Revalidatie na een beroerte: richtlijnen en aanbevelingen voor zorgverleners. Den Haag: Nederlandse Hartstichting; 2001.

9. Alexander MP. Medical, Neurologic and functional outcome of stroke survivors. In: Mills VM, Cassidy JW, Katz DI, editors. Neurological rehabilitation: a guide to diagnosis, prognosis and treatment planning: Blackwell Science; 1997. p. p.29-59.

10. Code C. Multifactioral processes in recovery from aphasia: Developing the foundations for a multileveled framework. Brain and Language. 2001;77(1):25-44.

11. Chapey R, Duchan J, F., Elman R, J., Garcia L, J., Kagan A, Lyon J, et al. Life Participation Approach for people with Aphasia: A Statement of Values for the Future. American Speech-Language-Hearing Association; 2009 [updated 2009 2009; cited 1997]; Available from.

12. Penn C. Content, culture and conversation. In: Duchan JF, Byng S, editors. Challenging Aphasia Therapies: Broadening the discourse and extending the boundaries: Psychology Press; 2004. p. 83-101.

13. Parr S, Pound C, Byng S, Moss B, editors. The Stroke and Aphasia handbook. London: Connect; 2004.

14. Basso A. Aphasia and its therapy. Oxford University Press; 2003.

15. Ghika-Schmid F, van Melle G, Guex P, Bogousslavsky J. Subjective experience and behavior in acute stroke:The Lausanne Emotion in Acute Stroke Study Neurology. 1999;52(22).

16. Nystrom M. Aphasia - an existential loneliness: A study on the loss of the world of symbols International Journal of Qualitative Studies on Health and Well-Being. 2006;1(1):38-49.

17. Mason I. Developing and implementing aphasia-friendly stroke information for patients, families and carers. Nursing Times. 2006;102(47):32-3.

18. Greener J, Enderby P, Whurr R. Speech and language therapy for aphasia following stroke. Cochrane Database of Systematic Reviews 1999;4.

19. Taylor Sarno M. Aphasia Therapies: Historical perspectives and moral imperatives. In: Duchan JF, Byng S, editors. Challenging Aphasia Therapies: Broadening the discourse adn extending the boundaries: Psychology Press; 2004. p. 19-32.

20. Worrall LE, Frattali C. Neurogenic Communication Disorders: A functional approach. New York-Stuttgart: Thieme; 2000.

21. La Pointe L. Functional and pragmatic directions in aphasia treatment. . In: de Bleser R, Papathanasiou I, editors. The sciences of aphasia (Volume 1): From theory to therapy. Oxford: Elsevier Science Ltd.; 2002.

22. La Pointe LL. The sociology of aphasia. Journal of Medical Speech-Language Pathology. 2002;March. 
23. Paemeleire F, Vercruysse L. Leven met afasie. Gent; [cited 2008]; Available from: www.levenmetafasie.be.

24. Santos ME, Farrajota ML, Caldas AC, Sousa LD. Problems of patients with chronic aphasia: different perspectives of husbands and wives? Brain Injury. 1999;13(1):23-9.

25. Glueckauf RL, Blonder LX, Ecklund-Johnson E, Maher L, Crosson B, Gonzalez-Rothi L. Functional Outcome Questionnaire for Aphasia: overview and preliminary psychometric evaluation. NeuroRehabilitation. 2003;18(4):281-90.

26. Parr S. Living with severe aphasia: tracking social exclusion. Aphasiology. 2007;21(198-123).

27. Kagan A, LeBlanc K. Motivating for infrastrucuture change: Toward a communicatively accesible, participation based stroke care system for all those affected by aphasia. Journal of Communication Disorders. 2002;35(2):153-69.

28. Howe TJ, Worrall LE, Hickson LMH. What is an aphasia-friendly environment. Aphasiology. 2004;18(11):1015-37.

29. Ministerie van Volksgezondheid Welzijn en Sport. Equal treatment in practice: vision and measures for people with disabilities, make it happen! In: Ministry of Health WaS, editor.; 2004. p. 16.

30. Heijmans AT. Reactie Concept plan van aanpak Pakketmaatregel AWBZ. Tilburg: WMo adviesraad Tilburg; 2009.

31. Kailes Jl. A User's Perspective on Midlife (Age 18 to 65) Aging with Disability. In: Medicine lo, editor. Workshop on Disability in America: A new look: summary and background papers. Washington: The National Academie Press; 2006. p. 194-204.

32. WHO. ICF international homepage. 2001 [updated 2001; cited]; Available from: http://www.who.int/classifications/icf/site/icftemplate.cfm?myurl=introduction.html\%20\&mytitle=Introduction.

33. Howe TJ, Worrall LE, Hickson LMH. What is an aphasia - friendly environment? Aphasiology. 2004;18(11):1015-37.

34. Simmons-Mackie N, Damico JS. Acces and social inclusion in aphasia: interactional principles and applications. Aphasiology. 2007;21(1):81-97.

35. Paterson B, Scott-Findlay S. Criticial issues in interviewing people with traumatic brain injury. Qualitative Health Research. 2002;12:399-409. 



\section{Chapter 2:}

\section{Social participation in working age people with aphasia: A review of the literature}

Based upon:

Dalemans RJP, de Witte L, van den Heuvel W, Wade D. A description of social participation in working age people with aphasia: a review of the literature. Aphasiology 2008;22(10):1071-1091. 
Social participation in working age people with aphasia: a review of the literature

Background: Communication impairments following stroke impact upon social interactions and life experience. To look beyond body functions and activities into actual performance in life, knowledge about participation of working age persons with aphasia is necessary.

Aims: To describe what is known in the literature about participation in working age persons with aphasia after stroke and to assess the quality of these studies, a systematic literature search was performed for the period 1960-2005 in Pubmed, CINAHL, Psychinfo and Cochrane. The journal Stroke (1970-2005) was searched by hand as well as the online content of the journal Aphasiology (1999-2005). Search terms were derived from the International Classification of Functioning, Disability and Health (ICF). Aspects of domestic life, interpersonal interactions and relationships, education and employment, and community, civic and social life were included. Three investigators assessed the relevance of the identified studies using selection criteria.

Main contribution: From 1592 hits, 18 articles were analysed. Comparison between studies was very difficult, due to a lack of consistency in the conceptual framework used in the studies, small sample sizes and a large variety in instruments. However, this review reveals a decrease in domestic life. Interpersonal interactions and relationships changed after aphasia onset with shifts in contacts from friends to professionals, shifts in roles as partner, family member, parent, friend, citizen. A decrease in employment activities is reported and return to work is often to a less demanding level. No studies were found describing community, civic and social life.

Conclusion: Participation in different aspects of life is diminished in persons with aphasia. However, knowledge about this is scattered and fragmented. Many researchers did not clearly define the concept of participation. Data should be interpreted with extreme caution and no firm conclusions can be made. There is a need for further research in this area, specifically clarifying the concepts used. 


\section{Introduction}

Stroke is one of the most common causes of long-term disability. About one-third of patients with stroke have aphasia $(1,2)$. Stroke is mostly seen as a condition of the elderly (3). However, 20 to $25 \%$ of this patient population is below the age of 65 (4-6). Although relatively small in numbers, these younger clients experience potentially significant implications on their lives. Aphasia brings profound negative motivational, behavioural, social and emotional changes (7). People with aphasia in the age between 20 and 65 years face an enormous challenge to regain a meaningful level of participation in society, to fulfil their roles as parent, partner, colleague or club member (8-10). This in contrast with relatively old fellow patients, for whom the challenge of living with aphasia as a consequence of their stroke is of a partly different nature; work is no longer an issue, children are mostly no longer living with them and social relationships are different. Since stroke in working age people is relatively infrequent, there is not much evidence in the literature to help health care professionals make decisions on prognoses.

Very little attention has been paid to the evaluation of long-term prognosis, functional outcome and aspects of participation that specifically concern young patients (8). Further, people with aphasia are often not included or not described as a separate group in studies investigating aspects of participation in people with stroke.

Although the Life Participation Approach (11) encourages clinicians and researchers to focus on the real-life goals of people affected by aphasia, there is still little evidence about the way in which people with aphasia participate in life. Perhaps even less is known about the younger age group, confronted with different problems from senior individuals with aphasia. Information about the participation of this younger age group is necessary in order to adjust care to their specific needs and facilitate their chances for social and occupational reintegration.

Social and occupational reintegration of individuals with health condition is a declared primary goal of the World Health Organization. The International Classification of Functioning, Disability and Health (ICF) (12) defines participation as involvement in a life situation. The ICF shifts focus to social life, how people live with their health conditions and how these health conditions can be improved to achieve a productive, fulfilling life in the context in which they live. Both personal factors (demographic, socio cultural, education, labour, income, accommodation, address) as well as environmental factors (the physical, social and attitudinal environment in which people live and conduct their lives) can have an important impact on the participation in life of people with aphasia (13).

The major emphasis in existing aphasia literature is primarily on the linguistic and associated aspects. Justifiable attention is paid to the process of maximising progress and minimising impairments in the early months after onset, but efforts could also be devoted to supporting people in the process of learning to understand and live with their aphasia (14). It is important to get insight into the way working age persons with aphasia participate. This information could be useful to adjust rehabilitation in a way that is meaningful to this population.

The goal of this study was to present a review of the literature concerning social participation of working age persons with aphasia after stroke (20-65 years). 
The following definition of participation is used in this study: Participation is the performance of people in actual activities in social life domains through interaction with others in the context in which they live. Four social life domains are included, namely; 1) domestic life; 2 ) interpersonal life (including formal relationships as well as informal social relationships, family relationships and intimate relationships); 3) education (informal, vocational training and higher education) and employment (renumerative and non-renumerative, excluding domestic work); 4) community, civic and social life, including religion, politics, recreation and leisure (hobbies, socializing, sports, arts and culture).

\section{Methods}

\section{Search strategy:}

Publications were searched in Medline (Pubmed) (1960-2005), CINAHL (1960-2005) and Psychinfo (1953-2005) databases. In addition, both the journal Stroke (1970-2005) and the online content of the journal Aphasiology (1999-2005) was searched by hand. The electronic databases were searched from the beginning date of the source until the end of 2005, explaining the different starting dates of the literature search in the different databases. The journal Aphasiology is also abstracted in CINAHL and Psychinfo, so publications before 1999 were also found through these sources. In all search strategies the terms 'stroke' and 'cerebrovascular accident' were combined with the terms 'aphasia' and 'dysphasia' and their medical subheadings. The search was on title and/or abstract using the limits 'adults` and 'English'.

\section{Procedure:}

Three investigators blind to each other, performed the search and assessed the relevance of the selected studies by using a three-point scale ( $0=$ irrelevant; $1=$ possibly relevant; 2 = relevant) in the first two phases. The scores of the three investigators were summed; references with a total score below three were discarded as irrelevant. The references were scored in 3 phases, followed by an assessment of the quality of the selected studies:

In phase one articles were selected on title. Articles meeting the following criteria were included: published in the period 1960-2005; written in English; the concepts aphasia, dysphasia and/or stroke are used in the title; aspects of social participation (domestic life, interpersonal relations, education (cognition, knowledge), employment, leisure activities, community life) and/or quality of life and/or (long term) outcome and/or well-being and/or self-esteem (self-concept) are mentioned in the title.

Articles were excluded when only the acute phase was described. To include only original publications of research, editorial comments, dissertations and book chapters were excluded.

In order to determine whether authors of selected articles published other relevant articles, their publications were searched and screened on title. Other articles were gathered through conversations with experts.

During phase two, the choice of articles was done using the abstract rather than the title alone. Articles meeting the following criteria were included: the concepts aphasia, dysphasia and/or stroke are used in the abstract; aspects of social participation and/or 
quality of life are described in the abstract; sample includes also people below 65 year; the publication is a review, quantitative or qualitative research or case report.

Articles were excluded when only the acute phase was described, when functional outcomes without aspects of participation were administered or when the methodology was not reported or unclear.

In phase three, one investigator scored the full text articles. Articles were excluded if the sample of the qualitative research included less then 6 persons (to exclude single case-reports) with aphasia between 20-65 y of age; the sample of the quantitative research included less then $10 \%$ persons with aphasia; the group of aphasia was not separately outlined in the population characteristics; the methodology was not described; the used measurement instruments were not mentioned; the statistical analysis or qualitative analysis was not described; the aim of the study included no aspects of social participation as defined and the aspects of social participation were not separately described as outcome; if the results are not mentioned separately for the aphasia group. Because the concepts functional outcome (=secondary activities of daily living), quality of life and participation are often intertwined, articles that described functional outcomes, quality of life as well as aspects of participation were included. Articles describing quality of life that used instruments to measure quality of life and well-being were excluded as well as articles describing feelings instead of performance. Also articles that described quality of life and used instruments that measure aspects of social participation, but who only described those results in relation to quality of life, were excluded. Articles describing participation in persons with aphasia, who had a mean age above the age of 65, were excluded. Articles not describing the persons with aphasia separately in the sample and result section were excluded. Articles only reporting the spouses' perception of persons with aphasia were excluded, just like articles concerning the adjustment or needs of the spouse.

\section{Assessment of the quality of the selected studies:}

Since few of the studies respond to the criteria used in the Cochrane database (for example: no RCT) two criteria lists (separate lists for the quantitative studies and the qualitative studies) were developed in order to assess the quality of the selected studies. The list for quantitative studies was based upon different criteria lists for nonrandomized studies $(15,16)$. It consists of 15 items, describing aspects of informativity $(6$ items), external validity (4 items) and internal validity (5 items) (see appendix 1 ). The list for qualitative studies was based upon two articles describing the quality and standards for qualitative research $(17,18)$. The list (see appendix 2 ) consists of 14 items, describing aspects of informativity (6 items) and reliability/validity ( 8 items).

\section{Data analysis:}

Studies were categorized as a quantitative study, a qualitative study or a review. The reviews were used to find original papers but were not included in the analyses. The data in the articles were transferred into a database. Prepared forms were used to analyse the quality of the selected studies. Other forms were used to describe the participants, the methods used, the concepts used and the outcomes of the different studies in relation to the social life domain. Because of the different characteristics of the data, the quantitative and qualitative studies were analysed separately. 


\section{Results}

The search for publications resulted in 1592 hits, of which 93 articles were selected in phase 1 (see figure 1). Four of those were reviews: one about employment (19), one about quality of life (20), one about sexual changes (21) and a fourth review was found in which different domains of participation were reviewed with regard to an aphasiafriendly environment (13).

Figure 1: Search results databases

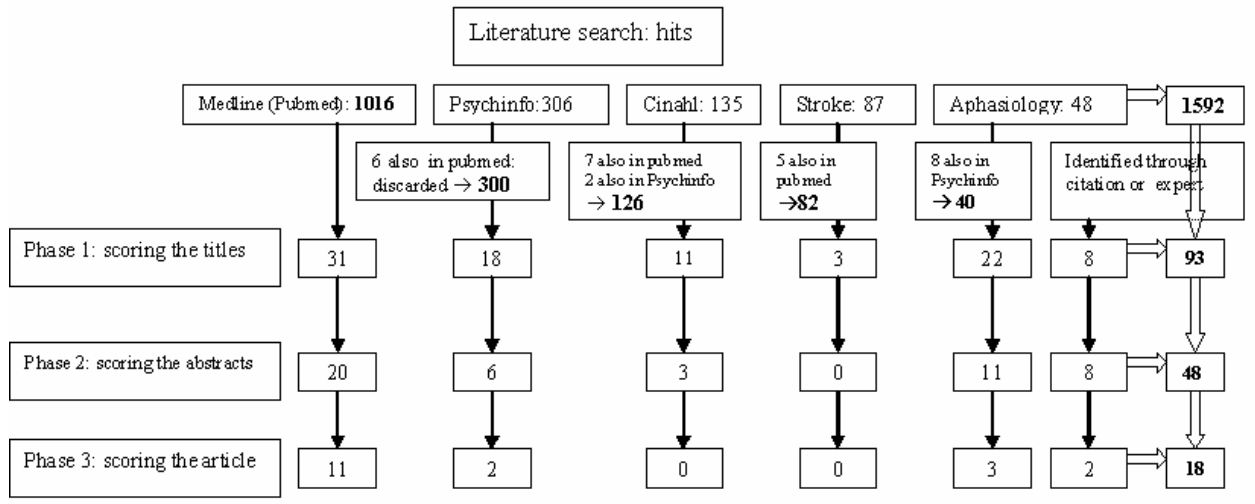

The end result across databases and phases yielded 18 publications (12 quantitative studies and 6 qualitative studies) to be included in our study. The total score (maximum score $=15$ ) on the quality assessment of the quantitative studies ranged from 5 to 13 (see table 1). The lowest scores were on the aspects measuring internal validity: 3 out of 12 studies made use of a comparison group. 
Table 1: Quality assessment of the selected quantitative studies (ranked from higher quality to lower quality on the assessment, in order of year)

\begin{tabular}{|c|c|c|c|c|c|c|c|c|c|c|c|c|c|c|c|c|c|c|c|}
\hline \multirow[t]{2}{*}{ Study } & \multicolumn{6}{|c|}{ Informativity } & \multirow[t]{2}{*}{$\begin{array}{l}\text { Sub } \\
\text { total }\end{array}$} & \multicolumn{4}{|c|}{$\begin{array}{l}\text { External } \\
\text { validity }\end{array}$} & \multirow[t]{2}{*}{$\begin{array}{l}\text { Sub } \\
\text { total }\end{array}$} & \multicolumn{5}{|c|}{$\begin{array}{c}\text { Internal } \\
\text { validity }\end{array}$} & \multirow[t]{2}{*}{$\begin{array}{l}\text { Sub } \\
\text { total }\end{array}$} & \multirow[t]{2}{*}{ Total* } \\
\hline & $a$ & $b$ & $c$ & $d$ & $e$ & $f$ & & $g$ & $h$ & $i$ & $j$ & & $k$ & $I$ & $m$ & $n$ & 0 & & \\
\hline $\begin{array}{l}\text { Smith, } \\
1985\end{array}$ & + & + & + & + & + & + & 6 & + & + & + & + & 4 & + & - & + & + & - & 3 & 13 \\
\hline $\begin{array}{l}\text { Hilari et } \\
\text { al., } 2003\end{array}$ & + & + & + & + & + & + & 6 & - & + & + & + & 3 & + & - & + & + & - & 3 & 12 \\
\hline $\begin{array}{l}\text { Santos } \\
\text { et al., } \\
1999\end{array}$ & + & + & + & + & + & + & 6 & - & - & + & + & 2 & + & + & + & - & - & 3 & 11 \\
\hline $\begin{array}{l}\text { Hinckley } \\
\& \\
\text { Packard, } \\
2001\end{array}$ & + & + & + & - & + & + & 5 & - & + & - & + & 2 & + & + & + & + & - & 4 & 11 \\
\hline $\begin{array}{l}\text { Lemieux } \\
\text { et al., } \\
2002\end{array}$ & + & + & + & + & + & + & 6 & - & + & + & + & 3 & + & - & + & - & - & 2 & 11 \\
\hline $\begin{array}{l}\text { Hinckley, } \\
2002\end{array}$ & + & + & + & + & - & + & 5 & - & + & + & + & 3 & + & - & + & + & - & 3 & 11 \\
\hline $\begin{array}{l}\text { Wade et } \\
\text { al., } 1986\end{array}$ & - & + & + & - & + & + & 4 & + & + & - & + & 3 & + & - & + & + & - & 3 & 10 \\
\hline $\begin{array}{l}\text { Black- } \\
\text { Schaffer } \\
\text { \& Os- } \\
\text { berg, } \\
1990\end{array}$ & - & + & - & + & + & + & 4 & - & + & + & + & 3 & + & - & + & + & - & 3 & 10 \\
\hline $\begin{array}{l}\text { Caporali } \\
\& \text { Basso, } \\
2003 \\
\end{array}$ & + & + & - & + & + & + & 5 & - & + & + & + & 3 & + & - & + & - & - & 2 & 10 \\
\hline $\begin{array}{l}\text { Taylor- } \\
\text { Sarno, } \\
1992\end{array}$ & + & + & + & + & - & + & 5 & - & + & + & - & 2 & + & - & - & - & - & 1 & 8 \\
\hline $\begin{array}{l}\text { Hinckley, } \\
1998\end{array}$ & - & + & + & - & - & - & 2 & - & + & + & + & 3 & + & - & - & - & - & 1 & 6 \\
\hline $\begin{array}{l}\text { Salonen, } \\
1995\end{array}$ & + & - & - & - & - & + & 2 & - & + & - & + & 2 & + & - & - & - & - & 1 & 5 \\
\hline
\end{tabular}

*Max.score $=15$ 
The total score (maximum score $=14$ ) on quality assessment of the qualitative studies ranged from 4 to12. There was no study found that met the criterion on attention to negative cases and only one study that met the criterion on reflexivity (see table 2).

Table 2: quality assessment of the selected qualitative studies (ranked from higher quality to lower quality on the assessment, in order of year)

\begin{tabular}{|c|c|c|c|c|c|c|c|c|c|c|c|c|c|c|c|c|c|}
\hline \multirow[t]{2}{*}{ Study } & \multicolumn{5}{|c|}{ Informativity } & \multirow[t]{2}{*}{ Subtotal } & \multicolumn{8}{|c|}{ Reliability/Validity } & & \multirow[t]{2}{*}{ Subtotal } & \multirow[t]{2}{*}{ *Total } \\
\hline & $a b$ & $c$ & $d$ & $e$ & $f$ & & $g$ & $h$ & $i$ & $j$ & $k$ & I & $n$ & 1 & & & \\
\hline $\begin{array}{l}\text { Le Dorze } \\
\& \text { Bras- } \\
\text { sard, } \\
1995\end{array}$ & ++ & + & + & + & + & 6 & + & + & + & + & - & + & + & . & & 6 & 12 \\
\hline
\end{tabular}

\begin{tabular}{|c|c|c|c|c|c|c|c|c|c|c|c|c|c|c|c|c|c|}
\hline Parr, 2001 & + & + & + & + & + & + & 6 & + & + & - & + & - & - & + & - & 4 & 10 \\
\hline $\begin{array}{l}\text { Garcia et } \\
\text { al., } 2000\end{array}$ & + & + & + & + & + & + & 6 & + & + & - & + & - & - & + & - & 3 & 9 \\
\hline $\begin{array}{l}\text { Elman \& } \\
\text { Bernstein- } \\
\text { Ellis, } 1999\end{array}$ & + & + & - & $?$ & + & + & 4 & + & - & + & - & - & - & - & 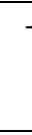 & 2 & 6 \\
\hline $\begin{array}{l}\text { Carriero } \\
\text { et al., } \\
1987 \\
\text { (case } \\
\text { report, } 10 \\
\text { cases) }\end{array}$ & + & - & + & + & - & - & 3 & - & - & - & - & - & - & + & & 1 & 4 \\
\hline $\begin{array}{l}\text { Shadden } \\
\text { \& Agan, } \\
2004 \\
\text { (case } \\
\text { report, } 2 \\
\text { cases) }\end{array}$ & + & - & + & - & + & - & 3 & - & - & - & - & - & - & - & & 1 & 4 \\
\hline
\end{tabular}

*Maximum score $=14$ ? = doubtful

The following aspects of the selected articles are described in table 3: authors and publication year of the study, social life domain studied, design, country in which the study is conducted, sample selection, mean age and range of the research population and sample size. The first study meeting the selection criteria was published in 1985.

There are 12 quantitative studies selected and 6 qualitative studies, including two case reports. Nine articles describe aspects of domestic life, 13 articles describe aspects of interpersonal interactions and relationships, 12 articles report on education and employment and only three articles on community, civic and social life. Three studies compare outcomes of persons with aphasia with those of relatives or friends (22-24). One study compares a younger age group with an older (>44 y) age group (25) and one study compares a group in treatment and a non-treatment group (26). 


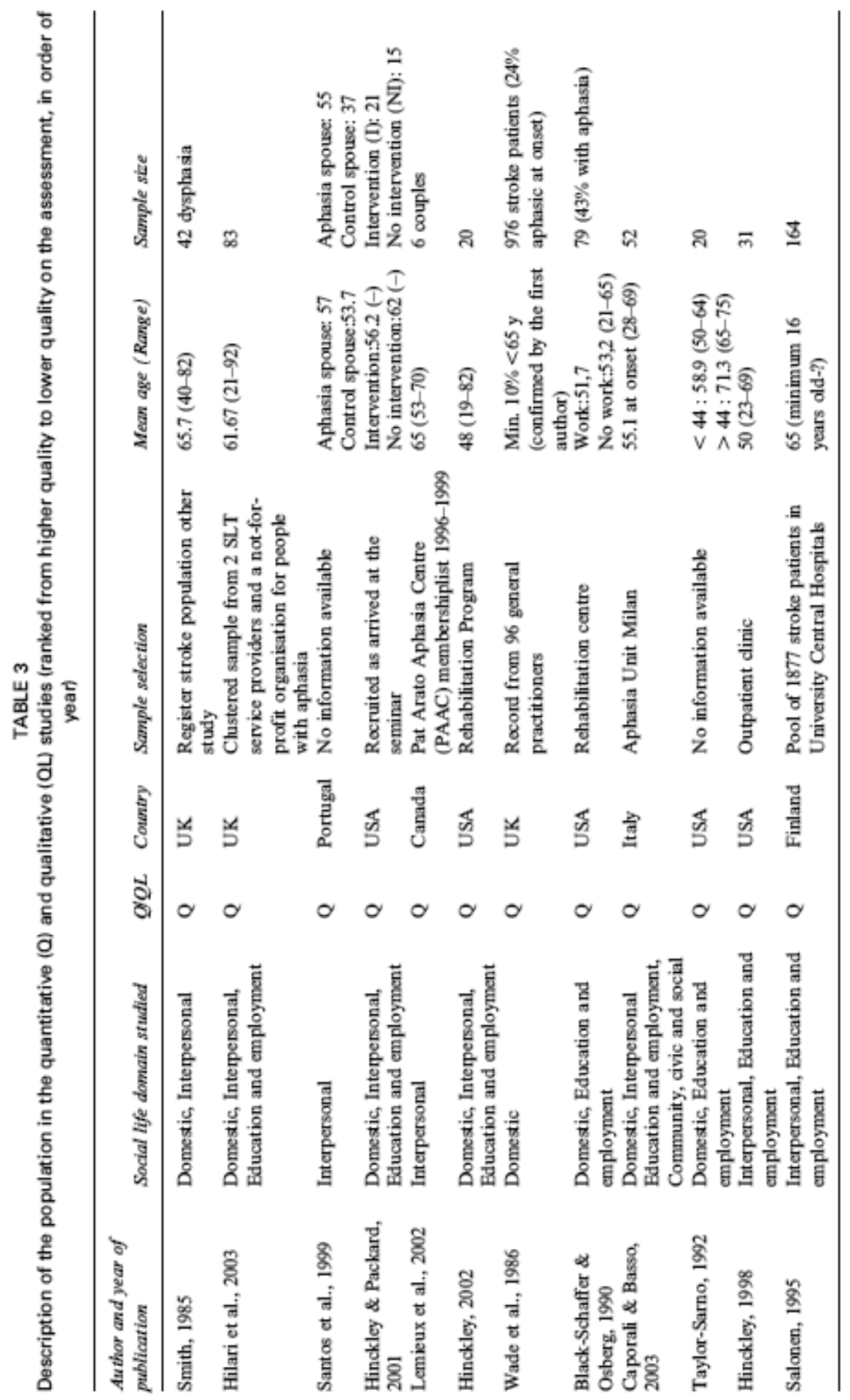




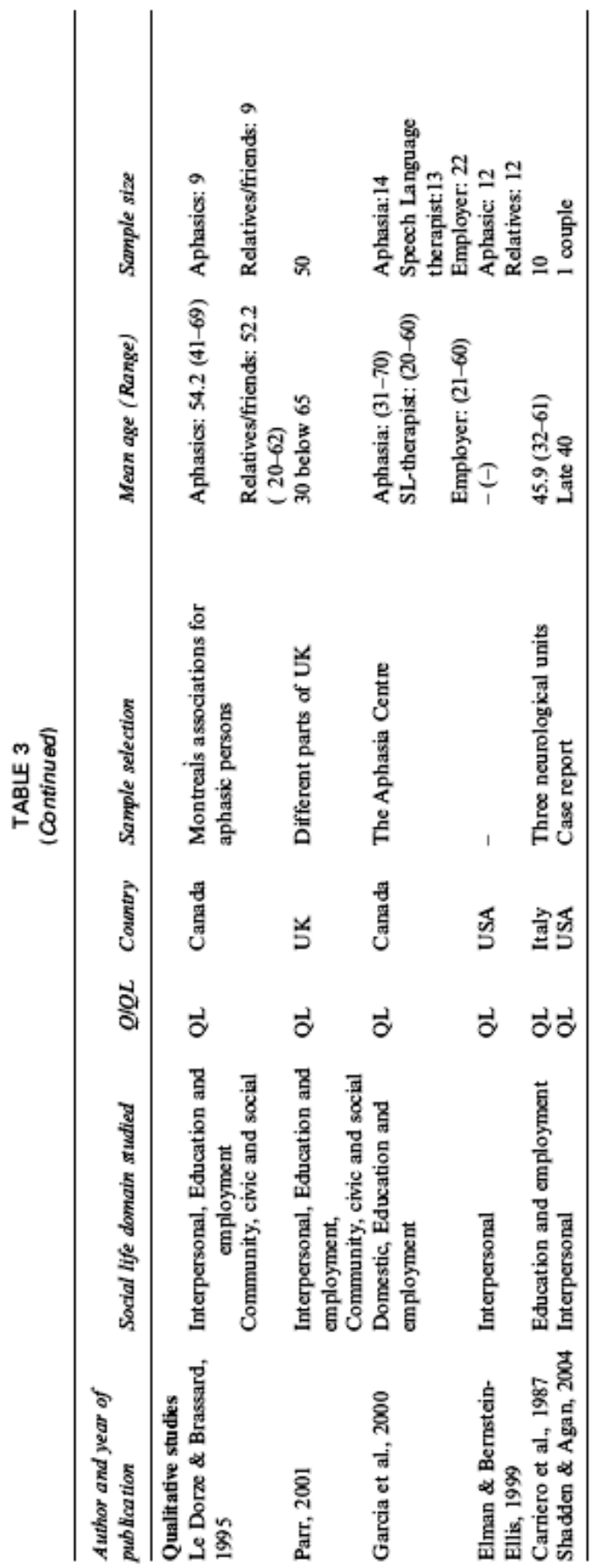


Major findings

Domestic life

In table 4 the nine studies (8 quantitative studies and one qualitative study) reporting aspects of domestic life are described. In the studies included in this review, domestic life is conceptualised as social activities, including shopping, homemaking and other secondary activities of daily living.

Studies, describing aspects of domestic life that met the selection criteria, were published over the period 1985-2003. Many instruments were used to assess function, including existing measurement instruments as well as self made questionnaires. The Frenchay Activities Index (27) (28) was used in three studies (26, 29, 30). This scale comprises 15 individual activities summed to give an overall score from 0 to 45 (high) on social activities. The scores on the FAl in the different studies varied, but in no study, a high score on the FAI was found. The Community Integration Questionnaire (CIQ) (31) was used in two studies $(30,32)$. The CIQ contains three subscales. The Home Integration (max. score $=10$ ), Social Integration (max. score $=12$ ) and the Productivity Scale (max. score =7). The subscale 'Home Integration' measures the performance frequency of activities such as housekeeping, paying bills and shopping. A higher total score is associated with higher independence.

In the studies with the highest evidence $(29,30,33)$, a decrease in domestic activities was reported. In the different studies, low scores on the FAI and The CIQ were reported, indicating a decrease in household activities in people with aphasia. Further, studies that made use of self made questionnaires reported a decrease in participation in domestic life as well.

Interpersonal life

Interpersonal life within the social life domain includes formal relationships as well as informal relationships (friends), family relationships and intimate relationships (sexual relationships and the relation with the spouse). Table 5 outlines the identified studies ranked in order of the quality assessment and year.

With regard to interpersonal relations, 13 studies were found. Nine studies had a quantitative study design $(24,26,30,32-36)$. Three studies had a qualitative study design $(9,22,23,37)$ and one case-report was included $(7,38)$. The studies were equally spread over the period 1985-2004. Studies made either use of self-made questionnaires (33-36), the Family Assessment Device (26), the CIQ $(26,32)$ or the Social Support Survey (30). Concepts concerning interpersonal interactions and relationships were defined differently, vaguely or not at all in the range of studies.

Interpersonal interactions and relations were altered in persons with aphasia and individuals in their immediate environment, according to the publications with the highest evidence. There was a shift from contacts with friends and family to contacts with professionals, even many months post onset (28). The remaining contacts with friends and family changed with feelings of frustration, friction, misunderstanding, sadness, loneliness, experience of being an outsider, loss of control and loss of authority $(9,23,24,37)$. Two studies, with moderate to weak evidence noted a decrease in social contacts $(34,35)$, with difficulties in coping with the change in life (35). Sexuality was described in two articles, $(24,37)$, and both reported a decrease in sexual activity. 
Hinckley (2002) and Hinckley and Packard (2001) reported positive changes in interpersonal interactions after following an intensive treatment program. Also, Elman and Ellis (1999) and Shadden and Agan (2004) described positive changes in interpersonal interactions after group treatment. Persons with aphasia were more social, independent and, likely to help other persons.

\section{Education and employment}

In this study, education consists of informal, vocational training and higher education and employment consists of renumerative and non-renumerative employment, excluding domestic work.

The social life domain education and employment was described in eight quantitative and four qualitative studies (see table 6). The selected studies were published over the period 1987-2003. In six quantitative studies self-made questionnaires were used $(26,32,34,35,39)$. The CIQ was used in two quantitative studies $(26,32)$. Operationalisations used in the studies were full-time employment, part-time employment, university studies, vocational training, voluntary work. In two studies employment was not defined at all.

Of the twelve studies included, ten focused exclusively on persons with aphasia. Four studies conducted a study focussing on regaining employment $(34,39-41)$. Three articles that described different domains of participation also described aspects of employment $(9,23,35)$. Two articles described employment in a treatment intervention study $(26,32)$. Three articles that reported outcomes concerning quality of life, presented data about employment as well $(25,30,36)$.

In all the quantitative and qualitative studies, a decrease in employment was reported. Return to work is often characterised by reduced hours, return to another job or return to the same job with modifications. Often there was no return at all (see table 6).

Community, civic and social life

The community, civic and social life domains include recreation and leisure activities (hobbies, socializing, sports, arts and culture). No article was found describing leisure activities as an important part of the study. Data related to leisure activities were gathered in four studies (two quantitative studies and two qualitative studies) which focused on other domains of participation $(9,23,32,34,35)$ (see table 7). The instruments used in these studies were self-made questionnaires, with exception of the study of Hinckley (2002) who made use of the Community Integration Questionnaire.

A decrease in leisure activities was reported in all four studies (Caporali and Basso, 2003; Hinckley, 2002; Le Dorze and Brassard, 1995; Parr, 2001). No study described the participation of persons with aphasia in organized religion, or in citizenship. 


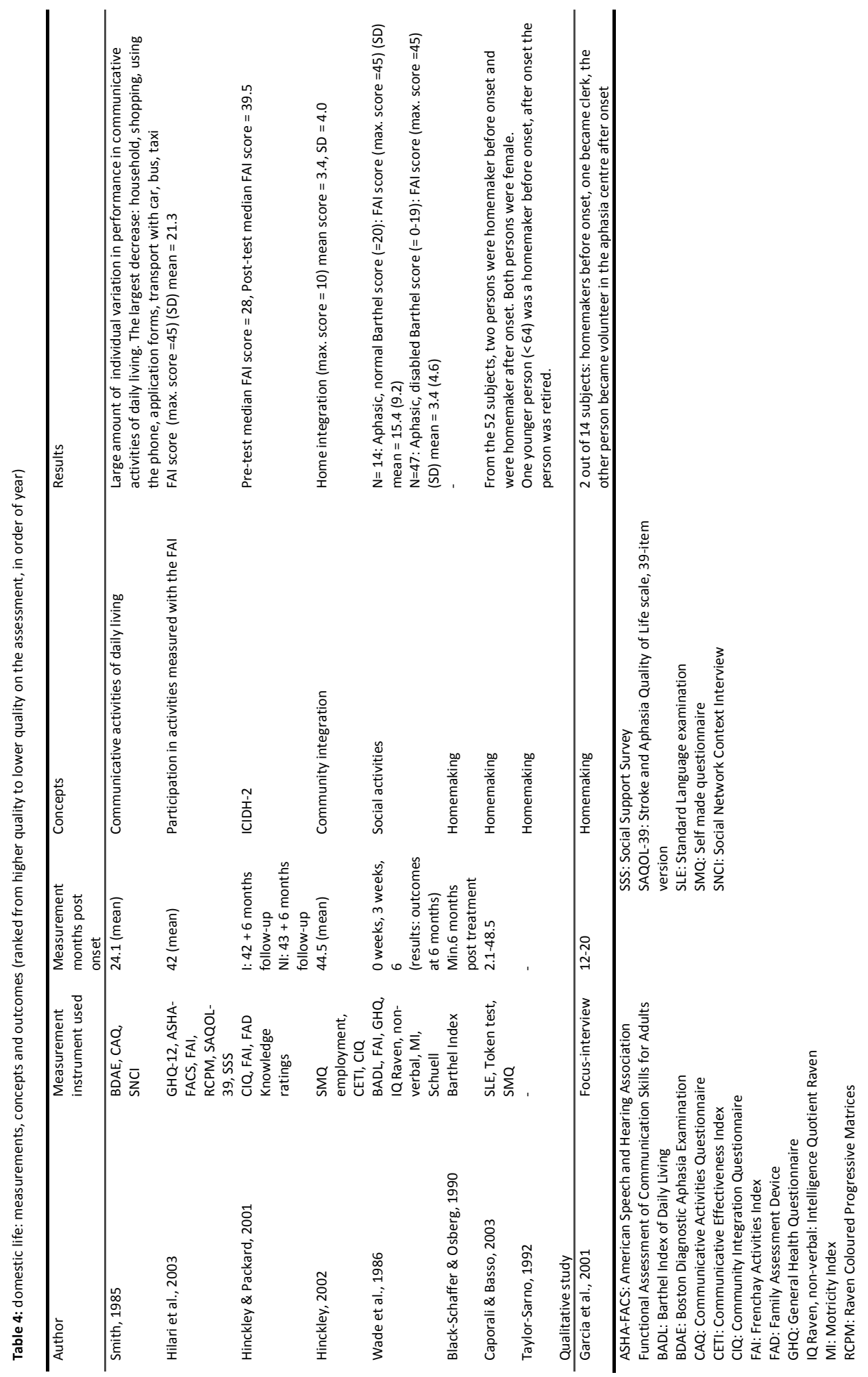




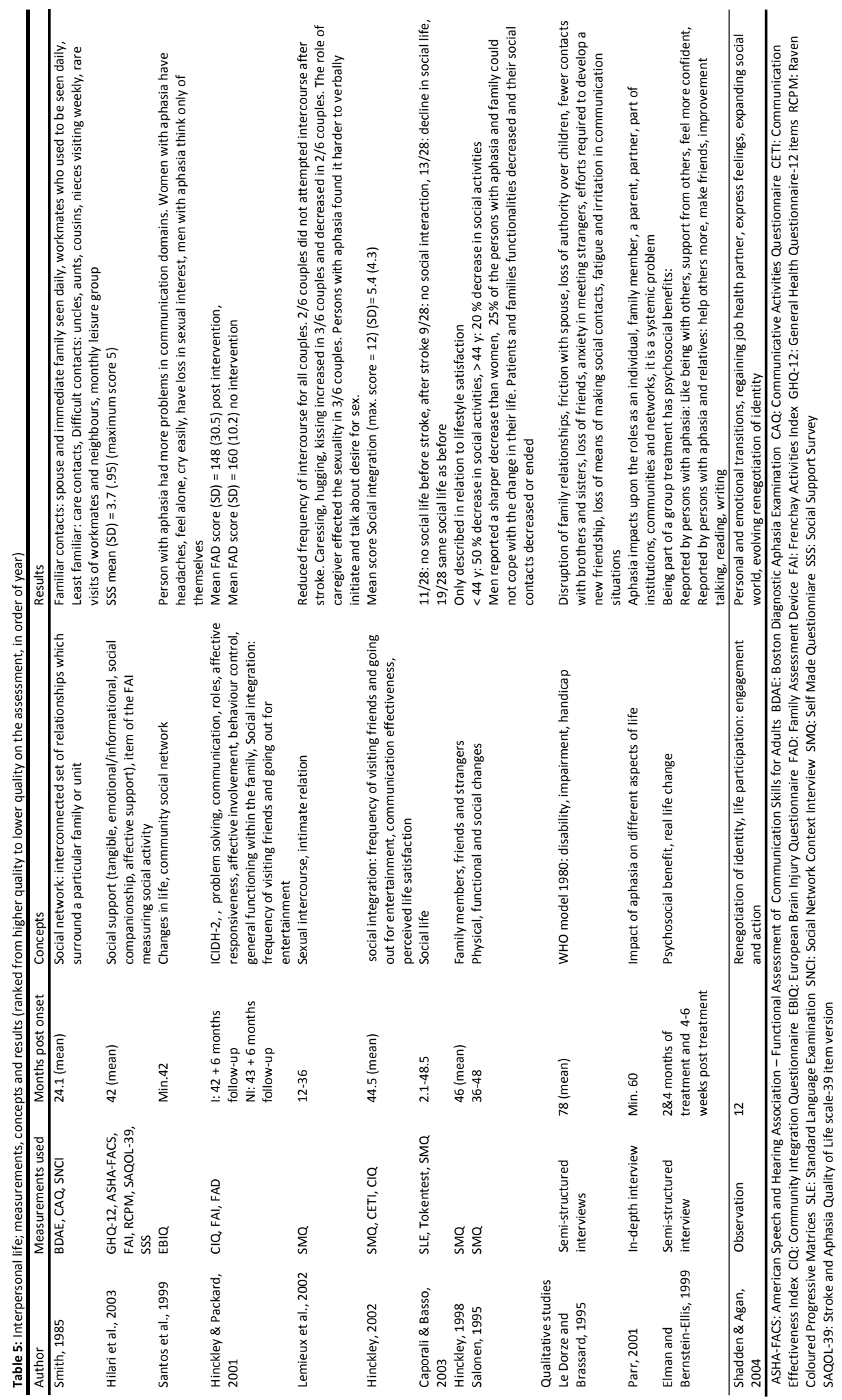




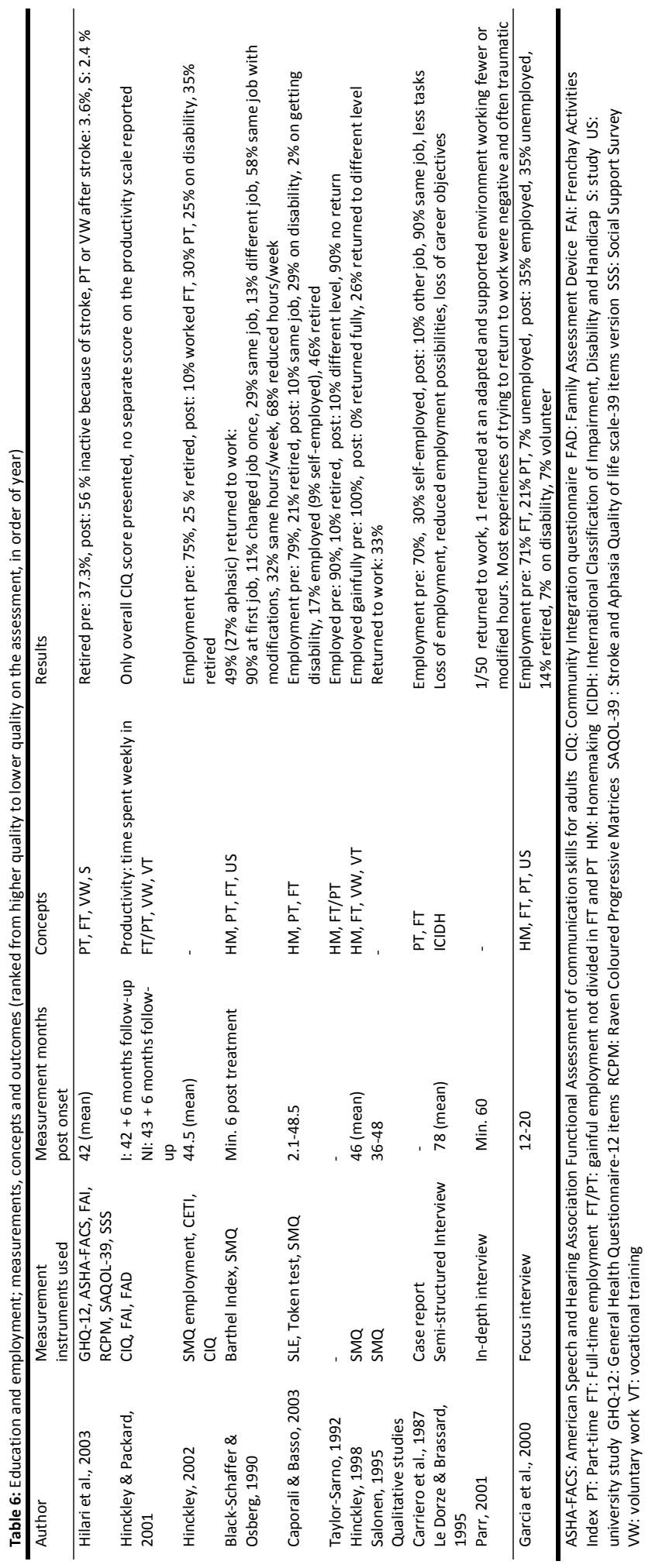




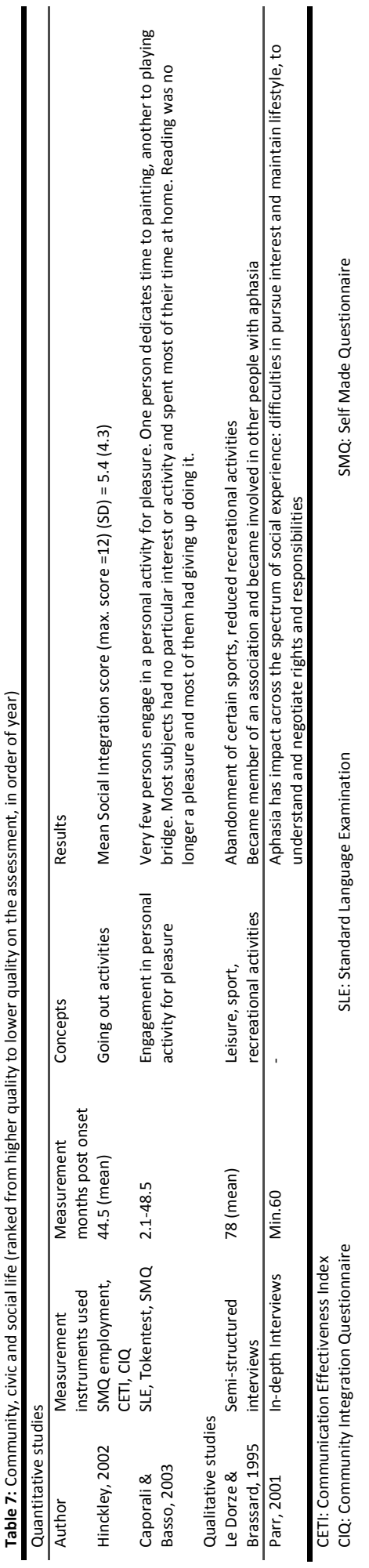




\section{Discussion}

\section{Main findings}

A systematic review of the literature was conducted on the participation of working age persons with aphasia (20-65 y) in four life domains. Although many hits were found, only 18 articles met the selection criteria. The published knowledge about the level of and alterations in participation of working age persons with aphasia, appears to be very limited.

In the studies analysed, a decrease in participation was reported in all four social life domains, including domestic life, interpersonal life, education and employment and community and civic life.

Domestic life has been a study object for a relatively long period. However, the concepts used to describe domestic life are very different: homemaking, social activities, and household are a few examples of concepts used in self-made questionnaires to assess aspects of domestic life. Two instruments are used relatively frequently, namely the FAI ( 3 studies) and the home integration subscale of the CIQ ( 2 studies). The concepts used in the FAl (for example preparing meals, washing up, washing clothes, light housework, heavy housework, local shopping, social outings) and the CIQ (shopping, preparing meals, housework, care for children, social arrangements) are very similar and capture the concept of domestic life as defined in the ICF (42): the acquisition of necessesities, household tasks and caring for household objects and assisting others. Although different instruments were used, it becomes clear in this review that studies generally report a decrease in different aspects of domestic activities.

In the area of interpersonal interactions and relationships most of the existing evidence, although limited, points to a reduction in the quality of interpersonal relationships of persons with aphasia and those in their immediate environment. Aphasia impacts also upon the lives of people surrounding the person with aphasia and this again has an impact upon the participation of persons with aphasia in social contacts. It must be stated that the studies in this area used very different definitions and are not very conclusive.

The concepts used in the studies concerning education and employment were very different and often vaguely described and the samples of the patients were often selected. There was a frequent use of self-made questionnaires. Two studies made use of the productivity subscale of the $\mathrm{CIQ}$ (work situation, training program situation, volunteer activities). In all the included studies there was a decrease in employment after stroke. Many studies reported a return to a job at a different level or to another job with less demanding tasks. To reach a more detailed conclusion with regard to employment, concepts should be defined more clearly as also indicated in the systematic review of Wozniak et al. (2002). It is neither clear how the different demands of jobs (desk work versus hand labour) are related to reintegration in employment activities, nor how aphasia impacts upon job activities in comparison to physical problems or other neurophysiologic problems.

The participation of persons with aphasia in community, civic and social life seems to be ignored as a study domain. No study could be found that took other areas such as ability to participate in religion or citizenship into consideration. Although leisure 
activities play an important role in the well-being of persons, this study domain seems to be unexplored.

Despite these preliminary conclusions, they are made with prudence in the light of the current quality of the literature for the younger group of persons living with aphasia. The selected studies do not provide a clear picture of the exact impact of aphasia on participation in the different social life domains. The methodological quality of the studies was often weak: no use of an equally disabled comparison group without aphasia, frequent use of self-made questionnaires, seldom use of representative samples, no age and gender specific outcomes, often use of small sample sizes.

In all the life domains studied, the use of self-made questionnaires was very common. This may be because the concepts used in existing instruments do not meet the objectives of the studies. Another reason may be a lack of knowledge with regard to existing instruments. Even more, it would be possible that existing instruments are not feasible for people with aphasia. Two key measures seem to emerge, namely the FAI and the $\mathrm{CIQ}$. The FAl is a very short instrument with 15 items, which mainly focuses on domestic life (nine items with regard to domestic life, three items about mobility, two items about leisure activities and one item about gainful work). Also the CIQ consists of a total of 15 questions, divided into three subscales, thus covering a wider range of life domains.

\section{Limitations of this study}

We found that participation is often vaguely defined in the included studies. The variety in definitions makes comparisons very difficult. In most studies, a clear conceptual framework is missing. In 2001 the WHO presented the ICF (International Classification of Functioning, Disability and Health). In this classification system, there are four main constructs: Body Structure, Body Function, Activity/Participation, and Contextual Factors. Activity is defined as the execution of a task or action by an individual and participation is defined as involvement in a life situation (43). The concept of participation as defined in the ICF is not known as a medical subheading in the electronic databases. This complicated the search strategy to find the correct key words to hit upon the relevant literature concerning participation in people with aphasia. In order to find as many relevant publications as possible, we used a wide search strategy. The databases Medline (Pubmed), Psychinfo and Cinahl were searched thoroughly for the period 1960-2005, making use of a combination of MeSH terms and text words that covered a wide range of the research population. Further, we studied all publications selected by three researchers, using outlined selection criteria. We are therefore reasonably confident that we did not exclude relevant articles concerning this domain.

Although the selection criteria were well described, the fact that only one author scored the full articles may be regarded as a limitation. It is important to note that, in all cases, consensus with one other author was attained in case of uncertainty about the relevance of an article.

None of the studies described in this review (with exception of the study of BlackSchaffer et al.) only included participants below the age of 65 . This makes it impossible to make a clear distinction in results between the persons with aphasia younger than 65 and the older age group. However, by setting the mean age limit to $65 \mathrm{y}$ old, the focus remains on a relatively younger age group. 
In this study, publications with regard to the perceptions of spouses on participation were eliminated. However, this could be an important source of information as this body of literature is quite large.

\section{Future research}

Future research into social participation of stroke survivors with aphasia and the factors influencing this is necessary to fill in the many white spots in knowledge appearing in this literature review. Such research should be guided by a clear conceptual framework and well-defined concepts. These could possibly be derived from existing frameworks like the ICF-model of the Disability Creation Process-model (44). Next, there is a need for reliably and valid measurement instruments as operationalisations of these concepts. Suitable and valid instruments should be used. In this review, two instruments (the FAl and the $\mathrm{CIQ}$ ) appear to be used relatively often. It is recommended to study the psychometric and clinimetric properties of these instruments to measure participation in persons with aphasia.

Apart from these conceptual and measurement topics, several other topics deserve priority. The first is to study the role of the environment in participation of people with aphasia. In this review it appears that individuals in the immediate environment seem to play an important role, but it is unclear what this role exactly is. It also appears that aphasia impacts upon the lives of people in the immediate environment of patients, which makes the role of these people close to the person with aphasia very intricate.

A second priority is to make a comparison between stroke survivors with and without aphasia, for a better understanding of the exact impact of aphasia.

A third priority is to study the different demands of jobs in relation to the reintegration in employment activities and to study the impact of aphasia versus other problems related to the different job demands. In working age people with aphasia return to work should be a major goal in therapy. This review shows that very little is known about the factors influencing success in this respect.

\section{Conclusion}

This review is one of the first attempts to provide an overview of what is published about participation in working age people with aphasia. Only seven of the studies included in this review were published after publication of the ICF (2001). Only $25 \%$ of the stroke population is below the age of 65 years. As a result, it is not surprising that such little literature exists for the selection criteria used.

All together, it can be concluded that little is known about social participation of people with aphasia (20-65 y). There was rarely a consistent conceptual framework used in the reviewed studies. Many researchers did not clearly define the concept of participation. Sample sizes used in the studies were often small. In addition, there appears to be a lack of good instruments measuring different aspects of participation. No study compared persons with aphasia with equally disabled persons without aphasia. Data should be interpreted with extreme caution and no firm conclusions can be made. 


\section{References}

1. Pedersen PM, Jørgensen HS, Nakayama H, Raaschou HO, Olsen TS. Aphasia in acute stroke: Incidence, determinants, and recovery 1995.

2. Laska AC, Hellblom A, Murray V, Kahan T, Von Arbin M. Aphasia in acute stroke and relation to outcome. J Intern Med. 2001 May;249(5):413-22.

3. Teasell RW, McRae MP, Finestone HM. Social issues in the rehabilitation of younger stroke patients. Archives of physical medicine and rehabilitation2000 Feb;81(2):205-9.

4. Kostalova B, Frenken F, Hoeymans N. Stroke 2001-2004: Health care future research: National Atlas for Public Health and Health Care: RIVM: National Institute for Public Health and the Environment; 2006 Contract No.: Document Number|.

5. Centers for Disease control and Prevention. 2006 [updated 2006; cited]; Available from: Division for Heart Disease and Stroke Prevention <../DHDSP/index.htm>, National Center for Chronic Disease Prevention and Health Promotion <http://www.cdc.gov/nccdphp/>.

6. National Institue for the Public Health and the Environment. Stroke:general practitioner registration. 2000.

7. Hemsley G, Code C. Interactions between recovery in aphasia, emotional and psychosocial factors in subjects with aphasia, their significant others and speech pathologists. Disbaility and Rehabilitation. 1996;18:567-84.

8. Neau JP, Ingrand P, Mouille-Brachet C, Rosier MP, Couderq C, Alvarez A, et al. Functional recovery and social outcome after cerebral infarction in young adults. Cerebrovascular Disorders. 1998 SepOct;8(5):296-302.

9. Parr S. Psychosocial aspects of aphasia: whose perspectives? Folia phoniatrica et logopaedica : official organ of the International Association of Logopedics and Phoniatrics (IALP).2001 Sep-Oct;53(5):266-88.

10. National Aphasia Association. Impact of Aphasia on Patients and Families:Results of a Needs Survey. 2005 [updated 2005; cited]; Available from: http://www.aphasia.org/impact.php.

11. Chapey R, Duchan JF, Elman RJ, Garcia L, Kagan A, Lyon JG, et al. Life Participation Approach to Aphasia: A Statement of Values for the Future. 2001 [updated 2001; cited]; Available from: http://www.asha.org/public/speech/disorders/LPAA.htm.

12. WHO. ICF international homepage. 2001 [updated 2001; cited]; Available from: http://www.who.int/classifications/icf/site/icftemplate.cfm?myurl=introduction.html\%20\&mytitle=Intr oduction.

13. Howe TJ, Worrall LE, Hickson LMH. What is an aphasia - friendly environment? Aphasiology. 2004;18(11):1015-37.

14. Pound C, Parr S, Lindsay J, Woolf C. Beyond aphasia: therapies for living with communication disability. . Bicester: Winslow Press; 2000.

15. Prins J, Blanker MH, Bohnen AM, Thomas S, Bosch JLHR. Prevalence of erectile dysfunction:a systematic review of population based studies. International Journal of Impotence Research. [

]. $2002 ; 14(6): 422-32$.

16. Downs SH, Black SE. The feasibility of creating a checklist for the assessment of the methodological quality of both randomised and non-randomised studies of health care interventions. Journal of Epidemiology in Community Health. 1998;52:377-84.

17. Popay J, Rogers A, Williams G. Rationale and Standards for the systematic review of Qualitative Research in Health Services Research. Qualitative Health Research. 1998;8:341-51.

18. Mays N, Pope C. Education and debate: Qualitative research in health care Assessing quality in qualitative research. British Medical Journal. 2000;320:50-2.

19. Wozniak MA, Kittner SJ. Return to work after ischemic stroke: a methodological review. Neuroepidemiology. 2002 Jul-Aug;21(4):159-66.

20. Bays CL. Quality of life of stroke survivors: a research synthesis. The Journal of neuroscience nursing : Journal of the American Association of Neuroscience Nurses.2001 Dec;33(6):310-6.

21. Emick-Herring B. Sexual changes in patients and partners following stroke. Rehabilitation nursing : the official journal of the Association of Rehabilitation Nurses. 1985 Mar-Apr;10(2):28-30. 
22. Elman RJ, Bernstein-Ellis E. Psychosocial Aspects of Group Communication Treatment: preliminary findings. Seminars in speech and language. 1999;20(1):65-72.

23. Le Dorze G, Brassard C. A description of the consequences of aphasia on aphasic persons and their relatives and friends, based on the WHO-model of chronic diseases. Aphasiology. 1995;9:239-55.

24. Santos ME, Farrajota ML, Castro-Caldas A, de Sousa L. Problems of patients with chronic aphasia: different perspectives of husbands and wives? Brain Injury. 1999 Jan;13(1):23-9.

25. Taylor-Sarno M. Preliminary findings in a study of age, linguistic evolution and quality of life in recovery from aphasia. Scandinavian journal of rehabilitation medicine Supplement 1992;26:43-59.

26. Hinckley JJ, Packard ME. Family education seminars and social functioning of adults with chronic aphasia. Journal of Communication Disorders. 2001 May-Jun;34(3):241-54.

27. Cavanagh SJ, Hogan K, Gordon V, Fairfax J. Stroke-specific FIM models in an urban population. Journal of Neuroscience Nursing. 2000 Feb;32(1):17-21.

28. Wade DT, Legh-Smith J, Langton Hewer R. Social activities after stroke: measurement and natural history using the Frenchay Activities Index. International Rehabilitation Medicine. 1985;7(4):176-81.

29. Wade DT, Hewer RL, David RM, Enderby PM. Aphasia after stroke: natural history and associated deficits. Journal of neurology, neurosurgery, and psychiatry 1986 Jan;49(1):11-6.

30. Hilari K, Wiggins R, Byng S, Smith S. Predictors of helath-related quality of life (HRQL) in people with chronic aphasia. Aphasiology. 2003;17(4):365-81.

31. Willer B, Rosenthal M, Kreutzer JS, Gordon W, Rempel R. Assessment of the community integration following rehabilitation for traumatic brain injury. Journal of Head Trauma and Rehabilitation. 1993;8(2):75-87.

32. Hinckley JJ. Vocational and social outcomes of adults with chronic aphasia. Journal of Communication Disorders. 2002 Nov-Dec;35(6):543-60.

33. Smith L. Communicative activities of dysphasic adults: a survey. British Journal of Disorders of Communication. 1985 Apr;20(1):31-44.

34. Caporali A, Basso A. A survey of long-term outcome of aphasia and of changes of gainful employment. Aphasiology. 2003;17(9):815-34.

35. Salonen T. Report of a questionnaire survey of poststroke patients with aphasia and their families. Topics in stroke Rehabilitation. 1995;2(3):72-5.

36. Hinckley JJ. Investigating the predictors of lifestyle satisfaction among younger adults with chronic aphasia. Aphasiology. 1998;12 (7/8):509-18.

37. Lemieux L, Cohen-Schneider R, Holzapfel S. Aphasia and sexualtiy. Sexuality and disability. 2002;19(4):253-66.

38. Shadden BB, Agan JP. Renegotiation of Identity: The social Context of Aphasia Support Groups. Topics in Language disorders. 2004;24(3):174-86.

39. Black-Schaffer RM, Osberg JS. Return to work after stroke: development of a predictive model. Archives of physical medicine and rehabilitation1990 Apr;71(5):285-90.

40. Carriero MR, Faglia Z, Vignolo LA. Resumption of gainful employment in aphasics: preliminary findings. Cortex. 1987; 26:667-72.

41. Garcia LJ, Barrette J, Chantal L. Perceptions of the obstacles to work reintegration for persons with aphasia. Aphasiology. [qualitative study]. 2000;14(3):269-90.

42. World Health Organisation. ICF checklist, version 2.1., a clinician form. 2003; september:1-15.

43. WHO. International Classification of functioning, disability and health. Geneva; 2001.

44. Fougeyrollas P, Cloutier R, Bergeron H, Cote J, St Michel G. Quebec Classification: disability creation process. Quebec; 1999. 
Appendix 1: methodological quality criteria list for quantitative studies

\begin{tabular}{lrc}
\hline Informativity & Yes & No \\
& $=1$ & $=0$ \\
\hline
\end{tabular}

The purpose of the study is clearly described

The method of the data collection is properly described

The main outcomes to be measured are clearly described in the introduction or methods section

The description of the characteristics of the population is sufficient

The response rate is $\geq 70 \%$, or the information of the no responders is

sufficient

The main findings of the study are clearly described: simple outcome data should be reported for all major findings

Subtotal (max. 6)

\section{External validity}

The subjects asked to participate are representative for the entire population from which they were recruited

The inclusion and exclusion criteria are described

The age range is specified

The study period is described

Subtotal (max. 4)

\section{Internal validity}

The data are prospectively collected

A comparison group is used and properly described

The measurement instrument(s) is/are described

The main outcome measures used are accurate (valid and reliable)

Age specific and gender specific outcomes are reported

Subtotal (max. 5)

Total (max. 15) 
Appendix 2: methodological quality criteria list for qualitative studies

\begin{tabular}{lrc}
\hline Informativity & Yes & No \\
& $=1$ & $=0$ \\
\hline
\end{tabular}

The purpose of the study is clearly described

The method of the data collection is properly described

The description of the characteristics of the population is sufficient

A full range of possible cases or settings is sampled

The main findings of the study are clearly described: written account should include sufficient data to judge whether interpretations are supported by the data

A wide range of different perspectives is described

Subtotal (max. 6)

\section{Reliability/validity}

Use of data triangulation

Use of investigator triangulation

Use of methodology triangulation

Use of respondent validation (member checking)

Attention to negative cases

Reflexivity: personal and intellectual bias is made plain at the outset

The main outcome measures used are accurate (valid and reliable)

Age specific and gender specific outcomes are reported

Subtotal (max. 8)

Total (max. 14) 



\section{Chapter 3:}

\section{Measures for rating social participation in people with aphasia}

Based upon:

Dalemans RJP, de Witte L, Lemmens J, Wade D, van den Heuvel W. Measures for rating social participation in people with aphasia: a systematic review. Clinical Rehabilitation 2008;22(16):542-555. 
Measures for rating social participation in people with aphasia

Background: Re-establishing participation in social life is an important aim of rehabilitation, but instruments to measure participation in people with aphasia are rare.

Aims: To identify and describe measures of social participation that may be specifically useful when measuring participation in people with aphasia.

Methods and procedures: A systematic review of the literature concerning participation instruments was conducted. Then six speech and language therapists evaluated the suitability of selected participation measures for use in people with aphasia and a systematic literature review concerning the feasibility, internal consistency, validity, reliability and responsiveness of the measures selected by the therapists was carried out.

Results: In total 12 instruments measuring aspects of participation were found: seven measured actual performance and five measured actual performance combined with experienced problems. Two were considered unsuitable for people with aphasia, leaving ten. Six speech and language therapists working with people with aphasia scored the ten selected instruments, and two instruments were judged as possibly suitable for use in people with aphasia: the Community Integration Questionnaire (CIQ) and the Nottingham Extended Activities of Daily Living (NEADL). However, The Community Integration Questionnaire is much closer to the concept of participation. The literature review concerning the psychometric properties of the $\mathrm{CIQ}$ revealed that very little is known about the use of this instrument in people with aphasia.

Conclusion: The Community Integration Questionnaire is possibly suitable for use in people with aphasia when measuring participation. The psychometric properties of this instrument are very limited for this group. 


\section{Introduction}

In 1980, the WHO published ICIDH (1) as a manual of classification relating to the consequences of disease. The original ICIDH model acknowledges a role of the environment by stating that 'handicaps thus reflect interaction with an adaptation to the individual's surroundings. However, it has been criticized for its lack of an explicit recognition of the role of the environment in this model. In 2001, the WHO presented the International Classification of Functioning, Disability and Health (ICF) (2). Components of functioning and disability changed from impairment, disability and handicap into body function and structure, activities and participation. Components of contextual factors include environmental factors and personal factors. Participation is defined as involvement in a life situation.

The ICF presents two possible levels for measuring the outcome of rehabilitation. Activities are behaviours undertaken by people, and participation refers to the gaining of social roles through participation in social activities. People with aphasia clearly will have difficulties in communicative activities and therefore are very likely to have restrictions upon their participation. However, measurement of participation is difficult, because the construct as defined in the ICF is rather vague and it is likely that measurement in people with aphasia will be especially difficult due to their communication problems.

Aphasia is the impairment of language skills, with problems in verbal expression, auditory comprehension, reading and writing. Aphasia is a prominent cause of limitation on communication activities such as using the phone or writing a letter. Aphasia will have relatively little direct impact upon performance of personal and domestic activities of daily living, which are usually the prime focus of measurement in stroke studies. Aphasia will particulary affect complex social activities such as work, participating in community activities and leisure activities involving other people. These activities probably contribute most to a person`s roles, but are rarely measured in stroke studies. Participation is also rarely measured directly.

The impact of aphasia is well described in qualitative studies of people with aphasia who describe social isolation, discrimination, exclusion from work, education and leisure pursuits, and limited community support and benefits $(3,4)$. Perhaps the greatest toll that aphasia exacts on individuals with stroke and their families lies in the area of family relationships and socialization (5). It introduces changes and challenges to establish and maintain a satisfying lifestyle (6). A recent review (7) showed that participation in people with aphasia is not studied systematically.

Thus it is important, both in principle and on the basis of the concerns of patients, to measure outcome at the level of social participation especially when considering people with aphasia (8) (9).

The aim of the present study is to identify and describe existing measures of participation that may be specifically useful according to speech and language therapists when measuring participation in people with aphasia.

\section{Methods}

Because the definition of participation in the ICF is rather vague, the following definition, based upon the comments of Whiteneck (10) was used: "the performance of 
people in actual activities in social life domains through interaction with others in the context in which they live." (7)

The first step (see figure 1) was to identify all published measures of participation through a computerized literature search. One investigator conducted the search for generic participation measures using Pubmed (1960-2005), CINAHL (1960-2005), Cochrane (1960-2005) and PSYCHINFO (1953-2005).

Figure 1: Steps in selecting the participation instruments

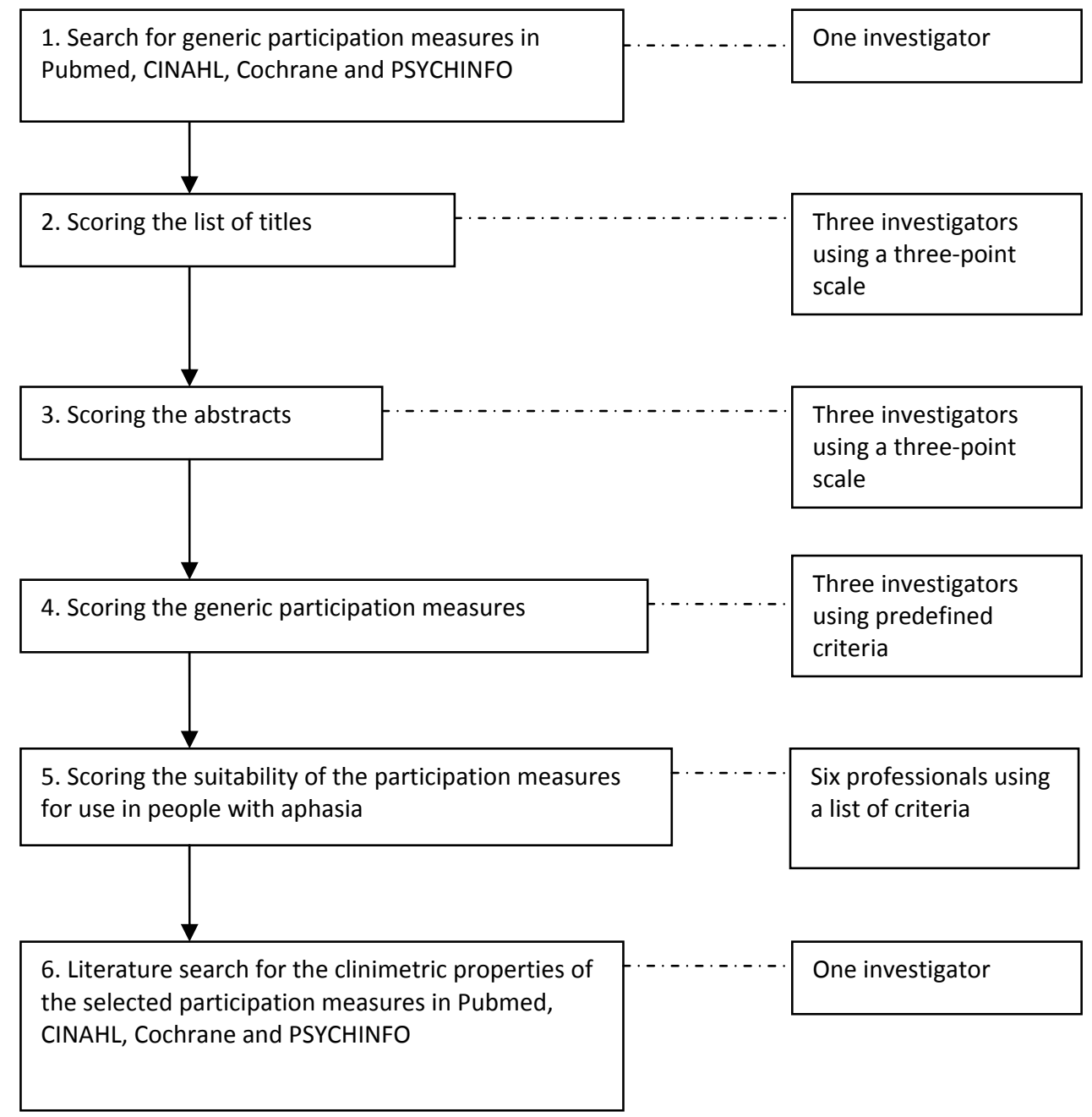


Free text words as well as controlled vocabulary specifying participation and instruments were combined with the free text words and controlled vocabulary specifying handicap (used in the 70s, 80s and 90s to incorporate the concept of participation) and chronic disease. Appendix 1 outlines the search strategy used in Pubmed. A similar strategy was used in the other databases. Although the importance of contextual factors (environmental and personal factors) in facilitating or hindering participation is unquestionable, they are not measures of participation itself, so we did not include them as search terms. The search was on title and/or abstract, using the limits adults and English.

Three investigators (RD, LdW, JL), blinded from each other, assessed the relevance of the listed titles (see figure 1, step 2). They used predefined selection criteria- with a three-point scale $(0=$ irrelevant; 1 = possibly relevant; 2 = relevant). References with a total score below three were discarded as irrelevant. Titles were judged relevant if they referred to the following guiding terms: measurement, tool, index, test, scale, questionnaire, instrument, chronic disease, handicap, disability, participation, life, social integration, employment, education, homemaking, shopping, hobbies, activities, quality of life. Titles referring to $\mathrm{CT}, \mathrm{MRI}, \mathrm{EEG}$, screening or disease were considered not relevant.

Next, the resulting abstracts were scored by the same investigators (RD, $L d W, J L)$, following the same procedure (see figure 1, step 3). The abstracts were scored as relevant if the characteristics of the participation measurement were described. Instruments directly associated with a disease or disability, with exception of stroke, were considered not relevant as well as instruments measuring only personal activities without measuring social activities.

Other articles from each author in the list of selected abstracts, were screened on title and scored according to the same procedure. Other instruments were gathered through conversations with experts (speech and language therapists, physiotherapists and occupational therapists) and through the database of the centre of expertise on measurement instruments (ECMR.nl).

The next step (step 4 in figure 1) was for three investigators (RD, LdW, JL) to score the listed instruments using predefined criteria to make sure that the instruments measure aspects of participation as defined (7). The criteria were that the instrument measured actual performance and aspects of participation as defined. Measurements that depended upon an outside observer rating without asking questions were excluded. Participation instruments that measured both participation and experienced problems were included if there were separate scales for actual performance and experienced problems.

Then the list of participation instruments selected was independently judged by six speech and language therapists working with people with aphasia, to decide whether they were appropriate for use in people with aphasia.

In order to develop a list of criteria about the suitability of an instrument for people with aphasia, criteria were derived from the literature and Aphasia Associations (11-17). The scoring list consisted of criteria that concern burden ( 3 items), layout ( 2 items) and overall scoring ( 4 items) indicating suitability for use in this specific population. The items were scored on a four-point scale $(0=$ no, $1=$ mostly not, $2=$ mostly yes, $3=$ yes, total range 0-27). 
Scoring of suitability was undertaken independently by two speech and language therapists working in a rehabilitation setting, two working in a nursing house, one working in a hospital and one speech and language therapist working in a private practice. Whether or not the scale had been used with people with aphasia was not disclosed to the speech and language therapists. Instruments with a total score less than 18 (each item must be scored with a mean two) were rated as not suitable.

After selection of potentially suitable measures, a second literature search was carried out in MEDLINE (via PubMed), CINAHL and PSYCHINFO for the period 19602005 in order to find data on their psychometric properties of the instruments. The names of the selected instruments (in full as well as abbreviated) were combined with terms indicating psychometric parameters, namely administration, feasibility, responsiveness, internal consistency, validity, reliability.

\section{Results}

In the computerized literature search a total of 2232 hits were found, 77 of which describing 34 different instruments. The scoring agreement between the three investigators was good (agreement percentage: $92 \%$ scores in the same category). Two more instruments were gathered by contacts with experts and the centre of expertise on measurement instruments (18). One of those three instruments was published after the time-period in the search strategy, namely the Participation Scale (19) and one instruments was not found because the selected search terms were not used in title and abstract $(20,21)$.

In the first stage, 12 of the 37 instruments were selected as relevant. For example, three instruments were excluded (the Nottingham Health Profile (22), the Reintegration to Normal Living Index (23) and the Subjective Index of Physical and Social Outcome (24)) because statements referring to the actual performance as well as statements referring to the experienced problems are scored within the same scale. The scoring agreement between the three investigators in this stage was good (agreement percentage; $75-100 \% 3$ scores in the same category). In table 1 the search results of phase one are presented, including the names of the 12 instruments and their use in people with aphasia.

Table 2 reports the names of the instruments, the domains measured (3-12), the number of items, the administration possibilities and the scoring procedures.

Seven instruments measure actual performance in aspects of participation. The number of items in these instruments ranges from 15 to 136. 
Table 1: Identified participation instruments

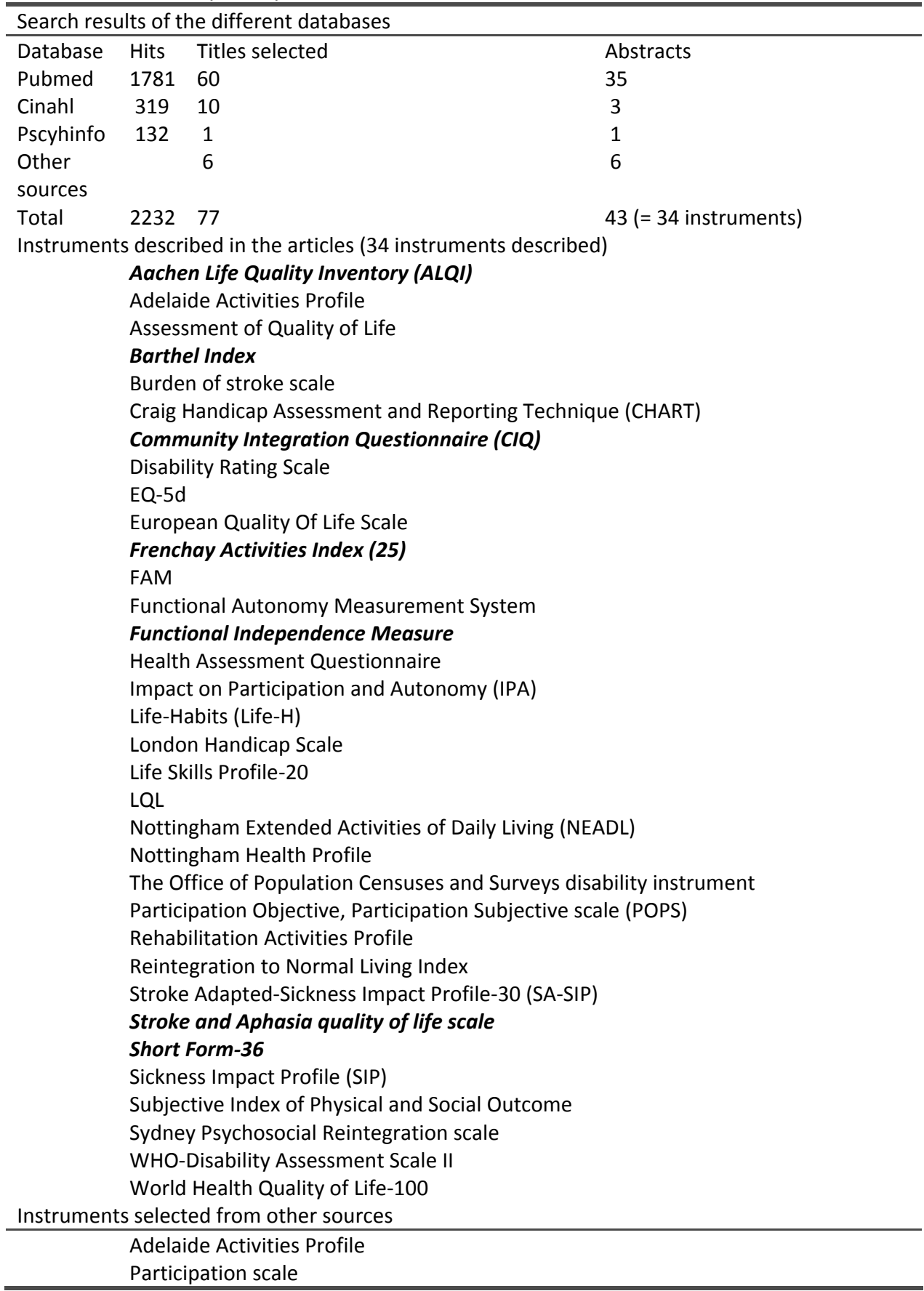

BOLD: selected participation instruments

Italic: the instrument is used in studies concerning people with aphasia 
Five instruments measure both aspects of actual performance and experienced problems. The number of items in these instruments ranges from 18 to 117 . These five instruments make use of more than one scoring scale, one to measure the actual performance and one to measure the experienced problems. The Life Habits questionnaire (26) also makes use of a scoring scale to measure satisfaction. Five of the twelve instruments are used in at least one study with people with aphasia, namely the Community Integration Questionnaire (27), Frenchay Activities Index (27), Stroke-Adapted Sickness Impact Profile (28), Sickness Impact Profile(29) and the Aachen Life Quality Inventory (20).

Of the twelve instruments, two instruments were discarded because they are too complex for people with aphasia, namely the Craig Handicap Assessment and Reporting Technique (30) and the Life Habits Questionnaire (26). The statements are too long, important words are not placed at the end of the sentence, the statements are not always comprehensible, the lay-out is not well outlined. In the Life Habits Questionnaire, the person is not addressed directly and not always is the same word used for the same concept.

Suitability for assessment in people with aphasia

By using the suitability scoring list, the speech and language therapists scored two instruments as potentially suitable for use in people with aphasia (see table 3): the Community Integration Questionnaire $(31,32)$ and the Nottingham Extended Activities of Daily Living (33). These instruments measure actual performance in activities in social life domains.

The Community Integration Questionnaire (CIQ) consists of 15 questions. The overall score ranges from 0 to 29. A higher score indicates better integration. The $\mathrm{CIQ}$ can be further divided into three subscores, corresponding to integration in home, social integration and productivity. The $\mathrm{CIQ}$ received the highest score on the item; I would use this instrument for people with aphasia ${ }^{\prime}(13 / 18)$ and the highest total score on the suitability list $(22.5 / 27)$. The response set is consistent throughout the administration and the structure of the instrument assures a careful ordering of the items. No use is made of visual support.

The Nottingham Extended Activities of daily living (NEADL) consists of 21 questions (scoring possibilities; 0: not at all to 3: alone easily). The overall score can range from 0 to 63. A higher score indicates higher activity. The NEADL is divided into four domains, namely mobility, in the kitchen, domestic tasks and leisure activities. The NEADL has an adequate number of items (21), a consistent response set and the structure of the instrument assures a careful ordering of the items. However, there is a lack of visual support and the answering possibilities are not visualised for each question separately. Further, only four out of 21 questions measure aspects of participation. Therefore, the decision was made to focus on the Community Integration Questionnaire in the next step of the research. 


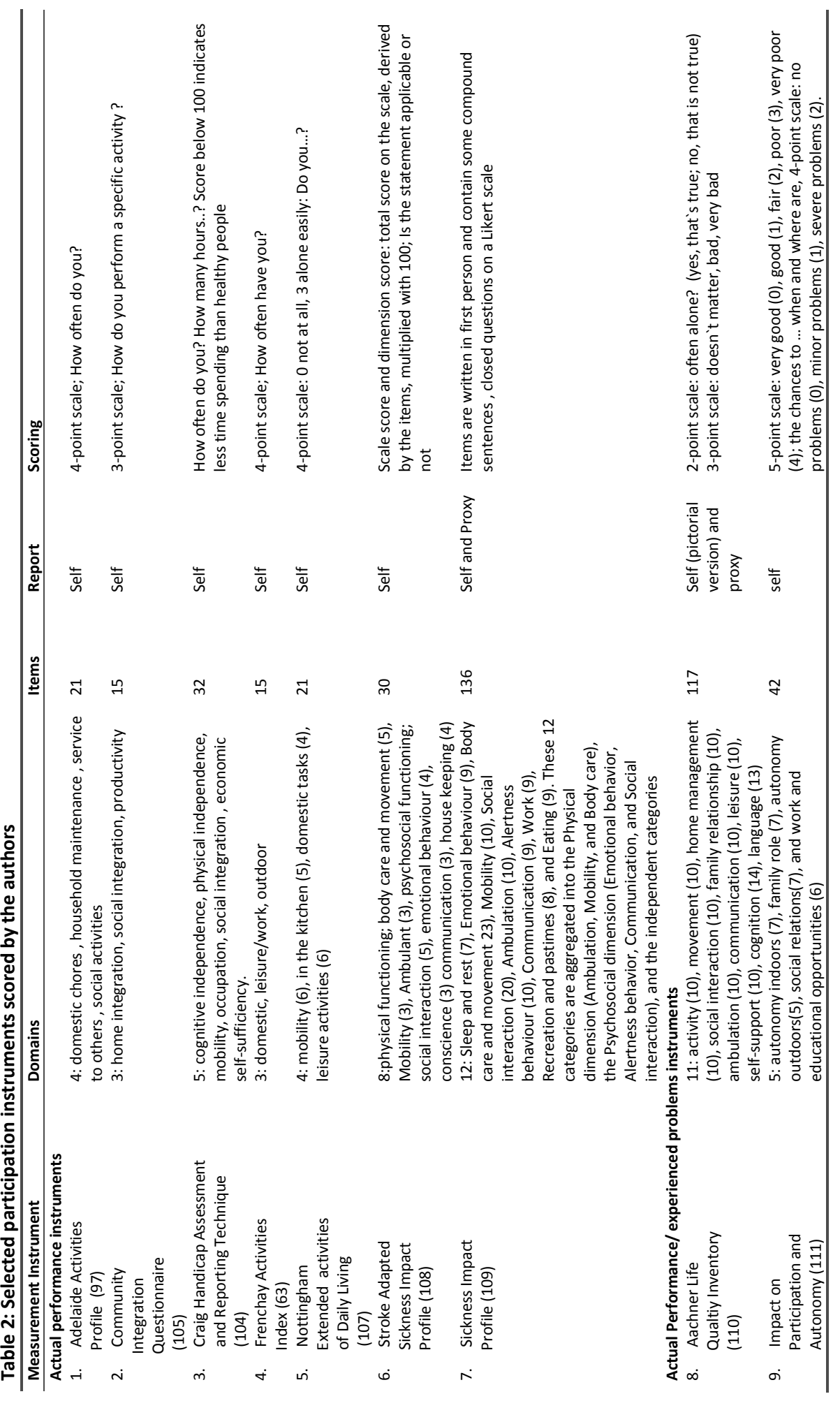


CHAPTER 3

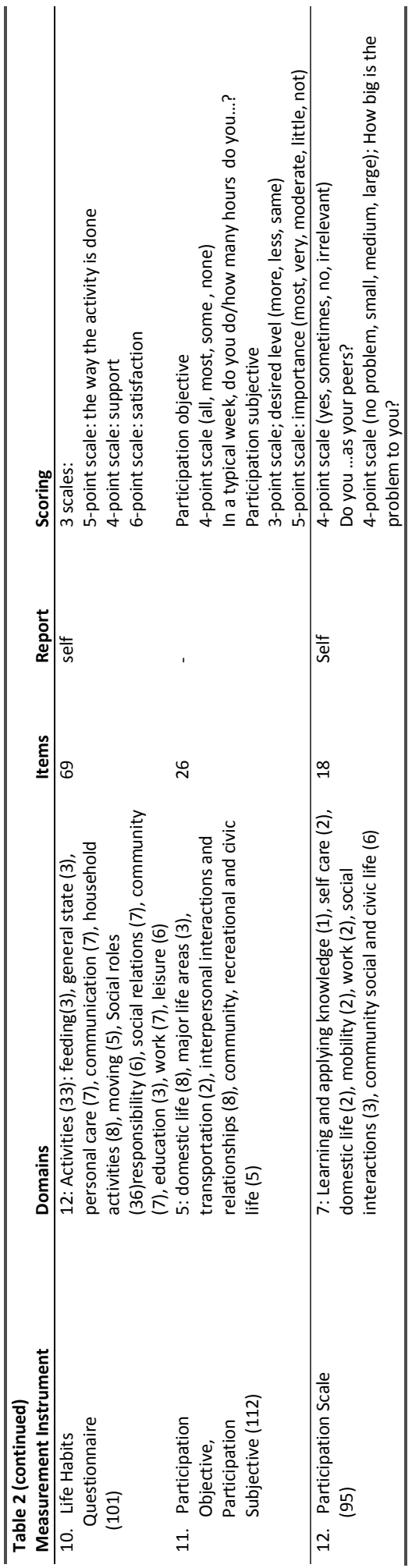




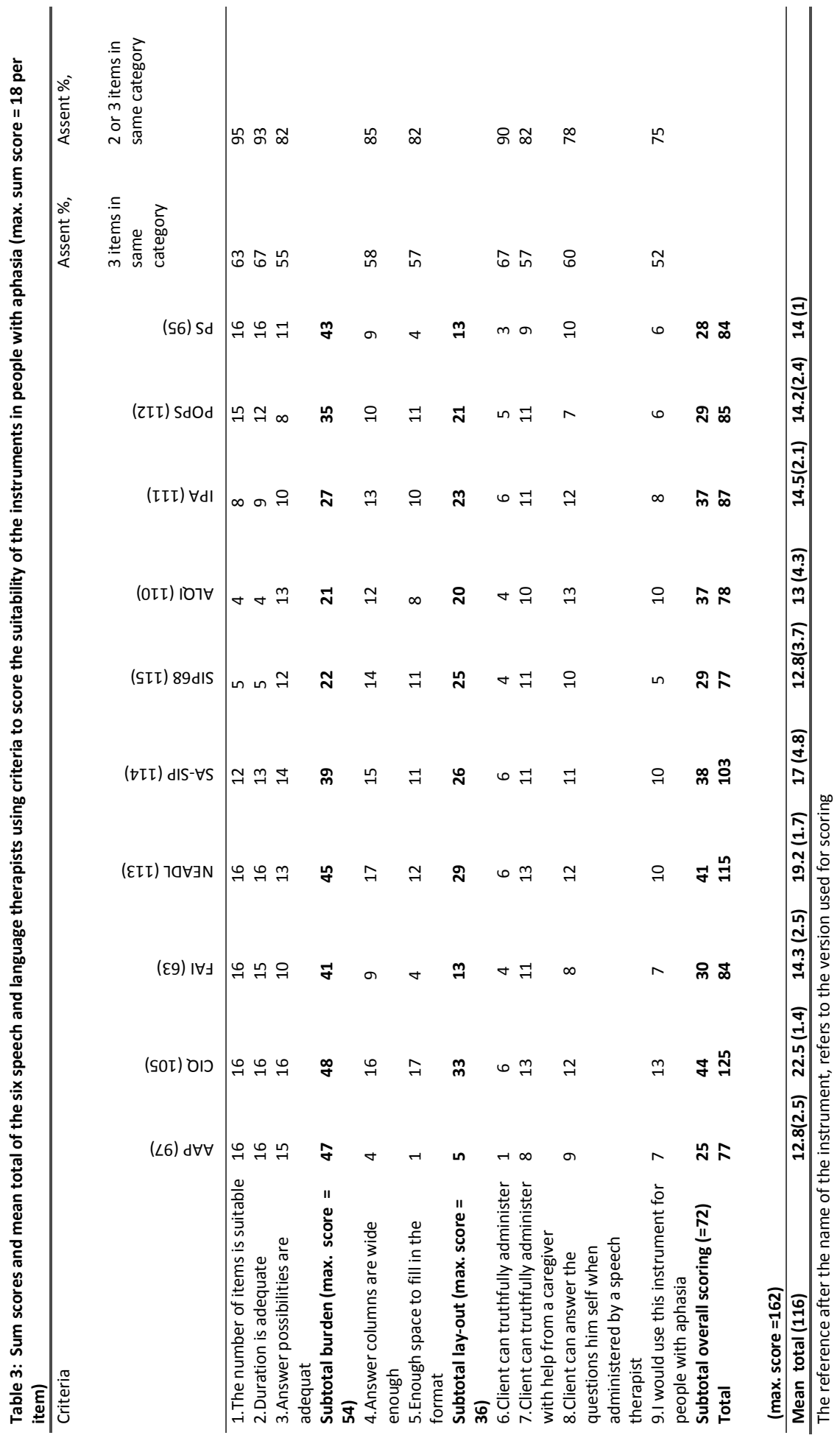


Table 3 reports that there is no instrument at all that can be administered by the client himself. Administration needs to be done with help. Whether the help is received from a caregiver or from a speech and language therapist makes little to no difference according to the six speech and language therapists.

The agreement percentage between the six speech and language therapists (scoring 2 or 3 in the same category) on the nine items ranged from $75 \%$ to $95 \%$ for the ten instruments (see table 3).

\section{Psychometric properties of the selected instruments}

Table 4 presents the psychometric properties of the Community Integration Questionnaire (closest to the concept of participation as defined). Many studies have investigated the psychometric properties of the Community Integration Questionnaire, all in a traumatic brain injury population. The psychometric properties presented in table 4 refer not to the properties in people with aphasia (because those data are not available) but generally to the population with neurological damage in which the instruments are used.

The psychometric properties are good with exception of the reliability for the productivity and social integration scale. There are no clear data available concerning the responsiveness.

Table 4: Psychometric properties of participation measures useful in people with aphasia

\begin{tabular}{|c|c|}
\hline \multicolumn{2}{|c|}{ The Community Integration Questionnaire } \\
\hline References & $(105,117-128)$ \\
\hline Population & Traumatic brain injury, also applicable to all individuals, disabled or not, living outside institutions. \\
\hline Concept & $\begin{array}{l}\text { Refers to being in (returning to) the mainstream of family and community life, by persons with impairments and } \\
\text { disabilities due to injury, chronic illness, or old age. A finite set of indicators of community integration, it does not } \\
\text { encompass all possible indicators of integration. Recommended to use the CIQ in concert with similar assessments of } \\
\text { impairment, disability, environmental barriers, and demographic descriptors. }\end{array}$ \\
\hline Items & $\begin{array}{l}15 \text { : overall score can range from } 0 \text { to } 29 \text { : higher score indicates greater integration, divided into three sub scores: } \\
\text { integration in the home, social integration, and productivity. }\end{array}$ \\
\hline Administration & $\begin{array}{l}\text { By either the person with impairment or a proxy, provided that the individual being assessed is present. The most } \\
\text { common method of data collection is an in-person interview, but telephone interviewing is quite common. Responses } \\
\text { indicate performing the activity alone, with another person, or that the activity is typically performed by someone } \\
\text { else. }\end{array}$ \\
\hline Feasibility & Clear structure with a good ordering of the items, only 15 items, assessment duration 15 minutes. \\
\hline Responsiveness & $\begin{array}{l}\text { Hall et al. (1996) reported a very small increase from the first to the second year of injury. Corrigan et al. (1998) found } \\
\text { trends toward improvement in all three subscales and total score in a cross-sectional study covering one through four } \\
\text { years of injury. Willer et al. (1999) reported gain in CIQ (sub) scores for people with TBI getting residential } \\
\text { rehabilitation services between the second and third year of injury. }\end{array}$ \\
\hline Validity & $\begin{array}{l}\text { Developed with use of a panel consisting of both consumers and speech and language therapists with expertise in TBI } \\
\text { outcome studies ,CIQ; Functional Independence Measure(FIM); Functional Assessment Measure (FAM); Disability } \\
\text { Rating Scale (DRS): Three factors emerged: Home Competency, Social Integration, and Productive Activity. Each CIQ } \\
\text { scale score showed significant correlations in the expected direction with the FIM+FAM and DRS items. Significant } \\
\text { relationships were seen between CIQ scores and both the Social Activity and Inactivity subscales of the Chronic IIIness } \\
\text { Problem Inventory ( } r=-0.43, p<0.005 \text { and } r=-0.68, p<0.005 \text {, respectively) (129). }\end{array}$ \\
\hline Reliability & $\begin{array}{l}\text { Results of reliability studies have been mixed. Based on the (Pearson) correlations reported in the earliest study, the } \\
\text { interrater reliability of the CIQ appears in the "acceptable" range (Willer et al., 1993). However, the intraclass } \\
\text { correlation coefficient (130), resulted in much lower numbers, according to a later investigation (Tepper et al., 1996), } \\
\text { especially for the Home }(\mathrm{H}) \text { dimension. The most recent research (Sander et al., 1997) suggests that in home } \\
\text { integration there is the greatest discrepancy between reports by subjects with TBI and those by their proxies. In the } \\
\text { latter study, the person with TBI tends to report higher values than the proxy for all three components. }\end{array}$ \\
\hline
\end{tabular}




\section{Discussion}

One participation instruments was found, possibly suitable for the use in people with aphasia. The Community Integration Questionnaire is much closer to the concept of participation than the Nottingham Extended Activities of Daily Living. Although 4 items consist questions about participation, the Nottingham Extended Activities of Daily Living cannot be considered as a participation instrument as a hole.

People with aphasia are often excluded from research. One important reason is the difficulty to measure anything when the question is based upon language abilities in persons with language problems. To measure what a person does despite the presence of aphasia is very problematic. How can one be sure that the person with aphasia understands the question? How can one be sure that the person with aphasia can correctly express the things he wants to say? In this study instruments are confirmed as possibly suitable according to the investigators and the experts when the following strategies are used: simplified language, multimodal presentation of the questions (support by pictograms, drawings), a small set of response choices, a careful ordering of items, a short assessment length. Negatives used in questions, items formulated in complex sentences and a large memory demand should be avoided when assessing people with aphasia. No instrument could be found that fully answered to all the above-mentioned strategies.

Compared to activities, participation is a more complex process and more dependent upon environmental factors and will be measured mostly with self-reports (34). Even when people with aphasia are able to answer the questionnaire, it will be difficult to distinguish changes in participation that are specifically due to aphasia from that due to other factors.

From the twelve initially selected participation instruments, the Community Integration Questionnaire could possibly be suitable for assessing participation in people with aphasia. However, the six speech and language therapists stated that help from a close other or a speech and language therapist will be necessary when assessing any instrument.

In order to stay as close as possible to the comprehension and expression of the person with aphasia, it might be better to use open or semi-structured interview protocols. The person with aphasia can use the strategies that are most helpful to him. The interviewer can check more easily if he has understood the person with aphasia correctly, by paraphrasing, verbal, and non-verbal feedback. Interviewing can be very valid and reliable when used correctly. However, this is a very time intensive procedure.

\section{Limitations of the study}

Participation is a complex concept, making the boundaries of the concept vague. Therefore, it is possible that we have missed some participation measurements, because of the search terms used. However, by using the search terms participation, quality of life, activities, as well as other concepts referring to aspects of participation, we have limited the possibility of missing a participation instrument. By making the definition of participation more concrete and by using selection criteria, we have eliminated instruments that do not answer the selection criteria. Further, we have 
found measurements that did not actually measure participation as we defined it. However, it remains difficult to make judgements. There was often no $100 \%$ agreement on selection or scoring. Everybody makes judgements based upon their own experience and in the context in which they work and live, even when clear selection criteria are used.

The list of possibly suitable instruments for use in people with aphasia is very small, even smaller than the number of instruments that already have been used in aphasia studies. It might be that the researchers in those studies made use of instruments which were judged not suitable in this study- because there were no other instruments available.

\section{Implications}

Further research is necessary concerning the feasibility and the psychometric properties of the Community Integration Questionnaire and the Nottingham Extended Activities of Daily Living in people with aphasia. Because the Community Integration Questionnaire is much closer to the concept of participation, this should be the preferred measure for further investigation. There is a need to optimise this instrument for use in people with aphasia, for example by developing visual and other methods of assistance to support persons with aphasia during assessments.

\section{Clinical messages}

Instruments are possibly suitable for use in people with aphasia when using simplified language, multimodal presentation of the questions, small set of response choices, careful ordering of items, short assessment length.

The Community Integration Questionnaire should be the preferred measure when assessing participation in people with aphasia. 


\section{References}

1. WHO. International Classification of Impairments, Disabilities and Handicaps: a manual of Classifciation Relating to the Consequences of Disease. Geneva, Switzerland: World Health Organization; 1980.

2. WHO. International Classification of functioning, disability and health. Geneva; 2001.

3. Parr S, Byng S, Gilpin S. Talking about aphasia: Living with loss of language after stroke. 1997.

4. Parr S. Psychosocial aspects of aphasia: whose perspectives? Folia phoniatrica et logopaedica : official organ of the International Association of Logopedics and Phoniatrics (IALP) 2001 Sep-Oct;53(5):266-88.

5. Glueckauf RL, Blonder LX, Ecklund-Johnson E, Maher L, Crosson B, Gonzalez-Rothi L. Functional Outcome Questionnaire for Aphasia: overview and preliminary psychometric evaluation. NeuroRehabilitation. 2003;18(4):281-90.

6. Lyon JG, Carisiki D, Keisler L, Rosenbek J, R. L, Kumpula J, et al. Communication partners: enhancing participation in life and communication for adults with aphasia in natural settings. Aphasiology. 1997;11(7):693-708.

7. Dalemans RJP, de Witte L, van den Heuvel W, Wade D. A description of social participation in working age people with aphasia: a review of the literature. Aphasiology (accepted). 2007.

8. Holland AL. Functional outcome assessment of aphasia following left hemisphere stroke. Seminars in Speech and Language. 1998;19(3):249-59; quiz 59-60.

9. Worrall L. A conceptual framework for a functional approach to aquired neurogenic disorders of communication and swallowing. In: Worrall LE, Frattali C, editors. Neurogenic communication disorders: a functional approach. New York Stuttgart: Thieme; 2000. p. 1-81.

10. Whiteneck G. Conceptula Models of Disability: Past, Present and Future. 1st ed. Medicine lo, editor. Washington, D.C.: the National Academies Press; 2006.

11. Pragma project. Pragma: aphasia, communication, information. 2002.

12. Aphasia, what now? tips to stimulate comprehensibility [database on the Internet]. vereniging afasie v.z.w. 2005 [cited. Available from: www.afasie.be.

13. Hirsch FM, Holland AL. Beyond Activity: Measuring Participation in Society and Quality of Life. In: Worrall LE, Frattali C, editors. Neurogenic Communication Disorders: a Functional Approach. New York Stuttgart: Thieme; 2000. p. 35-55.

14. Communicating with people who have aphasia: some do's and don't's [database on the Internet]. 2006 [cited. Available from: http://www.aphasia.org/index.php.

15. American Speech Language Hearing Association. Family Adjustment to aphasia. 1997-2005.

16. Make it simple! European guidlines for producing simple-to read-information for persons with a mental impairment [database on the Internet]. ILSMH European Organisation. 1998 [cited.

17. Aphasia Association the Netherlands. Communication tips. 2002.

18. ECM. Centre of expertise on measurements in revalidation (Ecm). 2006 [updated 2006; cited]; Available from: http://www.irv.nl/irv/ecm/index.asp.

19. van Brakel WH, Anderson AM, Mutatkar RK, Bakirtzief Z, Nicholls PG, Raju MS, et al. The Participation Scale: measuring a key concept in public health. Disability and Rehabilitation. 2006 Feb 28;28(4):193203.

20. Engell B, Hutter BO, Willmes K, Huber W. Quality of life in aphasia: Validation of a pictorial self-rating procedure. Aphasiology. 2003;17(4):383-96.

21. Clark MS, Bond MJ. The Adelaide Activities Profile: a measure of the life-style activities of elderly people. Aging (Milano). 1995 Aug;7(4):174-84.

22. Ebrahim S, Barer D, Nouri F. Use of the Nottingham Health Profile with patients after a stroke. Journal of Epidemiology and Community Health. 1986 Jun;40(2):166-9.

23. Wood-Dauphinee SL, Opzoomer MA, Williams JI, Marchand B, Spitzer WO. Assessment of global function: The Reintegration to Normal Living Index. Archives Physical and Medical Rehabilitation. 1988 Aug;69(8):583-90.

24. Trigg R, Wood VA, Hewer RL. Social reintegration after stroke: the first stages in the development of the Subjective Index of Physical and Social Outcome (SIPSO). Clinical Rehabilitation. 1999 Aug;13(4):341-53. 
25. Cavanagh SJ, Hogan K, Gordon V, Fairfax J. Stroke-specific FIM models in an urban population. Journal of Neuroscience Nursing. 2000 Feb;32(1):17-21.

26. Noreau L, Desrosiers J, Robichaud L, Fougeyrollas P, Rochette A, Viscogliosi C. Measuring social participation: reliability of the LIFE-H in older adults with disabilities. Disability and Rehabilitation. $2004 \mathrm{Mar}$ 18;26(6):346-52.

27. Hinckley JJ, Packard ME. Family education seminars and social functioning of adults with chronic aphasia. Journal of Communication Disorders. 2001 May-Jun;34(3):241-54.

28. Hilari K, Byng S, Lamping DL, Smith SC. Stroke and Aphasia Quality of Life Scale-39 (SAQOL-39): evaluation of acceptability, reliability, and validity. Stroke. 2003 Aug;34(8):1944-50.

29. Widen Holmqvist L, von Koch L, Kostulas V, Holm M, Widsell G, Tegler H, et al. A Randomized Controlled Trial of Rehabilitation at Home After Stroke in Southwest Stockholm. Stroke. 1998;29(3):591-7.

30. Nelson E, Wasson J, Kirk J, Keller A, Clark D, Dietrich A, et al. Assessment of function in routine clinical practice: description of the COOP Chart method and preliminary findings. Journal of Chronical Diseases. 1987;40 Suppl 1:55S-69S.

31. Willer B, Ottenbacher KJ, Coad ML. The community integration questionnaire. A comparative examination. American Journal of Physical and Medical Rehabilitation. 1994 Apr;73(2):103-11.

32. Willer B, Rosenthal M, Kreutzer JS, Gordon W, Rempel R. Assessment of the community integration following rehabilitation for traumatic brain injury. Journal of Head Trauma and Rehabilitation. $1993 ; 8(2): 75-87$.

33. Lincoln NB, Gladman JR. The Extended Activities of Daily Living scale: a further validation. Disability and Rehabilitation. 1992 Jan-Mar;14(1):41-3.

34. Whiteneck G, editor. Conceptual and definitional issues in postacute care outcomes assessment. Outcomes Research in Post-Acute care: The intersection of Science, Policy and Practice Conference; 2003; Washington, DC. 
Appendix 1: The used search strategy and the literature search results in Pubmed

\begin{tabular}{|c|c|c|c|c|}
\hline \multicolumn{5}{|c|}{ Limits: English, 1960-2006, title/abstract, adults } \\
\hline Population & Hits & Combination OR & $\begin{array}{l}\text { Combination } \\
\text { AND }\end{array}$ & Result \\
\hline \#1 Disability & 20268 & & & \\
\hline \#2 Handicap & 1920 & & & \\
\hline \#3 Chronic disease & 53262 & & & \\
\hline \#4 Chronic disease [MesH] & 53670 & \#12 115286 & & \\
\hline \multicolumn{5}{|l|}{ Intervention } \\
\hline \#5 Measurement & 54201 & & & \\
\hline \#6 Index & 103134 & & & \\
\hline \#7Scale & 66461 & & & \\
\hline \#8 Questionnaire & 62140 & & & \\
\hline \#9 Instrument & 13161 & & & \\
\hline \#10 Test & 172843 & & & \\
\hline \#11 Tool & 24857 & \#13 416096 & \#14: \#12 AND \#13 25646 & \\
\hline \multicolumn{5}{|l|}{ Intervention } \\
\hline \# 15 Outcome & 143835 & & \#16: \#14 AND \#15 4216 & \\
\hline \multicolumn{5}{|l|}{ Outcome } \\
\hline \#17 Participation & 12137 & & & \\
\hline \#18 Life & 102639 & & & \\
\hline \#19 Life [MeSH] & 26662 & & & \\
\hline \#20 Social & 52994 & & & \\
\hline \# 21 Integration & 5967 & & & \\
\hline \#22 Activities of daily living & 5751 & & & \\
\hline $\begin{array}{l}\text { \#23 Activities of daily living } \\
\text { [MeSH] }\end{array}$ & 19591 & & & \\
\hline \#24 Quality of life & 28960 & & & \\
\hline \#25 Quality of life [MeSH] & 26150 & & & \\
\hline \#26 Activities & 38970 & & & \\
\hline \#27 Domestic & 2871 & & & \\
\hline \#28 Shopping & 505 & & & \\
\hline \# 29 Homemaking & 38 & & & \\
\hline \# 30 employment & 8567 & & & \\
\hline \#31 employment [MeSH] & 10242 & & & \\
\hline \#32 eduaction & 41520 & & & \\
\hline \#33 Education (MesH) & 63254 & & & \\
\hline \#34 hobbies & 199 & & & \\
\hline \#35 hobbies & 119 & & & \\
\hline \#36 leisure activities & 1051 & & & \\
\hline \multirow[t]{2}{*}{ \#37 Leisure activities [MesH] } & 31963 & & & \\
\hline & & \#38 311582 & \#39: \#16 AND \#38 2534 & \\
\hline \multicolumn{5}{|l|}{ NOT } \\
\hline$\# 40 \mathrm{CT}$ & 46407 & & & \\
\hline \# 41 EEG & 12043 & & & \\
\hline \# $42 \mathrm{MRI}$ & 26512 & \# 4378402 & \#44: \#39 NOT \#43 & 1781 \\
\hline
\end{tabular}





\section{Chapter 4:}

\section{Psychometric properties of the Community Integration Questionnaire adjusted for people with aphasia}

Based upon:

Dalemans RJP, de Witte L, Beurskens S, van den Heuvel W, Wade D. Psychometric properties of the Community Integration Questionnaire adjusted for people with aphasia. Archives Physical and Medical Rehabilitation 2009; In press (10-2009). 
The Psychometric Properties of the Community Integration Questionnaire Adjusted for People with Aphasia

Objectives: To describe the feasibility of using an adjusted version of the Community Integration Questionnaire (CIQ) for people with aphasia and to report its psychometric properties in this population (internal consistency, factor analysis, test-retest reliability, convergent validity).

Design: A cross-sectional, interview-based psychometric study. Test-retest reliability was evaluated in 20 people (minimal to severe aphasia) by 2 different interviewers within a 2 week period.

Participants: In total 490 stroke survivors with (minimal to severe) aphasia were approached, of which 165 (34\%) participants returned the answering letter; 150 participants agreed to take part and were interviewed using a structured interview format.

Main outcome measures: $\mathrm{ClQ}$, Frenchay Aphasia Screening Test (FAST), Barthel Index, Darmouth Coop Functional Health Assessment Charts/WONCA Charts, Life Satisfaction Questionnaire.

Results: A total of 150 stroke survivors with aphasia completed a version of the CIQ adjusted for people with aphasia. The CIQ adjusted for people with aphasia is a feasible instrument. The results show good internal consistency for the $\mathrm{CIQ}$ as a whole (standardized Cronbach's alpha $=0.75$ ), excellent test-retest reliability (Intra Class Correlation Coefficient $=0.96$ ), and moderate correlations with the Barthel Index, the COOP-WONCA, and the Life Satisfaction Questionnaire with regard to construct validity. Significant relations were found with regard to age and aphasia severity.

Conclusion: The $\mathrm{CIQ}$ adjusted for people with aphasia seems to be an adequate instrument to assess social participation in people with aphasia. 


\section{Introduction}

In assessing outcomes in people following stroke, the emphasis has moved from impairment to its consequent effects on functional activity and participation in society. Participation is increasingly being recognized as an important domain of rehabilitation research (1-3). Participation is the performance of actual activities in the domains of social life (domestic life, interpersonal life, education and employment, and community, civic and social life) through interaction with others in the contexts in which people live (4). Communication is a key component of interaction and integral to full participation in society (5). People with aphasia are confronted with difficulties in communicative activities and therefore are likely to experience restrictions in his or her participation.

Recently, a systematic review was conducted to identify and describe measures of social participation that may be useful when it is measured in people with aphasia (6). The review found that the Community Integration Questionnaire (CIQ) is possibly suitable for use in people with aphasia. It is particularly suitable because it uses a consistent response set throughout the administration and the instrument ensures a careful ordering of items. It uses short, comprehensible statements, active verbs in the items, and positive language. Metaphors and abbreviations are avoided. All these aspects are important facilitators for use in people with aphasia; however, data regarding its performance in people with aphasia are absent.

The CIQ (7) is intended as a brief, reliable measure of an individual's level of integration in the home and community. A small group of experts developed it for persons who have experienced traumatic brain injury. It consists of 15 questions. Most items are scored on a scale of 0 to 2 . The overall score can range from 0 to 29. A higher score indicates better integration. The $\mathrm{CIQ}$ can be divided into 3 sub-scores, corresponding to integration in the home (12 points), social integration (12 points), and productivity (this subscale consists of 3 items added together into 1 productivity outcome score which depends on the combined score of the 3 items, maximum 5 points) (8). To optimize the applicability to people with aphasia, the instrument was slightly adapted with regard to the layout and grammar (9).

Although a number of scales have been developed over the past decade to assess social participation, most have been evaluated for psychometric properties in stroke samples excluding people with aphasia. Presumably, the use of measurement instruments in people with aphasia is considered difficult due to their communication problems.

The objective of this study was to describe the feasibility of using the CIQ in this population, and to report the psychometric properties of the adjusted $\mathrm{CIQ}$ for people with aphasia (in terms of internal consistency, factor analysis, test-retest reliability, construct validity, and known group differences).

\section{Methods}

We conducted a cross-sectional interview-based psychometric study in 150 people with different severities of aphasia, also including individuals with or without minimal aphasia $(n=32)$. 
We made changes to the CIQ based upon data from the literature $(9,10)$, consultations with expert professionals, and pilot testing with people with aphasia (11). Not only the $\mathrm{CIQ}$ itself but all instruments used in our study were adjusted as follows: a large font (size 16) was used, font style Verdana was used, key concepts were presented in bold type, each question was reduced to its essence (mean question length after simplification of the questionnaires: Barthel Index:9.7, range $=6-13$; COOP-WONCA: 11.5 , range = 8-12; CIQ: 6.9, range = 4-11; LSQ: 5, range = 3-9 ), questions were supported with specifically designed pictograms (see figure 1), an increased amount of white space was used between the question and the response set, each response set was supported by pictograms, and a separate page was used for each question so that people were not distracted by other questions.

Figure 1: examp le of an adjusted item of the Community Integration Questionnaire

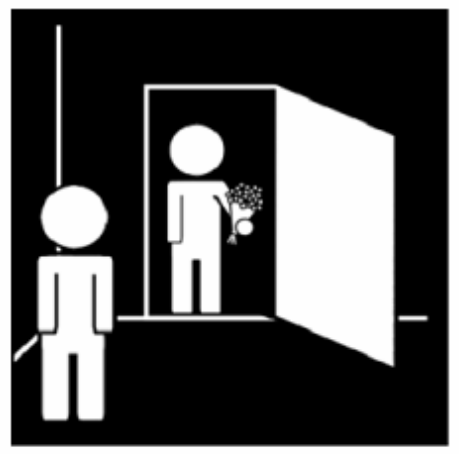

Who usually plans social arrangements?

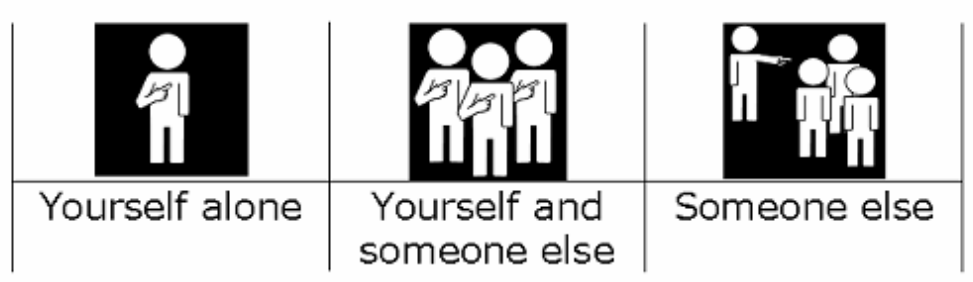




\section{Participants}

To recruit people with aphasia 81 speech and language therapists working in rehabilitation centers, hospitals, and in primary care were contacted. We also approached 3 not-for-profit organizations for people with aphasia. Two not-for-profit organizations for people with brain damage (also including people with stroke) and one stroke unit were approached to recruit participants with stroke. We asked them to recruit people with aphasia. We used the FAST (Frenchay Aphasia Screening Test) to assess the level of aphasia. The inclusion criteria were: being an adult (older than 18 years), being a stroke patient, living at home for more than 3 months since the stroke, having no known history of severe cognitive decline or mental health problems, and speaking and understanding Dutch before the stroke. Candidate participants received an information letter concerning the study which used an outline structure, short sentences, and frequently used words, and included an answering letter in which people could indicate if they were willing to participate in the study. To reduce the exclusion of people with more severe aphasia, caregivers were encouraged to respond on the patient's behalf. After the researcher received the answering letter, the candidate participants or the caregivers (in the case of severe aphasia) were contacted by telephone to make an appointment for the interview in the home setting.

\section{Procedures and Measures}

We interviewed the participants at home in a quiet environment. If the person with aphasia was tired, a break was included. Before the assessment started, the interviewer read aloud a statement of informed consent (using an outline structure, short sentences, and high frequency words). When aspects of the informed consent were not clear to the participant, the interviewer explained these aspects until the participant fully understood the statement of informed consent.

After informed consent was given, the participants were screened for aphasia using the Frenchay Aphasia Screening Test (FAST)(12). The total FAST score (maximum 30) was used to determine overall aphasia severity (0-10: severe aphasia, 11-20: moderate aphasia, 21-26: mild aphasia, 27-30: minimal aphasia). Based upon the FAST score the interview was adjusted to the communicative capabilities of the participant. For example, if the person with aphasia could not read, the interviewer pointed at the pictogram while asking the question, whereas if the participant could read, the interviewer pointed at the bolded key concept in the written question.

In order to investigate convergent validity the following instruments, adjusted for people with aphasia, were assessed in an interview format in addition to the CIQ: demographic data (age, gender, stroke onset, marital status, number of children, children living at home, living situation, highest level education, occupation, and employment status before stroke), the Barthel Index $(\mathrm{BI})(13,14)$ (an instrument to assess functional performance, consisting of 10 items), the COOP-WONCA Charts (an instrument to assess overall functional status, consisting of 6 items)(15), and the Life Satisfaction Questionnaire (LSQ) (consisting of 9 items)(16).

To investigate the feasibility of the $\mathrm{CIQ}$ adjusted for people with aphasia, a structured evaluation with yes/no answers was used in people with minimal, mild, and moderate aphasia. This evaluation was administered after the assessment of the CIQ. 
People with severe aphasia (FAST score: 0-10) were not questioned with regard to feasibility to avoid possible fatigue in collecting the other measurement data.

To investigate the test-retest reliability we interviewed 20 patients (minimal to severe aphasia) twice, within 10-14 days, using different interviewers on each occasion.

\section{Psychometric Analysis}

The criteria used to judge the psychometric properties of the CIQ adjusted for people with aphasia were based on other studies (17-20).

Data analyses were carried out with SPSS 16.0 and Mplus (Muthen\& Muthen version 5, 2007) for Windows.

To investigate feasibility the following aspects were analyzed descriptive: comprehension, assessment length, complexity of instruction, and scoring.

Acceptability was judged to be good if missing data was below $10 \%$, the floor and ceiling effects (i.e. high endorsement rates at the bottom and top ends of the response scale) were less than $80 \%$, and skewness was between 1 and -1 for at least $75 \%$ of the items.

Since most items were categorical the factor analysis (rotated factor analysis (Varimax with Kaiser Normalization)) was based on a polychoric correlation matrix. The factor model should be conceptually clear and meet the following criteria: items should have factor loading above .40 and should not cross load (i.e. load on 2 or more factors with values $\geq 0.4$ and with a difference of $<0.2$ between them) and there should be at least 3 items per factor.

Internal consistency was assessed using standardized Cronbach's Alpha (a positive rating for internal consistency was given when standardized Cronbach's Alpha was between 0.70-0.95). All factor s should have an internal consistency above 0.70 , otherwise the factor analysis was repeated with less factors.

Test-retest reliability was analyzed with Intra-Class Correlation coefficients (ICC $>0.75$ is excellent, from $0.60-0.74$ is good, from $0.40-0.59$ is moderate, and values less than 0.40 are poor (21)).

To investigate the construct validity we used the convergent validity by analyzing the following relationships (the expected association is given): higher COOP-WONCA score (indicating more problems) is related to lower CIQ scores (22), higher functional performance $(\mathrm{BI})$ is related to higher $\mathrm{CIQ}$ scores $(23,24)$, and higher life satisfaction (LSQ) is moderately related to higher social integration CIQ scores (25-27). Further the following expectations were analyzed: less severe aphasia (higher FAST scores) is related to higher $\mathrm{CIQ}$ scores, lower age is related to higher $\mathrm{CIQ}$ scores $(17,28)$.

\section{Results}

In total 490 people were approached of which 165 (34\%) participants returned the answering letter. There were no data available of the individuals who did not returned the answering letter, because they were not directly approached by the researchers. A total of 150 (31\%) participants who returned the answering letter agreed to take part. The reasons for not participating were: being too ill (4), participating in other research projects (3), having had another stroke (7), and change of mind (1). In table 1 the char- 
acteristics of the participants are presented, together with the characteristics of the 20 people tested twice, and the 15 people who withdrew.

Table 1: Characteristics of the participants

\begin{tabular}{|c|c|c|c|}
\hline Characteristic & $N=150$ & Test-retest $\mathrm{N}=20$ & $\mathrm{~N}=15^{*}$ \\
\hline Age & (\%) & & \\
\hline Range (years) & $\begin{array}{l}35-87: \\
7(5)<46 Y \\
76(51) 46-65 y \\
67(45) 65<y\end{array}$ & $35-82$ & $48-85$ \\
\hline Mean (SD) - Median & $64.2(11.0)-64$ & $64.9(12)-67.5$ & 65 (10.8)-66 \\
\hline $\begin{array}{l}\text { Gender } \\
\text { Male (\%) } \\
\text { Stroke onset (months) }\end{array}$ & 89 (59) & $12(60)$ & $8(53)$ \\
\hline Mean (SD)- Median & $90.6(80.9)-67.5$ & $91.4(81.9)-66$ & $90.9(39.4)-88$ \\
\hline $\begin{array}{l}\text { Partner } \\
\text { Yes (\%) } \\
\text { Children }\end{array}$ & $109(73)$ & $16(80)$ & $11(73)$ \\
\hline Mean (SD) - Range & $2.1(0.99)-0-5$ & $2.5(1.1)-1-5$ & \\
\hline $\begin{array}{l}\text { Children at home } \\
\text { Yes (\%) } \\
\text { Living situation }\end{array}$ & $22(15)$ & $5(25)$ & \\
\hline Urban (\%) & $64(43)$ & $6(30)$ & \\
\hline Highest education & & & \\
\hline Elementary School (\%) & $28(19)$ & $3(15)$ & \\
\hline $\begin{array}{l}\text { High school (\%) } \\
\text { Associate`s degree (\%) }\end{array}$ & $\begin{array}{l}55(37) \\
36(24)\end{array}$ & $\begin{array}{l}5(25) \\
7(35)\end{array}$ & \\
\hline Bachelor`s degree (\%) & $27(18)$ & $4(20)$ & \\
\hline University (\%) & $4(3)$ & $1(5)$ & \\
\hline Occupation & & & \\
\hline House hold (\%) & $11(7)$ & $2(10)$ & \\
\hline Blue collar (\%) & $76(51)$ & $8(40)$ & \\
\hline White collar (\%) & $63(42)$ & $10(50)$ & \\
\hline Job situation before CV & & & \\
\hline Retired (\%) & $41(27)$ & $5(25)$ & \\
\hline No job (\%) & $19(13)$ & $3(15)$ & \\
\hline Seeking job (\%) & $4(3)$ & $0(0)$ & \\
\hline Part-time job (\%) & $21(14)$ & $3(15)$ & \\
\hline Full- time job (\%) & $65(43)$ & $9(45)$ & \\
\hline FAST & (\%) & & \\
\hline Severe (0-10) & $13(9)$ & $1(5)$ & \\
\hline Moderate (11-20) & $30(20)$ & $5(25)$ & \\
\hline Mild (21-26) & $75(50)$ & $11(55)$ & \\
\hline Minimal (27-30) & $32(21)$ & $3(15)$ & \\
\hline
\end{tabular}

FAST: Frenchay Aphasia Screening Test, *withdrew from 165 who responded initially

The feasibility of the CIQ was good. Participants reported good comprehension of the items. The mean assessment duration was 15 minutes. The instrument appeared to be easy to conduct with simple instructions. Scoring was easy: scores from the subscales are summed together. Although people with severe aphasia were not interviewed with 
regard to feasibility, they all expressed verbally or non verbally that they were happy that they could express themselves through the measurements.

The acceptability of the CIQ adjusted for people with aphasia was good. There were no missing data, with the exception of one item: "who takes care of the children." This item did not apply to 128 of the participants. We followed the scoring guidelines of the $\mathrm{CIQ}$ : 'For item 4, if there are no children under 17 in the home, the average (mean) score for items 1 through 3 and item 5 should be substituted. (29) Two items were negatively skewed and 2 items were positively skewed. There were no floor and ceiling effects in the overall scores.

The factor analysis revealed 2 factors. The rotated factor analysis based on a polychoric correlation matrix is shown in table 2 for the $\mathrm{CIQ}$ items in the whole sample. Seven variables had significant loadings on factor 1 , four variables on factor 2 (see table 2).

Table 2: Factor loading on two factors for $\mathrm{CIQ}$ items adjusted for people with aphasia in total sample

\begin{tabular}{lll}
\hline $\mathrm{N}=150$ & Factor 1 & Factor2 \\
\hline Standardized Cronbach`s alpha & $0.852(0.850)$ & $0.504(0.423)$ \\
ICC & $0.850(0.811-0.884, \mathrm{p}<0.01)$ & $0.423(0.264-0.557), \mathrm{p}<0.01)$ \\
Who shops for necessities in the & 0.871 & 0.123 \\
household? & & \\
Who prepares meals? & 0.873 & 0.105 \\
Who does everyday housework? & 0.695 & -0.017 \\
Who cares for the children? & -0.251 & -0.189 \\
Who plans social arrangements? & 0.548 & 0.023 \\
Who looks after personal fi- & 0.655 & 0.063 \\
nances? & & \\
Frequency of shopping? & 0.677 & -0.106 \\
Frequency of leisure activities & 0.070 & -0.734 \\
Frequency of visiting friends & 0.317 & -0.455 \\
With who do you participate in & 0.008 & -0.643 \\
leisure activities? & & \\
Do you have a best friend? & -0.088 & -0.205 \\
Frequency of travel outside the & 0.574 & -0.467 \\
home & & \\
Productivity & -0.059 & -0.321 \\
\hline
\end{tabular}

Rotated Factor analysis (Varimax with Kaiser Normalization) based on polychoric correlation matrix

However, item 12 cross loaded on the two factors, furthermore, factor two had a low internal consistency (standardized Cronbach`s alpha $=0.504$ ), so factor analyses was repeated with one factor. The internal consistency of one factor was good 0.754 (see table 3). Deleting five items $(4,8,10,11,13)$ with low factor loading revealed an internal consistency of .787. 
Table 3: Factor loading on one factor for CIQ items adjusted for people with aphasia in total sample

\begin{tabular}{ll}
\hline $\mathrm{N}=150$ & Factor 1 \\
\hline Standardised Cronbach`s alpha & $0.754(0.671)$ \\
ICC & $0.671(0.588-0.744), \mathrm{p}<0.01$ \\
Who shops for necessities in the household? & 0.861 \\
Who prepares meals? & 0.875 \\
Who does everyday housework? & 0.694 \\
Who cares for the children? & -0.243 \\
Who plans social arrangements? & 0.548 \\
Who looks after personal finances? & 0.651 \\
Frequency of shopping? & 0.678 \\
Frequency of leisure activities & 0.134 \\
Frequency of visiting friends & 0.348 \\
With who do you participate in leisure activities? & 0.069 \\
Do you have a best friend? & -0.070 \\
Frequency of travel outside the home & 0.593 \\
Productivity & -0.034 \\
\hline
\end{tabular}

Test-retest reliability was excellent (ICC agreement $=0.96)$. Spearman's rho correlation coefficients were computed to assess the convergent validity: the relationships between the CIQ and the COOP-WONCA, BI, and the LSQ and age and severity of aphasia are presented in table 4 . The relationships were as expected.

Table 4: Correlations of the Community Integration Questionnaire scores with COOPWONCA, BI and LSQ and known group differences

\begin{tabular}{lll}
\hline & Social integration subscale & Total CIQ score \\
\hline COOP-WONCA total score & & $-.160^{*}$ \\
Barthel Index & $.354^{* *}$ & $.414^{* *}$ \\
Life Satisfaction Questionnaire & & $.365^{* *}$ \\
Severity Aphasia & & $-.326^{* *}$ \\
Age &
\end{tabular}

${ }^{* *} \mathrm{r}$ is significant at 0.01 level (2-tailed) ${ }^{*} \mathrm{r}$ is significant at 0.05 level (2-tailed)

\section{Discussion}

The present study was intended to describe the feasibility and to analyze the psychometric properties of the $\mathrm{CIQ}$ adjusted for people with aphasia.

We have shown that the CIQ can be used in people with aphasia up to a severe level with minor adaptations, and that the data collected seem both reliable and valid. The results suggested that the adapted questionnaire gives information comparable to that obtained using the original version in people with brain injuries without severe communication impairments $(8,30-32)$. We did note that one item, concerning child care, is not often applicable in a population of people after stroke, as has been noted before. Further, we remark that there was a relatively low response rate which could compromise the representativeness of the sample for this population. The characteris- 
tics of the 15 individuals who respond to the initial mailing but refused to participate, are comparable to those who did. It might be that the 325 individuals who were contacted by the different associations in the initial invitation letter did not meet all the inclusion criteria and therefore did not respond.

There is a good similarity between the factor analysis in this study and that in the study of Sander (8) with the same items loading on the home integration subscale . However, whereas Sander found three factors, we could only found two factors. Because the second factor had a low internal consistency, we decided to include only one factor. Sander used rotated factor analyses based on Pearson $r$, however the items in the $\mathrm{CIQ}$ are mostly categorical, therefore we decided to use a rotated factor analysis based on a polychoric correlation matrix. This might be an explanation for the differences found. Further, Sander used a separate scoring system for the 3 different items of the productivity subscale, leading to 3 items in the analysis, whereas in this study we used the original scoring system, leading to only 1 productivity score. This might be an explanation of the differences found.

The internal consistency of the CIQ as a whole was good and was comparable to that in the study of Willer et al. (7) (Cronbach's Alpha $=0.76$ ). The internal consistency of the CIQ subscales was not analyzed in this study because we found another factor structure, making it impossible to compare internal consistency with the subscales of the original $\mathrm{CIQ}$.

The test-retest reliability of the CIQ adjusted for people with aphasia was excellent, though the number of participants was rather small (cf. Willer et al. ${ }^{7} \mathrm{n}=16$, rho $=$ 0.91; van Baalen ${ }^{21} n=14, I C C=0.69$ ). Further testing in a larger population might be needed. All the same, the distribution of the participants in the test-retest was quite similar to the total research population in this study and by using different interviewers at the 2 measurement moments we have tested reliability in the most relevant and demanding way.

The expected relationships between the CIQ adjusted for people with aphasia and the other instruments were found. The weak relationship between the $\mathrm{CIQ}$ as a whole and the COOP-WONCA was surprising. Although there were no other studies that reported a relationship between the CIQ and the COOP-WONCA, one could expect at least a moderate relationship because the COOP-WONCA includes items concerning perceived problems in aspects related to social participation such as daily activities, social activities, and overall health.

With regard to age and severity of aphasia, similar relations were found in this study to the study of Kaplan (17) and Winkler et al. (33). The CIQ adjusted for people with aphasia appears to have found comparable psychometric properties as in other populations.

Because all the instruments in this study were adjusted to make them suitable for use in people with aphasia, we might have validated the other instruments as well, to a certain extent. With regard to measuring social participation in people with aphasia, the $\mathrm{CIQ}$ may be the best available instrument. One could discuss however, that integration may not be the same idea as participation. Participation is a construct that is more reflective of an insider'views wherein outcomes relate to engagement and experiencing accessibility, with full involvement and having an influence on the community. Because there is no 'golden standard' developed to measure participation, the 
use of the CIQ is a good attempt to capture a big part of a construct that is still in development.

In future research, it might be interesting to study the possibilities of self-reporting in people with minimal and mild aphasia, without an interview format and using the adjusted measurements. One presumes people complete questionnaires in a trustworthy manner; however, one can never be sure, even in a population without communicative impairments. Nonetheless, by making instruments better adjusted for use in people with aphasia, an important step is made towards including this population in stroke research. The fact that $100 \%$ of the participants were able to complete the adjusted CIQ in an interview format suggests that use of the CIQ adjusted for people with aphasia would allow most people with aphasia to participate in research, hence minimizing the need for proxy participants.

\section{Conclusions}

The CIQ seems to be a feasible, adequate, reliable, and valid instrument with which to assess social participation in people with aphasia.

\section{Acknowledgements}

Thanks to all the stroke survivors who participated in this study. 


\section{References}

1. Salter KL, Foley NC, Jutai JW, Teasell RW. Assessment of participation outcomes in randomized controlled trials of stroke rehabilitation interventions. International Journal of Rehabilitation Research. 2007 Dec;30(4):339-42.

2. van der Mei SF, van Sonderen EL, van Son WJ, de Jong PE, Groothoff JW, van den Heuvel WJ. Social participation after successful kidney transplantation. Disability and Rehabilitation. 2007 Mar 30;29(6):473-83.

3. van de Ven L, Post MW, de Witte L, van den Heuvel W. It takes two to tango: the integration of people with disabilities into society. Disability and Society. [research article]. 2005 may 2005;20(3):311-29 (19).

4. Dalemans RJP, de Witte L, van den Heuvel W, Wade D. A description of social participation in working age people with aphasia: a review of the literature. Aphasiology 2008;22(10):1071-91.

5. Eadie TL, Yorkston KM, KLasner ER, Dudgeon BJ, Deitz JC, Baylor CR, et al. Measuring Communicative Participation: a review of Self-Report Instruments in Speech-Language Pathology. American Journal of Speech-Language Pathology. 2006 november 2006;15:307-20.

6. Dalemans RJP, de Witte L, Lemmens J, Wade D, van den Heuvel W. Measures for rating social participation in people with aphasia: a systematic review. Clinical Rehabilitation. 2008;22(16):542-55.

7. Willer B, Ottenbacher KJ, Coad ML. The Community Integration Questionnaire: a comparitive examination. American Journal of Physical and Medical Rehabilitation. 1994 73:103-11.

8. Sander AM, Fuchs KL, High WM, Jr., Hall KM, Kreutzer JS, Rosenthal M. The Community Integration Questionnaire revisited: an assessment of factor structure and validity. Archives of Physical Medicine and Rehabilitation. 1999 Oct;80(10):1303-8.

9. Dalemans RJP, Wade D, Van den Heuvel W, De Witte L. Facilitating the participation of people with aphasia in research: a description of strategies. Clinical Rehabilitation. 2009;23 948-59.

10. Aleligay AA, WorrallL.E., Rose TA. Readability of written health information provided to people with aphasia. Aphasiology. 2008;22(4):383-407.

11. Dalemans RJP, Wade D, Van den Heuvel W, De Witte L. Doing research in people with aphasia: yes, we can! Clinical Rehabiliation (submitted). 2008.

12. Enderby PM, Wood VA, Wade DT, Hewer RL. The Frenchay Aphasia Screening Test: a short, simple test for aphasia appropriate for non-specialists. International Rehabilitation Medicine. 1987;8(4):166-70.

13. Collin C, Wade DT, Davies S, Horne V. The Barthel ADL Index: a reliability study. International Disability Studies. 1988;10(2):61-3.

14. Wade DT, Collin C. The Barthel ADL Index: a standard measure of physical disability? International Disability Studies. 1988;10(2):64-7.

15. Van Weel C. Functional status in primary care: COOP/WONCA charts. Disability and Rehabilitation. 1993 Apr-Jun;15(2):96-101.

16. Fugl-Meyer AR. Happiness and domain-specific life satisfaction in northern Sweden. Clinical Rehabiliation 1991;5:25-33.

17. Kaplan CP. The community integration questionnaire with new scoring guidelines: concurrent validity and need for appropriate norms. Brain Injury. 2001 Aug;15(8):725-31.

18. Hilari K, Byng S, Lamping DL, Smith SC. Stroke and Aphasia Quality of Life Scale-39 (SAQOL-39): evaluation of acceptability, reliability, and validity. Stroke. 2003 Aug;34(8):1944-50.

19. Nunnally JC, Bernstein IH. Psychometric theory. 3rd ed. New York: Mc-Graw-Hill; 1994.

20. Terwee CB, Bot SDM, de Boer MR, van der Windt DAWM, Knol DL, Dekker J, et al. Quality Criteria were proposed for measurement properties of health status questionnaires. Journal of Clinical Epidemiology. 2007;60:34-42.

21. van Baalen $B$, Odding $E$, van Woensel MP, ME. R. Reliability and sensitivity to change of measurement instruments used in a traumatic brain injury population. Clinical Rehabiliation. 2006;20(8):686-700.

22. Charlifue S, Gerhart K. Community integration in spinal cord injury of long duration. NeuroRehabilitation. $2004 ; 19(2): 91-101$.

23. Doig E, Fleming J, Tooth L. Patterns of community integration 2-5 years post-discharge from brain injury rehabilitation. Brain Injury. 2001 Sep;15(9):747-62. 
24. Fleming J, Tooth $\mathrm{L}$, Hassell M, Chan W. Prediction of community integration and vocational outcome 2-5 years after traumatic brain injury rehabilitation in Australia. Brain Inj. 1999 Jun;13(6):417-31.

25. Reistetter TA AB. Appraising evidence on community integration following brain injury: a systematic review. Occupational Therapy International. 2005;12(4):196-217.

26. Reistetter TA SJ, Trujillo L, Abreu BC. Examining the Community Integration Measure (CIM): a replication study with life satisfaction. NeuroRehabilitation. 2005;20(2):139-48.

27. Hansen NS, Forccheimer M, Tate DG, Luera G. Relationships among community integration, coping strategies and life satisfaction in a sample of persons with spinal cord injury. Topics in Spinal Cord Injury Rehabilitation 1998;4:56-72.

28. Fleming J, Tooth L, Hassell M, Chan W. Prediction of community integration and vocational outcome 2-5 years after traumatic brain injury rehabilitation in Australia. Brain Injury. 1999 Jun;13(6):417-31.

29. Ontario Brain Injury Association. The Community Integration Questionnaire: Scoring Guidelines. St.Catharines: OBIA; 2008 [updated 2008; cited 1991]; Available from: www.obia.on.ca.

30. Zhang L, Abreu BC, Gonzales V, Seale G, Masel B, Ottenbacher KJ. Comparison of the Community Integration Questionnaire, the Craig Handicap Assessment and Reporting Technique, and the Disability Rating Scale in traumatic brain injury. Journal of Head Trauma Rehabilitation. 2002 Dec;17(6):497-509.

31. Kuipers $P$, Kendall M, Fleming J, Tate R. Comparison of the Sydney Psychosocial Reintegration Scale (SPRS) with the Community Integration Questionnaire (CIQ): psychometric properties. Brain Injury. 2004 Feb;18(2):161-77.

32. Willer B, Ottenbacher KJ, Coad ML. The community integration questionnaire. A comparative examination. American Journal of Physical Medicine and Rehabilitation. 1994 Apr;73(2):103-11.

33. Winkler D, Unsworth C, Sloan S. Factors that lead to successful community integration following severe traumatic brain injury. Journal of Head Trauma and Rehabilitation. 2006;21(1):8-21. 



\section{Chapter 5:}

\section{Social participation through the eyes of people with aphasia}

Based upon:

Dalemans RJP, de Witte L, Wade D, van den Heuvel W. Social participation through the eyes of people with aphasia. International Journal of Language and Communication Disorders 2009; in press (July 2009). 
Social participation through the eyes of People with Aphasia

Background: Little is known about the way people with aphasia perceive their social participation and its influencing factors.

Aims: To explore how people with aphasia perceive participation in society and to investigate influencing factors.

Methods and Procedures: In this qualitative study 13 persons with aphasia and 12 central caregivers kept a pre-structured diary over two weeks, followed by a semistructured interview. Diaries and interviews were transcribed verbatim and analysed by two researchers independently using codes, categories and central themes inductively. Plausibility of the analyses was discussed several times with a third independent senior-researcher. In a focus group interview the results were discussed with the participants.

Outcomes and Results: The number of social activities and the character of these activities are not as important as the perceived engagement in the social activities for the participants. People with aphasia feel isolated but want to feel engaged. They feel burdensome to others and wish to function in an ordinary way. Extracting information from conversations is difficult but they want to know what is going on. Often they are not able to work and they wish to contribute to the community in other ways. Although they often feel stigmatised, they wish to be respected. Often they do not reach that goal. Perceived factors influencing engagement in social participation can be divided into personal, social and environmental factors. The following personal factors are reported: motivation, physical and psychological condition and communication skills. The social factors are: the role of the central caregiver and the characteristics of the communication partner(s), namely willingness, skills and knowledge. The environmental factors refer to quietness and familiarity of the place in which the person with aphasia live.

Conclusions: Social participation is a theoretical concept that people with aphasia do not use. Instead people speak in terms of engagement, involvement, having a feeling of belonging. People with aphasia describe the degree of engagement in activities in social life domains (i.e. the quality of activities) as more important than the quantity of performing activities. 


\section{Introduction}

Social participation is becoming more of a concern in health care and as a result changes may occur in the way people with aphasia receive treatment. Social participation is defined here as the performance of people in social life domains through interaction with others in the context in which they live. In 2001, the World Health Organization published the International Classification of Functioning, disability and health. They define participation as the involvement in life situations (1). Others have suggested that the meaningfulness of activities undertaken is also critical when considering social participation (2). Participation as conceived of in the World Health Organisation's International Classification of Functioning, disability and health (1) is a complex concept and it is unclear how people actually perceive participation.

To participate you need to interact. Interaction implies communication and communication abilities are disrupted in people with aphasia. Aphasia results in social and psychological strains which affect relationships and participation in different social life domains (3-6). Someone with aphasia is confronted with an enormous challenge to fulfil his or her roles, for example as a partner, parent, friend, club member, or employer. Aphasia rehabilitation usually aims to help patients regain sufficient communicative function to participate in life (7).

The psychosocial aspects of aphasia have been investigated in some detail, stressing the impact of motor and language impairments on the system of social relationships $(4,8-10)$, and the burden that these impairments represent for the social group to which the person with aphasia belongs ((11-14). Other studies have quantified participation and show that participation is reduced in people with aphasia (15-17), especially the contacts with friends (17).

However, little is known about how people with aphasia perceive their participation in social life and what factors influence this (18). The purpose of this study was to explore how people with aphasia perceive participation in society and to gain insight into the perceived influencing factors.

\section{Method}

A qualitative study design was chosen to get in-depth data and to focus on individual experience and perspectives. People with aphasia and their central caregivers kept a diary and were interviewed afterwards. Data were analysed and discussed with the participants (persons with aphasia and their central caregivers) in a focus group interview.

\section{Data collection}

Participants were approached by their rehabilitation practitioner, their speech language therapist or the chairman of the Regional Aphasia Association, and were asked to participate in this study. They had to meet the following criteria:

having aphasia caused by a stroke;minimum 6 months post onset;having a central caregiver who also agreed to participate in the study; be living at home; be at least 20 years old. 
Further, to ensure the inclusion of people with key characteristics relevant to the study, we used the following sampling criteria: people with different degrees of aphasia severity (severe, moderate, mild, minimal), male/female, different current levels of mobility, wide range time post onset.

People who agreed to participate received a letter in which the study was explained in aphasia-friendly language, using short sentences and an outlined structure. At the end of the letter the telephone number of the researcher was given, making it possible to receive more information. After consent was given, the researcher received the telephone numbers of the participants and made the first appointment.

During the first visit, the interviewer became acquainted with the participants. Further, the Frenchay Aphasia Screening Test (FAST) (19) was administered to measure the communicative abilities of the person with aphasia. The FAST consists four subscales: comprehension (10 items), expression (10 items), reading (5 items) and writing (5 items). The total FAST score (maximum 30) was used to determine overall aphasia severity (1-10: severe aphasia, 11-20: moderate aphasia, 21-26; mild aphasia, 27-30: minimal aphasia). The interviewer gave oral instructions - adjusting sentence length and using gestures dependent upon the communicative abilities of the person with aphasia - and written information regarding the diary.

Over two weeks the participants were asked to keep a record of activities undertaken by the person with aphasia in the different social life domains. The social life domains (domestic life, relationships, education and employment, leisure activities, community, civic and social life) were visually structured in the diary (see appendix 1): there was a separate space for each social life domain in the diary. An important advantage of writing a diary is the absence of time pressure. To facilitate the person with aphasia in reporting activities, a set of stickers presenting different activities, was included. The central caregiver could assist the person with aphasia writing down the activities. A separate space for each day was reserved for the partner to express his/ her point of view with regard to the participation of the person with aphasia.

The interviewer returned to pick up the diary and to make an appointment for the semi-structured interview two weeks later. In addition, the participants received the interview protocol. The data from the diaries formed the basis for the semi-structured interview by referring to the data in the diary at the beginning of the interview and by referring to examples reported in the diary during the interview.

The semi-structured interview took place in a quiet environment in the home of the participants. An interview protocol consisting of five main questions based upon the definition of social participation (actual performance of activities in social life domains in interaction with others in the context in which they live) guided the interview (see appendix 2). A short break was taken if the person with aphasia needed it.

Before the interview started the roles of the interviewer and the assistant were explained to the participants. The assistant observed non-verbal communication, took notes, and monitored the audiotape recording.

The person with aphasia was encouraged to make use of alternative and augmentative communication when needed. Paper and pencils, pictograms and photos were used to facilitate communication.

The central caregiver had a dual role during the interview, namely the role of translator (assisting the person with aphasia in communicating with the interviewer) 
and also the role of informant (reporting his or her point of view of the social participation of the person with aphasia).

After the data collection, the participants were invited to take part in a focus group interview to check our interpretation of the data. The results were first presented using a Power-Point presentation. Fragments were used anonymously to illustrate the results. Then the participants were invited to discuss the results. Notes were made by the interview-assistant. The interviewer encouraged all the participants to express their opinion and checked that all participants talked slowly, after one another, and stressed their central theme, so that people with aphasia could follow and participate more easily in the discussion.

\section{Ethical Considerations}

The procedure was explained and informed consent was obtained. To ensure that the rights of the persons with aphasia were maintained with regards to consent to participate, rechecking the individual's willingness to remain involved was included. The interviewer tried to be vigilant at all times to nonverbal signals indicating discomfort or stress. The participants were informed that they did not have to complete the diary nor to give an answer to the questions in the interview and that they could stop at any time. Only the interviewer and the interview-assistant had access to individual participant's responses and the anonymity of individuals was protected. The study was approved by the Medical Ethical Committee of the Institute for Rehabilitation Research (IRV).

\section{Data analysis}

The raw data were separately transcribed verbatim, making a clear distinction between the person with aphasia and his/her central caregiver. Data from the diaries were imported into Excel for each participant. Performed activities in the different social life domains were written down, as well as factors influencing these activities.

The interviews were imported into Kwalitan (20)(a program that supports the researcher in doing qualitative analysis; it takes care of an efficient storage of the data and offers several features to analyze the qualitative material) and analysed by two independent researchers and discussed with one senior-researcher. Analysis took place directly after the data collection. All the transcriptions were read in full to acquire a feeling for the context. Notes were made to summarize thoughts and descriptions of each participant. The analysis of the data focused on the perception of the person with aphasia; data from the central caregivers were mainly used as proxy information.

In the first phase, open coding was applied to the data from the first 10 participants. The transcriptions were divided into passages that characterized, clarified or explained aspects of participation. All data were coded independently by the two researchers. They came together regularly to discuss the codes. Mostly there was good agreement concerning the given codes. If the researchers disagreed, the different points of view were discussed until agreement was reached. Then codes were discussed with the senior-researcher. All codes were treated with equal value, with each perspective having equal weight. Codes related to each other were placed in initial categories. Overlapping, repetitive or irrelevant codes were eliminated. This was done 
independently by two researchers. Next, the codes were classified in categories and discussed with the senior-researcher and two more supervisors who were not involved so intensively with the data-analysis to receive a more independent point of view.

In a second phase, the meaningfulness, accuracy and consistency of the categories were assessed in discussion with the senior-researcher and the two supervisors.

Further, three more interviews took place to confirm data saturation, specifically checking that no new items or categories emerged.

In a third phase, results were presented and discussed with the participants in the focus group interview. Questions were asked to check if the participants agreed with the central concept and the presented categories. If consensus was found, their suggestions were taken into account to alter the categories.

\section{Results}

In total 20 people with aphasia and their central caregiver were approached. Of those, 12 couples participated in the study. Reasons for not participating in the study were unknown because the researcher could only approach the candidates with their permission. Also one person with aphasia living alone was included, to get a broader view, because in the first interviews having a partner at home seemed important for participating in society. This person - living alone - had a moderate aphasia and used a communication book to support her expression. In total, 13 persons with aphasia (including the additional three used to check data saturation) (see table 1) and 12 central caregivers (eleven spouses and one daughter) were included. The mean age of the persons with aphasia was 57,4 (range 45-71, 6 participants $\leq 55$ y). The communicative abilities varied considerably, one person had minor expression difficulties, but perceived a lot of problems, other persons had problems with comprehension as well as expression, with writing and/or reading (see table 1). Also the mobility level varied a lot between the participants, some walking independently, some using a walking stick or a walking frame and other sitting in a wheelchair.

Diaries were kept by twelve participants. One person, having a severe aphasia, chose not to fill in the diary because it required too much energy. The expressions in the diaries were very short, using one or two word sentences, making a combination between one word sentences and stickers, or only using the stickers to make clear which activities they had been doing. Some participants mentioned many influencing factors, others rarely named influencing factors. Sometimes a remark was placed by the central caregiver. Some central caregivers described the atmosphere of the day; others repeated the performed activities more in detail. One central caregiver gave a separate diary with his experience to make it less confronting for his partner.

The interview duration varied from 90 to 140 minutes. The participants agreed with each other most of the time. However, when one person left the room for a little while, sometimes other perceptions or remarks were given like:

${ }^{1}$ ["Partner Mia: 'It is really hard for her to discuss this."]

\footnotetext{
${ }^{1}$ (Quotations of the person with aphasia will be referred to as for example Mia; quotations of the partner of the person with aphasia will be referred to as for example Partner Mia; a series of quotations from one conversation will be marked with [beginning of quotation from one conversation and] ending of quotation from one conversation)
} 
["Partner Jef: I always have to tell him that he has to clean up his stuff, otherwise he does not do anything."]

The focus group interview lasted 90 minutes with a break of 30 minutes. The participants strongly agreed with the results and recognised it in their own situation. No new insights arose in this focus group interview. People gave more examples that confirmed the results.

\section{Social participation}

All the participants described a good social network before aphasia with many contacts with friends, colleagues, family or club members. Some participants reported they were the talkers, the joke makers in social occasions before aphasia onset, others described staying in the background before aphasia onset. The pre-morbid social preferences seemed to be differently important for the way people perceived their current social participation. Some talkers and joke makers felt as if they could not be themselves anymore even if they only had a minimal aphasia.

People with aphasia showed considerable variation in the amount of social activities undertaken, with some rarely leaving the house but others being more active. All persons with aphasia and their central caregivers described the possibilities in participating in society as diminished when having aphasia.

Many people talked about 'social participation' but in the way they talked about it, they seemed to be referring to their perceived engagement in social activities (see box 1). We felt that doing things, being active and participating in social life domains were not their most important goals. Instead they wanted to feel engaged and to have a voice. They wanted to function in an ordinary way, to be respected, to know what is going on, to do things with others without being a burden, to take part in the commu-

Box 1: perceived engagement in participation defined by:

- Being involved

- Not being burdensome

- Knowing what is going on

- Taking part

- Being respected nity.

\section{Involvement}

People with aphasia often felt isolated from others, for example when they attended family parties. They wanted to be involved, but they felt alone even though they were standing around a table with other people. Even when people with aphasia tried to participate in conversations, after a very short while the conversation was picked up by the other conversation partners without aphasia and they were left out again.

["Mia: They don't involve me. You could have told me that, I don't like it than."] ["Bert: I do not play well, the Clarinet. But, I keep going to the group to stay involved."] 


\section{Not burdensome}

Some people with aphasia said they felt they were a burden to others and therefore stopped doing certain activities. They wanted to be treated in an ordinary way and to be able to do things together with others, without being burdensome.

["Rita: They wanted that..from euh..God, you don't have a problem, come. To cheer me up. I want to be there, but euh...that doesn't work that way... yes, the dizziness and euh than the awful fatigue...at a certain moment I am totally lost and than I have to euh...leave them behind, than I say euh...so now follow through...I will sit down here... But yes, perhaps it is also my own fault...than I sit there and than I think...euh...as you want to shop well go along and let me be...]

\section{Knowing what is going on}

From the data it emerged that people were often not able to extract information from conversations. They could not take part in a club voting process, in a conversation in the pub or elsewhere, because they missed information or did not understand what was said. People with aphasia stated that they wanted to know what was going on, making participation in conversations and decisions possible.

["Bert: I think that they also also also could not follow me and don't understand, they...that I don't understand it either...No, no, I say it incorrectly, they don't understand that I don't understand it. Interviewer: And you don't say that you can't follow anymore? Bert: No. Interviewer: So you miss about $25 \%$ of what they are talking about? Bert: Yes and then I can not vote without my wife giving me more explanation."]

\section{Taking part}

Most of the persons with aphasia stopped working after aphasia onset, but they wanted to take part in the community, to do something for others.

[" Roos: I hope I can do voluntary work in a shop."]

\section{Being respected}

Many patients indicated that they were not seen as a 'whole person'. They sometimes even felt that unknown people thought they were crazy. They reported that people in the direct environment did not often take into account the wishes and possibilities of the person with aphasia.

["Jef: Yes, seeing those men there, there are a few that have a plate saying I have aphasia. I don't do that anymore... They don't give a shit, nothing! They don't call it out loud, they are very, how do I have to say it, euh, I euh, ohoh...(long silence) Interviewer: yes and how do you notice that, that they don't care? Jef: yes, yes, rapidly and much too much and to all to hectic and you can not keep track of it all."] 


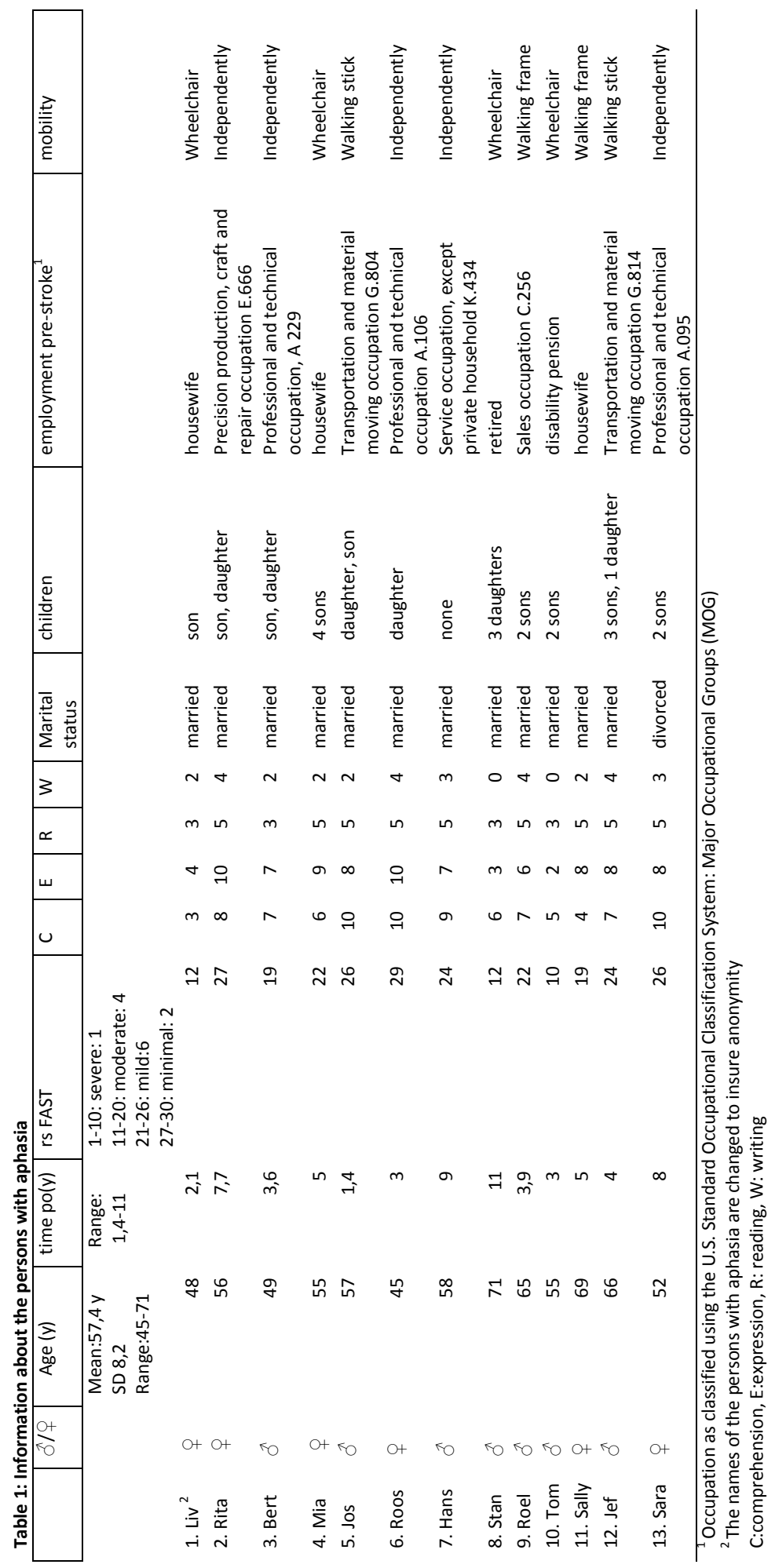




\section{Influencing factors}

Participants mentioned different factors promoting or hindering the level of engagement in participation. These can be categorised into personal, social and environmental factors (see box 2).

\section{Personal factors}

Motivation. There were persons with aphasia who did participate. Those persons wanted to stay active, to be part of something bigger and to act upon that: they were driven by motivation. They kept on trying, despite the reaction of others. They took time to relax and concentrated on possibilities. They prepared the activities they wanted to do.

["Partner Bert: He also just tries, you know. We were on holiday than and he went to get a sandwich. I came back and he had to laugh. He said: they thought I was an Italian. But all together, you got what you wanted, I said. Bert: yes, I ignore it. They just need to take me as I am."]
Box 2: Identified influencing factors:

\section{Personal factors:}

- Motivation

- Physical and psychological condition

- Communication skills

\section{Social factors:}

- The role of the central caregiver

- Characteristics of the communication partner

$$
\begin{aligned}
& \circ \text { knowledge } \\
& \circ \text { willingness } \\
& \circ \text { skills }
\end{aligned}
$$

\section{Environmental factors:}

- Quietness and familiarity of $a$ place

Other people with aphasia often withdrew themselves in situations they could not engage in, leaving the others doing the things they did. Occasionally, the person with aphasia was not interested anymore in other people and preferred to be left alone.

["Hans: To live on my own, that is no problem, to live with other people, I would rather be on my own."]

Physical condition and psychological condition. People with aphasia were confronted with many impairments restricting the ability to engage in participation activities: having another life tempo, having pain, losing balance, epileptic attacks, being tired almost all the time, having difficulties in remembering things, having troubles concentrating. They were often confronted with feelings of depression, loneliness, frustration, stress, sadness, disappointment, fear of falling, fearing for the reaction of others. Often they felt ashamed. People regularly had the feeling they did not belong anymore and some even had the feeling they could not live with others.

["Hans: I am embarrassed. People think that I am crazy and I am not. I don't dare to talk to strangers. I feel ashamed."] 
Communication skills. People with aphasia needed to communicate despite their communicative impairments. Taking time to prepare what they wanted to say helped. Making use of cards that structure communication situations, like making a telephone call, helped some persons with aphasia. Making use of communication books in which personal information was included made it possible to participate in conversations. They used short sentences, signs, prosody to make clear what they wanted to say. However, on many occasions they were unable to take part in conversation: they needed too much time to think, to say what they wanted or to understand what other people were saying.

["Jos: yes and euh, the speed for euh, which I am confronted with. yes (silence) also with euh, yes... with you that they want tell me or euh...no...(long silence) euh, how do you name it now, if I have something to say than I have to euh..think too long.Yes. Partner Jos: than it is already over, the thing you are thinking about."]

["Sara: I go to parties. Talking difficult. I use this (points at communication book)."]

\section{Social factors}

The role of the central caregiver. The central caregiver played an important role. Often, they stimulated the person with aphasia to take part, organised meetings with friends, stayed in the background so people would talk to the person with aphasia as well, and gave tips to the communicative partners to adapt the communicative strategies to the possibilities of the person with aphasia. They made contact with activity centres so the person with aphasia could join activities with other people.

One woman with aphasia was divorced, but remained good contact with her exhusband. He still supported her in some activities, like helping with filling in financial papers.

["Partner Rita: I try to let her do as much as possible, not that I don't want to do it, but if you take everything out of hands, she want get any further. You have to make the assumption that she is independent."]

On the other hand, there were also central caregivers who had the habit of taking over, doing everything for the person with aphasia, even the things he/she could do for him/herself. They had the tendency to overprotect, excluding the person with aphasia in making decisions concerning the financial situation, the children, etc...

["Partner Mia: I am so worried that she gets too excited about it and than I leave her out when I have a problem or when the kids come to us with a problem. I don't want her to get another attack."]

Characteristics of the communication partner(s). All participants did have social relationships. The relation with the partner and the family was mentioned the most during the interviews, followed by the relations with friends and health care professionals.

The participants reported that contacts with known as well as unknown people is complicated because of their communicative difficulties. They perceived their social contacts as diminished. The number of friends post aphasia decreased in most cases. 
Friends stayed away because they didn't know how to handle the new situation. When time passed by, making contact became even more difficult. Further, people did not seem to have the urge to make contact. The participants mostly perceived that they always had to take the initiative to see their friends. The closer the friendship was before aphasia onset, the bigger the chance that the friendship stayed intact after aphasia onset. A small number of participants perceived their social contacts as increased. Having more time was a promoting factor.

Some characteristics seemed to promote the engagement of people with aphasia. People who were rather quiet and had a lot of patience, made it easier to engage in social participation activities. Some participants pointed out that contact with older people was easier.

["Mia: there is one person older than me and than it's my turn. All the rest are older. I prefer it. I rather interact with older people instead of younger people. What the one can't do does the other, that's the way it goes. (not understandable), big mouth, I think with the older ones, it's much quieter."]

There seemed to be three important aspects with regard to the communication partner(s), namely willingness, skills and knowledge.

Knowledge: Knowing the person with aphasia and his possibilities made it easier to interact. However, a lot of people did not seem to know what aphasia is and how to deal with it.

["Roel: yes, that big word aphasia, no, I don't like that. Yes, that is true, it is something! It will be like that, yes, half of the people don't know the meaning. That's the problem. And than they say what does that mean? I don't know either. Do I have to say I have this and that and all that kind of stuff? That I have brains... I don't want to. Than I say, let it go. It is alright that way. But than they don't know how to get along with me and than they talk as if I am stupid or so."]

Willingness: It was inevitable that people who interact with persons with aphasia were prepared to ask questions, dared to talk to the person with aphasia, confronting him with possibilities instead of confronting the person with aphasia with their impairments. It demanded an attitude of willingness, taking effort, having patience, taking initiative, helping without mothering.

["Roel: I have a good friend. He gives me attention and when I doesn't understand me, he just keeps on telling, euh asking. He just asks me questions. And if he don't get it, euh understand me, he says we will discuss this later, perhaps then I do understand you."]

Reported obstructing factors were: taking no effort, having no patience, not accepting that the person with aphasia was changed. In addition, people who did take contact sometimes had the attitude of overprotecting the person with aphasia, not involving him/her in discussion or always confirming him/her so he or she would not get excited. 
["Hans: I am, I have lost my friends, I don't go anywhere anymore. With the guys, I went to there or there. I can't, when we are together, we have drunken something, you start to chitchat, that doesn't work. I can't drink much, also not. And than, you go."]

Communication partners sometimes had the tendency to stigmatise the person with aphasia, making misplaced jokes, treating the person with aphasia as if he was stupid.

["Interviewer: do you use a communication book? Liv: no, people look strange."]

A lot of candidate communication partners avoided the person with aphasia and were not able to empathise. Sometimes people seemed to be afraid to interact with persons who have a disability, avoiding them. This often made it impossible for the person with aphasia to take part.

Skills: Besides willingness, communication skills seemed to be important. From the data it became clear that making time to have a conversation, talking slowly and really listening, asking closed questions, taking a speaking pause when needed, and using short sentences were important communication strategies that characterised skilled communication partners.

Conversation situation: Hans is talking about his relationship with his sisters in law:

["Hans: They are all good with by euh with words. Her sisters are quiet and they euh listen good. They all can listen well. In the Dutch language they all were, they talk slowly. But not the youngest she talks too rapidly."]

Other people did not seem to adjust their communication strategy to the possibilities of the person with aphasia. People with aphasia told that people were talking at the same time and discussing more than one subject, that they talked too rapidly, changing from one subject into another without announcing it, that they asked question after question or that they did not talk at all to the person with aphasia. People with aphasia needed time to think about what they wanted to say. They reported that they often got blocked in communication when they were under time pressure, making it impossible to take part.

Conversation situation: Liv is talking about the diminished relation with her son:

["Interviewer: yes and can you talk about it, that the contact has changed now?

Liv: bwa, talks to rapidly. Interviewer: how does that come? Liv: no patience. Interviewer: does the talking goes to slowly for him? Liv: yes Interviewer: do you find that hard? Liv: yes, than the talking goes even worse."]

\section{Environmental factors}

A quiet, familiar place. Going to an activity centre or a care farm (farm were disabled people can participate in taking care for the animals, gardening etc) stimulated people with aphasia to be part of a group. It motivated people to get out their house; it made them feel alive. In self help groups people could express their feelings and troubles, especially when there was a separate group for people with aphasia and their partners. 
["Mia: I do not miss the contacts with my old friends anymore. The activity centre and there I go three days a week. Earlier, I stayed at home and than I sat there all alone... now I feel alive again!"]

Participants living in a quiet environment like a village, or living in a small community found it easier to walk around alone, meeting people they knew, who knew their communicative abilities. They found it easier to go shopping alone because people in the shops knew their life context.

["Jef: But I can live with it, very good, yes, really. You know, I live in a closed community here, in the pub too, people know me ...Yes, they all knew what has happened."]

Living in a city with a lot of distractions and background noises complicated being there. Often people did not know each other, people lived more individually, making contact more difficult.

["Rita: You look to the shops and euh the restlessness, the chaos and that is strange, you can not overlook things, and than I became fussy and than I go back home."]

Communication impairments restrict access to public services and transport. Participants reported that they did not have good access to public services, for example reading the time schedule, telling the driver when to stop, was difficult. Adjusted transport was often reported as an important aid. However, it took a lot of effort to get the right forms and to fill in the forms to get permission to make use of public services like transport.

["Sara: Lot of effort, talk to driver, to difficult."]

\section{Discussion}

People with aphasia as well as their central caregivers state that doing things, being active and participating in social life domains is often very difficult. There are important individual differences in the participation of people with aphasia in social activities, but social participation is largely absent and doing things does not make people necessarily feel more integrated. Most persons with aphasia feel isolated and excluded, but some people with aphasia succeed in feeling engaged in social activities. This is influenced by personal, social and environmental factors. People with aphasia wish to be useful, meaningful and part of the community. They have a strong idea on what they consider as an important way of living, best characterised as a level of engagement in participation.

In the ICF (21) participation is defined as the involvement in life situations. In the study of Dalemans (22) social participation is defined as the performance of people in actual activities in social life domains through interaction with others in the context in which they live. However, people not only want to 'perform'; they also want to find their performance meaningful. The study of Cruice (16) discussed how people with 
aphasia are dissatisfied with their levels of participation compared to their non-aphasic peers.

In this study it becomes clear that they do not necessarily want to do more, but that they want their interactions to be more satisfying. Whereas people without a disablement seem to think that social participation is better if they participate more, people with a disablement seem to find the quality of the performance in social activities more important than the quantity. This means that not only the actual performance should be the key indicator, but also the fulfilment of personal goals and societal roles. People with aphasia find it important to experience engagement in social activities. Perhaps this emerges through the experience of exclusion: people with aphasia report that they are often excluded from social activities. The process of interaction between the person with aphasia and the direct environment (close others and others) is central for the possibilities of engagement in social participation.

Other studies describe similar findings. Simmons-Mackie \& Damico (23) reported that who we are and how we react is based on our previous and concurrent social interactions. As people with aphasia become socially isolated, this condition can have an impact on their social competence as well as on other behaviours and traits that are based on social contact. Additionally, van de Ven (24) described in their study the central role of the process of interaction between the person with the disability and others in society to what they called the attainment of integration. There seems to be strong similarity between this study and the study of van de Ven et al. (2005). In their study subjective experiences of integration are feeling valued, being treated with respect and equality, counting as a person in society, casualness of participation in social activities, taking responsibility for being in control of one's own life, not feeling hindered in activities or choices by others or the disability and not being dominated by the disability.

Participants in this study report a number of influencing factors in reaching engagement in social participation. A motivated person with aphasia living with a stimulating caregiver in a quiet accessible environment with willing people surrounding him, who have knowledge and skills to adapt to the communicative possibilities of the person with aphasia, has a better chance to achieve engagement.

Also other studies described influencing factors: Rayner and Marshall (25) reported the importance of knowledge about aphasia and reported gains in the participation of people with aphasia after training volunteers as conversation partners. Howe et al.,(26) reviewed studies defining aphasia-friendly environments and stated that the following factors need to be considered: the range of conversation partner behaviours, the core behaviours for less frequent communication partners, the specific variables for making written information more aphasia friendly, facilitators and barriers related to systems, the attitudes of health professionals and the general public and general products and technology. They referred to factors in the social and physical context, whereas this study emphasises that the personal context also appears to play an important role.

\section{Methodological considerations}

Several strategies were undertaken to ensure trustworthiness of the results and analyses. Younger and older persons with various communicative possibilities, various mo- 
bility abilities and a wide range (1,4-11 years) post onset were included. Although data saturation was obtained, the research group remained rather small, making prudence necessary regarding the overall conclusions. Recruiting only one person who lives alone makes it difficult to compare this alternative experience meaningfully with the other 12 participants. Though it seems to be clear and confirmed that the central caregiver might play an important role in promoting the engagement of the person with aphasia in social participation activities.

The visual structure in the diary as well as the availability of the stickers may have influenced people in describing the activities and factors influencing participation. This is on the one hand a limitation of the study, but on the other hand made it possible for people with severe communicative disabilities to report in a very short way about their participation in life. The perception of the central caregiver was included in the diary, because his description could give an extra perspective. However, it is possible that the central caregiver did not express freely his full perception because only one diary per couple was used. Perhaps they found it too sensitive to report their own perception, confronting the person with aphasia with his impairments.

The interviews were always audio-taped and transcribed verbatim directly after the interview. Several strategies to stimulate the person with aphasia to express himself were undertaken: the non-verbal communication (an important source of information, certainly for those who could not express themselves with words) was registered in each interview, and the use of alternative communication was stimulated. We interviewed the person with aphasia and the central caregiver together. By using this setting, individuals were encouraged to use the ideas of others as cues to more fully elicit their own views. If the interviewer had the impression that the central caregiver or the person with aphasia did not express themselves fully because of the presence of the other, she encouraged the participants to express themselves completely. By interviewing the person with aphasia and the central caregiver together, we did not use the central caregiver as a proxy. There is a lot of debate concerning the use of proxies and some studies found that there are discrepancies between the outcome of proxies and people with aphasia $(27,28)$, however in this study the central caregiver had a role as translator and informant, mostly encouraging the person with aphasia to express himself.

By using the diary as well as the interview, different sources have been used to get a full view of the perceived participation and its influencing factors. By using a focus group interview the results were validated by all the participants.

The data were analysed by two researchers and discussed with a third senior researcher and two more independent senior researchers. Differences between the analyses were discussed until consensus was reached, always staying as close as possible to the data in the interviews. In this way personal bias has been limited.

\section{Implications of the study}

It is important to look beyond the communicative abilities into the factors influencing the interaction between the person with aphasia and the direct environment.

Although several studies have described the positive influences of involving the direct environment in therapy $(25,29-31)$, still the participants in this study report a lack of knowledge and skills of the people in the direct environment. For speech and language 
pathologists it is important to be more aware of the consequences of aphasia, not to overlook those consequences in real life and to prepare the person with aphasia and his direct environment to handle those consequences making it more possible to pick up their own life. We can not separate language from the communicative context, therefore it is important to train language in a way that is meaningful to the person. Rehabilitation of communication impairments should be trained to build a bridge for re-engagement in life. The life concerns of the person with aphasia and those confronted with the consequences of aphasia needs to be in the centre of decision making in care. Further, speech and language therapists need to interact and work together with other disciplines, to fine tune the rehabilitation to the needs of the person with aphasia in his own context.

\section{Acknowledgement}

Thanks to all the speech language therapists, rehabilitation practitioners and the chairman of the Aphasia Association Zuid-Limburg for their enthusiastic approach in finding participants. Thanks to Petra Franssen for her addition to this study. Thanks to all the participants for their important contribution to this study. 


\section{References}

1. World Health Organization. International classification of functioning, disability and health: ICF. WHO; 2001.

2. Participation Theme Working Report. Conceptualizing and measuring participation: A collaboration of: St.. John`s Rehabilitation Hospital, The Toronto Rehabilitation Institute, University Health Network, University of Toronto; 2005 Contract No.: Document Number|.

3. Andersson S, Fridlund B. The aphasic person's views of the encounter with other people: A grounded theory analysis. Journal of Psychiatric and Mental Health Nursing. 2002;9(3):285-92.

4. Parr S. Psychosocial aspects of aphasia: whose perspectives? Folia phoniatrica et logopaedica : official organ of the International Association of Logopedics and Phoniatrics (IALP). 2001 Sep-Oct;53(5):266-88.

5. Parr S. Living with severe aphasia: tracking social exclusion. Aphasiology. 2007;21(198-123).

6. Le Dorze G, Brassard C. A description of the consequences of aphasia on aphasic persons and their relatives and friends, based on the WHO-model of chronic diseases. Aphasiology. 1995;9:239-55.

7. Elman RJ. Social and Life Participation Approaches to Aphasia Intervention. In: La Pointe L, editor. Aphasia and Related Neurogenic Language Disorders. third ed: Thieme; 2005. p. 39-51 (274).

8. Cruice M, Worrall LE, Hickson LMH, Murison R. Finding a focus for quality of life with aphasia: Social and emotional health, and psyhological well-being. Aphasiology. 2003;17(4):333-53.

9. Davidson BJ, Worrall LE, Hickson LMH. Social communication in older age: Lessons from people with aphasia. Topics in Stroke Rehabilitation. 2006;13(1):1-13.

10. Worrall LE, Frattali C. Neurogenic Communication Disorders. 2000.

11. Calmels P, Ebermeyer E, Bethoux F, Gonard C, Fayolle-Minon I. Relationship between burden of care at home and functional independence level after stroke. Annales de Readaptation et de Medecine Physique 2002;45(3):105-13.

12. Denman A. Determining the needs of spouses caring for aphasic partners. Disability and Rehabilitation. 1998;20(11):411-23.

13. Gianotti G. Emotional, psychological and psychosocial problems of aphasic patients: An introduction. Aphasiology. 1997;11(7):635-50.

14. Visser Meily JMA, van Heugten C, Post MW, Schepers VP, Lindeman E. Intervention studies for caregivers of stroke survivors: A critical review. Patient Education and Counseling. 2005;56(3):257-67.

15. Code C. The quantity of life for people with chronic aphasia. Neuropsychological Rehabilitation. 2003;13(3):379-90.

16. Cruice M, Worrall L, Hickson LMH. Quantifying aphasic people`s social lives in the context of non-aphasic peers. Aphasiology. 2006;20(12):1210-25.

17. Hilari K, Northcott S. Social support in people with chronic aphasia. Aphasiology. 2006;20(1):17-36.

18. Dalemans RJP, de Witte L, van den Heuvel W, Wade D. A description of social participation in working age people with aphasia: a review of the literature. Aphasiology 2008;22(10):1071-91.

19. Enderby P, Crow E. Frenchay Aphasia Screening Test: validity and comparability. Disability and Rehabilitation. 1996 May;18(5):238-40.

20. Vincent Peters. Kwalitan Advice. 5.0 ed. Malden 2005.

21. WHO. ICF international homepage. 2001 [updated 2001; cited]; Available from: http://www.who.int/classifications/icf/site/icftemplate.cfm?myurl=introduction.html\%20\&mytitle=Intr oduction.

22. Dalemans RJP, de Witte L, van den Heuvel W, Wade D. A description of social participation in working age people with aphasia: a review of the literature. Aphasiology (accepted). 2007.

23. Simmons-Mackie N, Damico JS. Acces and social inclusion in aphasia: interactional principles and applications. Aphasiology. 2007;21(1):81-97.

24. van de Ven L, Post MW, de Witte L, van den Heuvel W. It takes two to tango: the integration of people with disabilities into society. Disability and Society. [research article]. 2005 may 2005;20(3):311-29 (19).

25. Rayner H, Marshall J. Training volunteers as conversation partners for people with aphasia. International Journal of Language \& Communication Disorders. 2003;38(2):149-64. 
26. Howe TJ, Worrall LE, Hickson LMH. What is an aphasia-friendly environment. Aphasiology. 2004;18(11):1015-37.

27. Cruice M, Worrall L, Hickson L, Murison R. Measuring quality of life: Comparing family members' and friends' ratings with those of their aphasic partners Aphasiology. 2005;19(2):111-29.

28. Hilari K, Owen S, Farrelly SJ. Proxy and self-report agreement on the Stroke and Aphasia Quality of Life Scale-39. Journal of neurology, neurosurgery, and psychiatry. 2007;78:1072-5.

29. Cunningham R, Ward C. Evaluation of a training programme to facilitate conversation between people with aphasia and their partners. Aphasiology. 2003;17(8):687-707.

30. Lyon JG, Chariski D, Keisler L, Rosenbek J, Levine R, Kumpula J, et al. Communication Partners: enhancing participation in life and communication for adults with aphasia in natural settings. Aphasiology. 1997;11(7):693-708.

31. Kagan A, Black SE, Duchan JF, Simmons-Mackie N, Square P. Training Volunteers as Conversation Partners Using "Supported Conversation for Adults with Aphasia "(SCA): a controlled trial. Journal of Speech, Language and Hearing Research. 2001;44:624-38. 
CHAPTER 5

Appendix 1: Visual structured diary

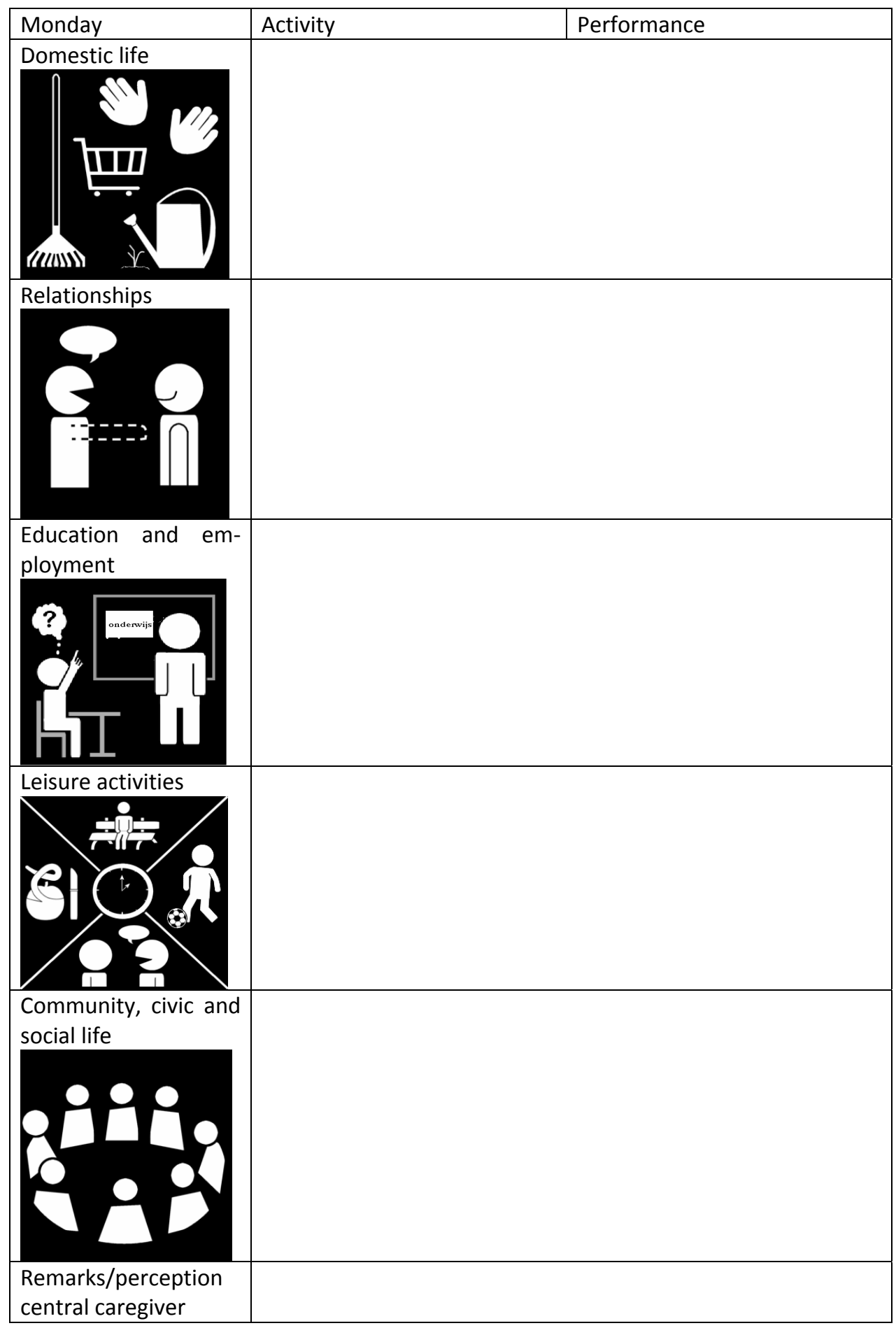




\section{Appendix 2: interview protocol}

Duration interview:

Date:

Place:

Interviewer: Ruth Dalemans

Observator:

Gender person with aphasia:

Aphasia type:

Wheelchair: yes/no

Birth Date:

\section{Introduction}

Today we come together for a study:

With this study we want to receive insight in how people with aphasia can participate in life. We want to know which factors makes participation easier and which factors makes participation difficult.

In total 8 to 15 persons with aphasia and their partner will be interviewed.

This interview is one of them.

I will shortly introduce the interview.

If you have questions, you may ask them at any moment.

When something is not clear, please do say so.

If I ask a question to which you do not wish to respond to, you don't have to.

\section{Personal data}

I propose to start with some personal data:

How old are you?

How old is your partner?

Do you have children? Yes, how many? How old are they?

What is your education?

\section{Transfer questions}

How long ago did you get a stroke?

Can you tell me something about it?

Social participation

Now, I would like to ask you some questions concerning your life as it is now.

For each question a picto or word will be at the table as a reminder/assistance.

1. What do you do on a regular day?

What do you do in your domestic life?

What do you do with friends?

How would you describe your relation with your children?

How would you describe your relation with your partner?

Do you work? What do you do for employment? How many hours?

What do you do in your leisure time?

2. If you look at what you do on a regular day, and you compare it with a day before you had aphasia? Would you say that your days are different now?

What has changed in your domestic life?

What has changed in your relation with others?

What has changed in your work, education?

What has changed in your leisure time?

3. Can you do the things you want to do?

4. What makes it difficult to do the things you do/want to do?

How do you handle this?

5. What helps you to do the things you do/want to do?

Thank for the interview, assure data stay anonymous

Explain the instruction for the diary 



\section{Chapter 6:}

\section{Social participation of people with aphasia and related factors}

Based upon:

Dalemans RJP, De Witte L, Beurskens A, van den Heuvel W, Wade D. An investigation into social participation of people with aphasia. Disability and Rehabilitation 2009; Provisionally accepted. 
An investigation into the social participation of stroke survivors with aphasia

Purpose: Aphasia can profoundly affect a person's capacity for social participation. The purpose of this study is to describe how people with aphasia participate socially, and to investigate the factors which are related to social participation.

Methods: A cross-sectional study was conducted in 150 people with aphasia using a structured interview format, adjusted to the communicative abilities of the participants. Data were analysed using descriptive statistics and multiple regression analyses. Measures used were the Frenchay Aphasia Screening Test, Barthel Index, Darmouth Coop Functional Health Assessment Charts/Wonca, Personal Factors Questionnaire, Environmental Factors Questionnaire and the Community Integration Questionnaire (CIQ).

Results: There was much variation in the social participation of people with aphasia (range total CIQ score: 4-25). The mean score on the CIQ was $14.2(\mathrm{SD}=4.9)$, with the social integration subscale score contributing the most to the total CIQ score. A low home integration score and a very low productivity score were found for this population. Age, gender, functional activities of daily living (ADL) performance and aphasia severity were related to social participation (adjusted $\mathrm{R}^{2}=.37$ ).

Conclusions: Aphasia negatively affects long term social participation, together with other factors: functional ADL performance, age and gender. Environmental factors and personal factors do not independently contribute to the level of social participation. 


\section{Introduction}

The World Health Organization published the International Classification of Functioning, Disability and Health in 2001. This model replaces the dimensions impairment, disability and handicap (ICIDH) with body structure and functioning the organ level, activity at the person level and participation at the societal level. Participation is defined as the involvement in life situations ${ }^{(1)}$. This model recognises the importance of personal and environmental factors. Recently, the level of a person's participation in society has become an important goal in health care.

Aphasia is a language defect at the organ level commonly experienced by people with damage to the left cerebral hemisphere, most frequently after stroke. It may be persistent in about $25 \%$ of stroke survivors ${ }^{(2,3)}$. Communication is central to human social intercourse, and consequently any defect affecting communication can affect a person's social participation because the latter depends on the ability to engage with others, to interact, to share and to maintain equality during those interactions ${ }^{(4)}$.The social impact of aphasia is therefore likely to be persistent and pervasive and even an apparently minor impairment of language may leave persisting functional difficulties that impact significantly on daily life, causing social isolation, loneliness, a loss of autonomy, restricted activities, role changes and stigmatisation ${ }^{(5,6)}$.

A recent review of the literature on the levels of social participation of working age people with aphasia ${ }^{(7)}$ found that little is known on the subject. A few further small studies have since been reported, but mostly in a relatively small population or case studies ${ }^{(8-11)}$ and often only focusing on social relationships ${ }^{(9,12-14)}$. Recent, unprecedented changes have occurred in the way treatment for aphasia is viewed and reimbursed, due to internal and external pressures. An integrated framework for therapy was devised by Byng, Pound and Parr ${ }^{(15)}$. This framework aims to meet the goal of promoting healthy living with aphasia. The Life Participation Approach for Aphasia Project Group (LPAA) proposed an approach of service delivery that meets the needs of people affected by aphasia in achieving their immediate and longer term life goals (16-18). This approach has been developed due to pressures coming from disability rights activists campaigning for change in philosophy and treatment, and from consumers frustrated by unmet needs and unfulfilled goals. Individuals with minimal social participation have limited access to peers giving them no opportunity to form friendships or make acquaintances. This level of participation is generally unacceptable and requires direct intervention ${ }^{(19)}$. Improved understanding of the social participation of people with aphasia might lead to more effective interventions ${ }^{(7,12)}$. That is what this study focuses on.

The study objectives are:

- to describe the social participation of people with aphasia;

- to investigate the factors related to the level of social participation of people with aphasia.

Several factors related to social participation were identified, based upon a previous qualitative study ${ }^{(20)}$ and upon the literature concerning social participation in this population. 
Social participation is defined as the performance of actual activities in the domains of social life (domestic life, interpersonal life, education and employment, community, and civic and social life) through interaction with others in the context in which a person lives ${ }^{(7)}$.

\section{Methods}

The candidates for this study were adult survivors of stroke meeting the following criteria: aged over 18 years, having aphasia, living a minimum of three months at home since a stroke, having no known history of severe cognitive decline or mental health problems, and speaking and understanding Dutch before the stroke. They were recruited by contacting 81 speech and language therapists working in rehabilitation centres, hospitals and in primary care and three not-for-profit organisations for people with aphasia. Additionally, two not-for-profit organisations for people with head injuries and one stroke unit were asked to help with recruiting participants meeting the same inclusion criteria but having no or minimal aphasia.

Potential participants received a letter with regard to the study design and a reply letter via which they could give permission for the researchers to make contact with them. The letter was written using short sentences, high frequency words and an outline structure. After permission was given, the researcher (RD) made telephone contact in order to arrange a meeting with the participant to administer the measurement instruments at the participant's home. To reduce the exclusion of people with severe aphasia, caregivers were also allowed to reply to the answering letter.

\section{Measurement protocol}

The administration of the questionnaires took place at home in a quiet environment in an interview-format. The structured interview was performed by one of six investigators who were trained in the administration of the questionnaires and in interviewing people with aphasia. If the person with aphasia was tired, a break was included. Before the assessment started, a statement regarding informed consent (using an outline structure, short sentences and high frequency words) was read aloud by the researcher. When aspects in the informed consent were not clear to the participant, these aspects were explained until the participant fully understood the statement of informed consent.

All the measurement instruments were adapted to make them suitable for use in people with aphasia ${ }^{(21)}$ through improving layout (including pictograms, much white space, font style Verdana and font size 16) and grammar (e.g. simplifying sentences and words) while keeping the content of the questionnaires intact.

To measure participation and the possible related factors, we selected instruments with a minimal cognitive load (short duration, use of high frequency words, using the same word for the same concept) to gather as much information as possible with a minimal burden for the participant, using:

The Frenchay Aphasia Screening Test (FAST) ${ }^{(22)}$ to assess the aphasia severity (0-10: severe aphasia, 11-20: moderate aphasia, 21-26: mild aphasia, 27-30: minimal aphasia) and to facilitate adaptation of the interview to the communicative abilities of the participants (e.g. if the person with aphasia was not able to read, the interviewer pointed 
at the pictogram while asking the question, whereas if the respondent was able to read, the interviewer pointed at the bolded key concept in the written question). The Frenchay Aphasia Screening Test is a reliable test which can be used by non-specialists. Studies have shown good test-retest reliability, and the test itself is quick and simple to use ${ }^{(22)}$.

Demographic information (age, gender, time since stroke onset, marital status, number of children, children living at home, living situation, level of education, occupation and employment status before stroke) (10 items).

The Barthel Activities of Daily Living Index ${ }^{(23)}$ ( maximum score 20: higher score indicating more activities of daily living (ADL) independency) to assess functional performance. The Barthel Index consists of 10 items that measure a person's daily functioning, specifically the activities of daily living and mobility. The items include feeding, moving from wheelchair to bed and return, grooming, transferring to and from a toilet, bathing, walking on level surface, going up and down stairs, dressing, continence of bowels and bladder. It is a reliable instrument ${ }^{(24)}$.

The Darmouth Coop Functional Health Assessment Charts/Wonca (COOP-WONCA) (25) (6 items; maximum score 30: higher score indicating more problems) to assess overall functional status (problems perceived in daily activities, social activities, health change and health status) and specifically to measure physical status (to receive an indication of fatigue) measured with the item about fitness and mental status measured with the item about feelings. The charts are well accepted by clients, with reasonable distributions of scores and evidence of construct validity. Moderate levels of reliability and sensitivity to change were demonstrated ${ }^{(26)}$.

The Community Integration Questionnaire $(\mathrm{CIQ})^{(27,28)}$ to measure social participation. The $\mathrm{CIQ}$ is a reliable and valid measurement consisting of 15 items. Most items are scored on a scale of 0 to 2 . The overall score can range from 0 to 29 . A higher score indicates better integration. The CIQ can be divided into three sub-scales, corresponding to integration in the home (12 points), social integration (12 points) and productivity (5 points) [20]. It was initially developed for people with traumatic brain injuries and was adapted for people with aphasia [19]; the adapted CIQ has good internal consistency (Cronbach's alpha $=0.75$ ), excellent test-retest reliability (Intra Class Correlation coefficient $=0.96$ ) and acceptable validity.

Some personal factors related to social participation were identified in an earlier qualitative study ${ }^{(20)}$. This qualitative study aimed to explore how people with aphasia perceive participation in society and to investigate influencing factors. Thirteen persons with aphasia and 12 central caregivers kept a pre-structured diary, followed by a semi-structured interview. In a focus group interview the results were discussed with the participants. Through the qualitative study six personal factors were identified. We decided to investigate these personal factors by using a questionnaire consisting of six items ( 6 items: keep on trying, positive attitude, not mattering what other people think of you, being motivated, taking time to relax and being prepared for activities). These items appeared to be interrelated (Cronbach's Alpha $=.698)$. Therefore, we decided to calculate sum scores. The maximum score is $30(1=$ totally disagree to $5=$ totally agree). Higher scores indicate what we will here call positivism. This instrument also showed good test-retest reliability $($ ICC $=.867)$. 
Some environmental factors related to social participation were identified in the same qualitative study ${ }^{(20)}$. Again, we decided to investigate all the environmental factors reported by the participants in the qualitative study, already mentioned above and assessed them by using a questionnaire including eight items: the presence of family and the presence of friends, knowledge about aphasia in the social environment, communicative adaptation (items: talking slowly and clearly) of the social environment towards aphasia, support given by the social environment, the amount of time pressure exerted by the social environment, and the quietness of the environment. This questionnaire uses a five-point scale $(1=$ totally disagree to $5=$ totally agree). These eight items also appeared to be interrelated (Cronbach's Alpha $=0.70$ ). Sum scores were calculated, with higher scores indicating a positive supporting social environment. The maximum score for environmental factors was 40 . The test-retest reliability of this scale was good $($ ICC $=.923)$.

\section{Data analyses}

All data were analysed using SPSS 16.0. The demographic data, social participation and factors related to social participation were summarised using descriptive statistics. The factors identified as potentially related to social participation are outlined in figure 1.

Figure 1: Factors potentially related to social participation

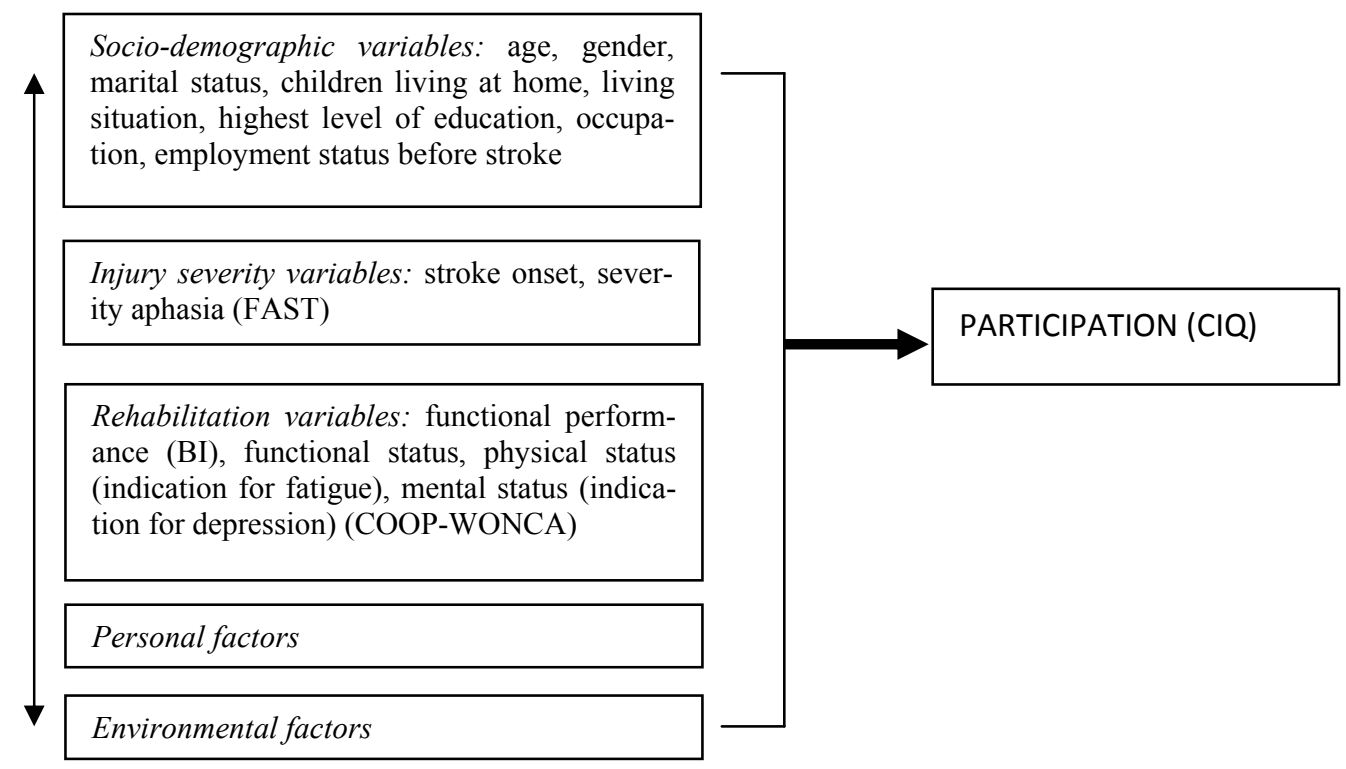

FAST: Frenchay Aphasia Screening Test, COOP-WONCA: the Darmouth Coop Functional Health Assessment Charts, CIQ: Community Integration Questionnaire 
The main outcome variable was social participation. In a first step the bivariate relationships of all possible determinants of social participation were examined using Spearman correlations (and the chi-square test for gender, living situation and marital status). Determinants that showed p-values below 0.10 were entered in the stepwise multiple regression analyses. In order to see the specific contribution of the severity of aphasia, this variable was entered last in the analyses. Prior to multiple regression analysis, routine data screening was conducted to identify variables with greater than $5 \%$ missing data and/or variables which were skewed. If variables had more than $5 \%$ missing data a mean substitution was chosen as an option to deal with the missing data. If skewness had occurred, square root data transformations were applied.

\section{Results}

In total, 490 people were approached of which 165 (34\%) returned the answering letter. There were no data available of the individuals who did not returned the answering letter, because they were not directly approached by the researchers. A total of 150 (31\%) participants who returned the answering letter agreed to take part. Reasons for the 15 not participating were: being too ill (4), participating in other research projects (3), having had another stroke (7) and change of mind (1). In table 1 the outcomes of the socio-demographic, injury severity, rehabilitation, personal and social variables are presented. 
Table 1: Socio-demographic, injury severity, rehabilitation, personal and social characteristics of the participants $(\mathrm{N}=150)$

\begin{tabular}{|c|c|c|}
\hline & Mean \pm SD & Range \\
\hline \multicolumn{3}{|l|}{ Socio-demographic variables } \\
\hline \multirow[t]{2}{*}{ Age (years) } & $64.2 \pm 11.0$ & $35-87$ \\
\hline & $5 \%<46 y, 51 \% 46-65 y, 45 \%>65 y$ & \\
\hline Male gender & 89 (59\%) & \\
\hline Partner & 109 (73\%) & \\
\hline Children & $2.1 \pm 0.99$ & $0-5$ \\
\hline Children at home (\%) & $22(15 \%)$ & \\
\hline Living situation urban (\%) & $64(43 \%)$ & \\
\hline \multicolumn{3}{|l|}{ Highest level of education (\%) } \\
\hline Elementary school & $28(19 \%)$ & \\
\hline High school & $55(37 \%)$ & \\
\hline Associate degree & $36(24 \%)$ & \\
\hline Upper bachelor degree & $27(18 \%)$ & \\
\hline University & $4(3 \%)$ & \\
\hline \multicolumn{3}{|l|}{ Occupation (\%) } \\
\hline Household & $11(7 \%)$ & \\
\hline Blue collar (white collar) & 76 (51\%) 63 (42\%) & \\
\hline \multicolumn{3}{|l|}{ Job situation before stroke (\%) } \\
\hline No job, not looking (no job, looking) & $19(13 \%)(4(3 \%))$ & \\
\hline Retired & $41(27 \%)$ & \\
\hline Part-time job (full-time) & $21(14 \%)(65(43 \%))$ & \\
\hline \multicolumn{3}{|l|}{ Injury severity variables } \\
\hline Stroke onset & $90.6 \pm 80.9$ & $6-372$ \\
\hline \multicolumn{3}{|l|}{ FAST (\%) } \\
\hline Severe aphasia (0-10) & $13(9 \%)$ & \\
\hline Moderate aphasia (11-20) & $30(20 \%)$ & \\
\hline Mild aphasia (21-26) & $75(50 \%)$ & \\
\hline No or minimal aphasia $(27-30)$ & $32(21 \%)$ & \\
\hline \multicolumn{3}{|l|}{ Rehabilitation outcome variables } \\
\hline COOP-WONCA (/30) & $16.7 \pm 4.4$ & $7-27$ \\
\hline Fitness (/5) & $3.4 \pm 1.3$ & \\
\hline Feelings (/5) & $2.3 \pm 1.2$ & \\
\hline Barthel Index (/20) & $16.7 \pm 4.2$ & \\
\hline 0-4: completely dependent & $3(2 \%)$ & \\
\hline 5-9: mostly dependent & $9(6 \%)$ & \\
\hline 10-14: dependent, able to do things & $20(13 \%)$ & \\
\hline 15-19: mostly independent & $67(45 \%)$ & \\
\hline 20: completely ADL-independent & $51(34 \%)$ & \\
\hline \multicolumn{3}{|l|}{ Personal and social factors } \\
\hline Personal factors (/30) & $21 \pm 3$ & $12-25$ \\
\hline Environmental factors $(/ 40)$ & $31.8 \pm 6$ & $15-39$ \\
\hline
\end{tabular}

FAST: Frenchay Aphasia Screening Test

There were no missing data, with the exception for one item, being 'who takes care of the children . 


\section{Level of social participation}

The mean score on the CIQ was 14.2 ( $\mathrm{SD}=4.9$, range $4-25)$. The mean score on the home integration $\mathrm{CIQ}$ subscale was 4.8 (SD $=3.6$, range $0-12$ ). The mean social integration score was $8.4(S D=2.2$, range $2-12$ ) and there was a very low productivity score ( mean $=1, S D=1.6$, range $0-5$; c.f. people with traumatic brain injury: mean $=4.3, S D=$ 2 [21]). Table 2 shows the actual level of social participation recorded for each item.

Table 2: Outcomes of the Community Integration Questionnaire (CIQ) (N=150)

\begin{tabular}{|c|c|c|c|c|c|}
\hline \multicolumn{6}{|c|}{ Outcomes on item level: Number of participants (\%) } \\
\hline Home integration subscale & $\begin{array}{l}\text { Yourself alone } \\
\text { (score 2) }\end{array}$ & \multicolumn{2}{|c|}{$\begin{array}{l}\text { Yourself and } \\
\text { someone else } \\
\text { (score 1) }\end{array}$} & $\begin{array}{l}\text { Someone else } \\
\text { (score 0) }\end{array}$ & $\begin{array}{l}\text { Not } \\
\text { applicable }\end{array}$ \\
\hline $\begin{array}{l}\text { Who usually does the shopping for } \\
\text { groceries or other necessities in your } \\
\text { household? }\end{array}$ & $37(25)$ & \multicolumn{2}{|l|}{$61(41)$} & $52(35)$ & \\
\hline $\begin{array}{l}\text { Who usually prepares meals in your } \\
\text { household? }\end{array}$ & $45(30)$ & \multicolumn{2}{|l|}{$28(19)$} & $77(51)$ & \\
\hline $\begin{array}{l}\text { Who usually does the normal everyday } \\
\text { housework? }\end{array}$ & $20(13)$ & \multicolumn{2}{|l|}{$55(37)$} & $75(50)$ & \\
\hline $\begin{array}{l}\text { Who usually cares for the children in } \\
\text { your home? }\end{array}$ & $2(1)$ & \multicolumn{2}{|l|}{$10(7)$} & & $138(92)$ \\
\hline $\begin{array}{l}\text { Who usually plans social } \\
\text { arrangements? }\end{array}$ & $36(24)$ & \multicolumn{2}{|l|}{$74(49)$} & $40(27)$ & \\
\hline $\begin{array}{l}\text { Who usually looks after your personal } \\
\text { finances? }\end{array}$ & $31(21)$ & \multicolumn{2}{|l|}{$42(28)$} & $77(51)$ & \\
\hline Social integration subscale & $\begin{array}{l}\geq 5 \text { times } \\
\text { (score } 2 \text { ) }\end{array}$ & \multicolumn{2}{|l|}{$\begin{array}{l}\text { 1-4 times } \\
\text { (score 1) }\end{array}$} & $\begin{array}{l}\text { Never } \\
\text { (score 0) }\end{array}$ & \\
\hline $\begin{array}{l}\text { How many times a month do you } \\
\text { participate in shopping? }\end{array}$ & $75(50)$ & \multicolumn{2}{|l|}{$59(39)$} & $19(11)$ & \\
\hline $\begin{array}{l}\text { How many times a month do you } \\
\text { participate in leisure activities? }\end{array}$ & $75(50)$ & \multicolumn{2}{|l|}{$59(39)$} & $16(11)$ & \\
\hline \multirow{2}{*}{$\begin{array}{l}\text { How many times a month do you visit } \\
\text { friends or relatives? }\end{array}$} & $61(41)$ & \multicolumn{2}{|l|}{$84(56)$} & $5(3)$ & \\
\hline & $\begin{array}{l}\text { With friend without } \mathrm{Bl} \text { or } \\
\text { combination friends } \\
\text { family } \\
\text { (score 2) }\end{array}$ & \multicolumn{2}{|c|}{$\begin{array}{l}\text { With friend with } \\
\text { BI or family (score } \\
\text { 1) }\end{array}$} & $\begin{array}{l}\text { Mostly alone } \\
\text { (score } 0 \text { ) }\end{array}$ & \\
\hline \multirow{2}{*}{$\begin{array}{l}\text { Do you do leisure activities alone or } \\
\text { with others? }\end{array}$} & $96(64)$ & \multicolumn{2}{|l|}{$27(18)$} & $27(18)$ & \\
\hline & Yes & \multicolumn{2}{|l|}{ No } & & \\
\hline \multirow{2}{*}{$\begin{array}{l}\text { Do you have a best friend in whom } \\
\text { you confide? }\end{array}$} & $81(54)$ & \multicolumn{2}{|l|}{$69(46)$} & & \\
\hline & Almost every day & \multicolumn{2}{|c|}{$\begin{array}{l}\text { Almost every } \\
\text { week }\end{array}$} & Seldom/never & \\
\hline $\begin{array}{l}\text { How often do you travel outside the } \\
\text { home? }\end{array}$ & $116(77)$ & $31(21)$ & & $3(2)$ & \\
\hline \multicolumn{4}{|c|}{ Productivity: Combination of work or retirement, education and voluntary work $\quad$ Score (\%) } & & \\
\hline \multicolumn{3}{|c|}{ - No work or retired, no education, no voluntary work } & $93(62)$ & & \\
\hline \multicolumn{3}{|c|}{ - No work, no education, doing voluntary work } & $13(9)$ & & \\
\hline \multicolumn{3}{|c|}{ - No work but looking or retired, no education, doing voluntary work } & $14(9)$ & & \\
\hline \multicolumn{3}{|c|}{$\begin{array}{l}\text { - } \quad \text { Part-time job or part-time education, no voluntary work } \\
\text { - } \quad \text { Retired and doing voluntary work five times or more/ month }\end{array}$} & $10(7)$ & & \\
\hline \multicolumn{2}{|c|}{$\begin{array}{ll}\text { - } & \text { Full-time job or full-time education } \\
\text { - } & \text { Retired and part-time education } \\
\text { - } & \text { Part-time job and part-time education }\end{array}$} & & $10(7)$ & & \\
\hline \multicolumn{3}{|c|}{$\begin{array}{l}\text { - Full-time job and part-time education or full-time education and part-time } \\
\text { job } \\
\text { - } \quad \text { Retired and part-time education and doing voluntary work }\end{array}$} & $10(7)$ & & \\
\hline
\end{tabular}


Table 3 presents bivariate correlations between the possible predicting factors and social participation measured with the CIQ. The predictors do not correlate very highly. Personal factors and environmental factors as measured were not significantly related to social participation.

Table 3: Bivariate correlations between possible predicting factors and social participation

\begin{tabular}{|c|c|c|c|}
\hline \multicolumn{4}{|l|}{ Socio-demographic variables } \\
\hline Age & $r=-.326$ & $\mathrm{p}<0.01$ & \\
\hline Gender & Chi-square=112.9 & (df 72) & .001 \\
\hline Marital status & Chi-square $=68.5$ & (df 72) & .594 \\
\hline Children living at home & $r=-.146$ & $p=.222$ & \\
\hline Living situation & Chi-square $=74.0$ & (df 72) & .411 \\
\hline Highest level of education & rho $=.152$ & $p=.065$ & \\
\hline Occupation & rho $=.112$ & $p=.169$ & \\
\hline Employment status before stroke & rho $=.135$ & $p=.069$ & \\
\hline Injury severity variables & $r=.097$ & $p=.235$ & \\
\hline Severity of aphasia & $r=.365$ & $\mathrm{p}<0.01$ & \\
\hline \multicolumn{4}{|l|}{ Rehabilitation variables } \\
\hline Functional performance (BI) & $r=.414$ & $\mathrm{p}<0.01$ & \\
\hline Functional status (COOP-WONCA) & $r=-.160$ & $p=0.05$ & \\
\hline Personal factors & $\mathrm{r}=.114$ & $p=.193$ & \\
\hline Environmental factors & $r=-.007$ & $p=.936$ & \\
\hline
\end{tabular}

BI: Barthel Index, Bold = variable entered in the multiple regression analyses

The results of stepwise multiple linear regressions performed on the total CIQ scores are presented in table 4 , in which the unique contribution of each variable can be seen. There were four variables that contributed significantly to the model: functional performance, age, gender and severity of aphasia. Those who were younger and those who were female were found to have a higher level of participation. The other main factors were functional performance (people with better functional ADL performance participated more) and the severity of aphasia, which added a significant contribution to the model $(t=2.989$, Sig. $=.003)$; a higher level of participation was achieved by those with a higher FAST score (indicating less severe aphasia). The COOP-WONCA did not contribute to the regression model. The mean variance of inflation factor (VIF) was 1.06, indicating that there is no problem with multicollinearity biasing the regression model. The Durbin-Watson value is 1.876 , indicating that the assumption of independent errors has been met. 
Table 4: Stepwise multiple linear regression analyses performed on the total Community Integration Questionnaire (CIQ) scores

\begin{tabular}{|c|c|c|c|c|c|c|c|c|c|}
\hline \multirow[b]{2}{*}{ Model } & \multicolumn{2}{|c|}{$\begin{array}{l}\text { Unstandardised } \\
\text { coefficients }\end{array}$} & \multicolumn{3}{|c|}{$\begin{array}{l}\text { Standardised } \\
\text { coefficients }\end{array}$} & \multicolumn{2}{|c|}{$\begin{array}{l}95 \% \text { Confidence } \\
\text { interval for B }\end{array}$} & \multirow[t]{2}{*}{$\mathrm{R}^{2}$} & \multirow[t]{2}{*}{ Adjusted $\mathrm{R}^{2}$} \\
\hline & B & SE B & Beta & $\mathrm{t}$ & Sign. & $\begin{array}{l}\text { Lower } \\
\text { bound }\end{array}$ & $\begin{array}{l}\text { Upper } \\
\text { bound }\end{array}$ & & \\
\hline 1 & & & & & & & & & \\
\hline $\begin{array}{l}\text { Barthel } \\
2\end{array}$ & .482 & .087 & .414 & 5.532 & .000 & .310 & .654 & .171 & .166 \\
\hline Barthel & .480 & .082 & .412 & 5.879 & .000 & .318 & .641 & & \\
\hline $\begin{array}{l}\text { Gender } \\
3\end{array}$ & 3.229 & .692 & .327 & 4.663 & .000 & 1.860 & 4.597 & .278 & .268 \\
\hline Barthel & .446 & .078 & .383 & 5.688 & .000 & .291 & .601 & & \\
\hline Gender & 3.063 & .663 & .310 & 4.622 & .000 & 1.753 & 4.372 & & \\
\hline $\begin{array}{l}\text { Age } \\
4\end{array}$ & -.116 & .030 & -.263 & -3.901 & .000 & -.175 & -.057 & .346 & .333 \\
\hline Barthel & .406 & .077 & .349 & 5.247 & .000 & .253 & .559 & & \\
\hline Gender & 2.617 & .662 & .265 & 3.951 & .000 & 1.308 & 3.926 & & \\
\hline Age & -.105 & .029 & -.238 & -3.595 & .000 & -.163 & -.047 & & \\
\hline FAST & .159 & .053 & .205 & 2.989 & .003 & .054 & .263 & .384 & .367 \\
\hline
\end{tabular}

\section{Discussion}

Our results show that there is much variation in the level of social participation of people with aphasia, with some reaching a very high score of 25 (max. score 29) and others reaching a very low score of 4 on the $\mathrm{ClQ}$. Also in other studies immense differences in the range of social participation was found ${ }^{(12,29)}$. With a mean score of 14.2 on the $\mathrm{ClQ}$, the level of social participation of people with aphasia is rather low compared to people with traumatic brain injury ${ }^{(30,31)}$. These results are consistent with other studies, which have shown that social participation in people with aphasia is diminished ${ }^{(7,9,12,13,32)}$ but our study included more people and people with a wider range of severity of aphasia.

We also showed that social participation is primarily related to stroke severity, both in terms of aphasia and in terms of physical dependence, and that other factors have surprisingly little influence.

A number of factors were identified that were related to social participation, namely age $(\beta=-.238)$, gender $(\beta=.265)$, functional performance in $A D L(\beta=.349)$ and severity of aphasia $(\beta=.205)$, which together explain $37 \%$ of the total variance. These findings are consistent with three stroke studies that also included patients with aphasia ${ }^{(28,33,34)}$. These studies found that multivariate stepwise linear regression analysis identified communication as an important predictor for social outcome, next to other variables such as functional performance, age and gender. Our findings are thus consistent with other studies. Also the study of Code ${ }^{(12)}$ reported that aphasia and physical functioning are important determinants for social engagement outside the house. Thus far, only $37 \%$ of the variance has been explained. There might be some important variables that influence social participation that were not measured. We tried to capture all the variables that might be related to social participation in our measurement set, as identified through our qualitative study ${ }^{(20)}$ and the literature ${ }^{(35-38)}$, in terms of personal factors and environmental factors to measure psychological variables as well as aspects of social support. We used the questionnaire with regard to personal factor as one instrument to investigate the relation with social participation because the 
internal consistency of the six items was rather high. However, it might be that individual items included in the questionnaire correlated with the $\mathrm{CIQ}$. It is possible that individual variation in the factors influencing social participation is so large that no group study will identify them. Six different investigators collected the data, which might have influenced the data collection, but by giving thorough training before data collection inter-rater reliability was made more likely. The CIQ showed good testretest reliability $(I C C=0.96)$, measured in 20 people on two different occasions within a time period of 10-14 days by two different data collectors involved in this study ${ }^{(28)}$.

This study found that functioning at the organ level and activities at the personal level are important predictors for social participation. A relationship between environmental factors and social participation, as suggested in the International Classification of Functioning, disability and health model (2001) and our earlier study, was not found in this study. The questionnaires that were used to measure personal and environmental factors showed good internal consistency. It is possible that the validity of these as measures of external factors is low, but alternatively it may be that each person's level of social participation is determined by a personally unique factor (such as choice) or small group of factors that are not shared with others. Also the study of Cruice et al. ${ }^{(29)}$ suggests that personal choices might play an important role in their social participation. According to Whiteneck, research is required to get insight in the interplay between environmental barriers and other, perhaps yet unidentified, factors, (39). There is a clear need for a classification of personal factors to allow for complete reporting on the experience of disability ${ }^{(40)}$.

It is an important finding that aphasia severity has a unique contribution to social participation, next to other factors like age, gender and functional performance. A lot of attention is given to the physical functioning of people with aphasia during the moment of release from rehabilitation, however more attention should be given to the severity of aphasia to understand the possibilities in participation in social activities. If health care professionals want to help in building a bridge to social participation for people having had a stroke, specific attention needs to be given to aphasia and its consequences. That is, the choice of aphasia assessment and intervention strategies should be directly influenced by outcome goals related to life participation in its broadest sense. Speech and language pathologists need to prepare people with aphasia by covering issues that involve living with a disability. Research should be conducted to get insight in the views of speech and language pathologists with regard to how equipped they feel to respond to life issues in the way that they respond to requests to work on language processing.

\section{Clinical implications}

Stroke severity, both in terms of aphasia and in terms of functional dependence, is an important determinant of the level of social participation. By reducing limitations in functional performance as well as by promoting communication, people with aphasia could gain greater social participation.

Although this study did not show that contextual factors influenced the level of participation, it is likely that aspects of context are important in individual cases and these factors should not be ignored as a result of this study. Health care professionals and other service providers need to promote communication and need to look beyond 
established theories and practices in order to attain authentic social participation for people with aphasia. This means creating an authentic involvement of the person with aphasia during and after rehabilitation and establishing user control. 


\section{References}

1. WHO. ICF international homepage. 2001 [updated 2001; cited]; Available from: http://www.who.int/classifications/icf/site/icftemplate.cfm?myurl=introduction.html\%20\&mytitle=Intr oduction.

2. Alexander MP. Medical, Neurologic and functional outcome of stroke survivors. In: Mills VM, Cassidy JW, Katz DI, editors. Neurological rehabilitation: a guide to diagnosis, prognosis and treatment planning: Blackwell Science; 1997. p. p.29-59.

3. Van Heugten $C$, editor. Revalidatie na een beroerte: richtlijnen en aanbevelingen voor zorgverleners. Den Haag: Nederlandse Hartstichting; 2001.

4. Lyon J, Shadden BB. Treating life consequences of aphasia's chronicity. In: Chapey R, editor. Language intervention strategies in adults. 4th ed. Baltimore: Williams and Wilkins; 2001. p. 297-315.

5. Simmons-Mackie N, Threats TT, Kagan A. Outcome assessment in aphasia: a survey. Journal of Communication Disorders. 2005 Jan-Feb;38(1):1-27.

6. Parr S. Living with severe aphasia: tracking social exclusion. Aphasiology. 2007;21(198-123).

7. Dalemans RJP, de Witte L, van den Heuvel W, Wade D. A description of social participation in working age people with aphasia: a review of the literature. Aphasiology 2008;22(10):1071-91.

8. Barrow R. Listening to the voice of living life with aphasia: Anne's story International Journal of Language and Communication Disorders. 2008;43(S1 (May 2008)):30-46.

9. Davidson B, Howe T, Worrall L, Hickson L, Togher L. Social participation for older people with aphasia: the impact of communication disability on friendships. Topics in Stroke Rehabilitation. 2008 JulAug;15(4):325-40.

10. Holland AL. Living successfully with aphasia: three variations on the theme. Topics in Stroke Rehabilitation. 2006 Winter;13(1):44-51.

11. Natterlund BS. A new life with aphasia: everyday activities and social support. Scandinavian Journal of Occupational Therapy. 2009 Mar 16:1-13.

12. Code C. The quantity of life for people with chronic aphasia. Neuropsychological Rehabilitation. 2003;13(3):379-90.

13. Worrall L, Hickson LMH. Quantifying aphasia people`s social lives in the context of non-aphasic peers. Aphasiology. 2006;20(12):1210-25.

14. Hilari K, Northcott S. Social support in people with chronic aphasia. Aphasiology. 2006;20(1):17-36.

15. Byng S, Pound C, Parr S. Living with aphasia: a framework for therapy interventions. In: Papathanasiou I, editor. Acquired neurological communication disorders: A clinical perspective. London: Whurr; 2000.

16. Kimbarow ML. Integrating Life Participation Approaches to Aphasia Treatment With Adult Learning Theory: A Synergistic Approach. Topics in Language Disorders. 2007;27(4):318-23.

17. Chapey R, Duchan J, F., Elman R, J., Garcia L, J., Kagan A, Lyon J, et al. Life Participation Approach for people with Aphasia: A Statement of Values for the Future. American Speech-Language-Hearing Association; 2009 [updated 2009 2009; cited 1997]; Available from.

18. Shadden BB, Hagstrom F. The Role of Narrative in the Life Participation Approach to Aphasia. Topics in Language Disorders. 2007;27(4):324-38.

19. Williams SE. Supporting social participation for individuals with significant communication disabilities. Center On Disabilities:Technology And Persons With Disabilities Conference 2005; 2005; California State University Northridge. 2005.

20. Dalemans RJP, de Witte L, Wade D, van den Heuvel W. Social participation through the eyes of people with aphasia. International Journal of Language and Communication Disorders. 2009; posted online 20 october 2009.

21. Dalemans RJP, Wade D, Van den Heuvel W, De Witte L. Facilitating the participation of people with aphasia in research: a description of strategies. Clinical Rehabilitation. 2009;23 948-59.

22. Enderby $P$, Crow E. Frenchay Aphasia Screening Test: validity and comparability. Disability and Rehabilitation. 1996 May;18(5):238-40.

23. Collin C, Wade DT, Davies S, Horne V. The Barthel ADL Index: a reliability study. International Disability Studies. 1988;10(2):61-3. 
24. Green J, Forster A, Young J. A test-retest reliability study of the Barthel Index, the Rivermead Mobility Index, the Nottingham Extended Activities of Daily Living Scale and the Frenchay Activities Index in stroke patients. Disability and Rehabilitation. 2001 Oct 15;23(15):670-6.

25. Van Weel C. Functional status in primary care: COOP/WONCA charts. Disability and Rehabilitation. 1993 Apr-Jun;15(2):96-101.

26. Kinnersley $\mathrm{P}$, Peters $\mathrm{T}$, Stott $\mathrm{N}$. Measuring functional health status in primary care using the COOPWONCA charts: acceptability, range of scores, construct validity, reliability and sensitivity to change. $\mathrm{Br} \mathrm{J}$ Gen Pract. 1994 Dec;44(389):545-9.

27. Willer B, Ottenbacher KJ, Coad ML. The Community Integration Questionnaire: a comparitive examination. American Journal of Physical and Medical Rehabilitation. 1994 73:103-11.

28. Dalemans RJP, de Witte L, Beurskens S, van den Heuvel W, Wade D. Psychometric properties of the CIQ adjusted for people with aphasia. Archives Physical and Medical Rehabilitation. 2009;in press (October 2009).

29. Cruice M, Worrall L, Hickson LMH. Quantifying aphasic people`s social lives in the context of non-aphasic peers. Aphasiology. 2006;20(12):1210-25.

30. Wood RL RN. Psychosocial adjustment 17 years after severe brain injury. Journal of Neurological Neurosurgery and Psychiatry. 2006;77(1):71-3.

31. Rath JF, Hennessy JJ, Diller L. Social Problem Solving and Community Integration in Postacute Rehabilitation Outpatients With Traumatic Brain Injury Journal of Advanced Nursing. 2003;48(3):137-44.

32. Black-Schaffer RM, Osberg JS. Return to work after stroke: development of a predicitive model. Archives Physical and Medical Rehabilitation. 1990;71:285-90.

33. Schepers VP, Visser-Meily AM, Ketelaar M, Lindeman E. Prediction of social activity 1 year poststroke. Archives Physical Medicine and Rehabilitation. 2005 Jul;86(7):1472-6.

34. Tilling K, Sterne JAC, Rudd AG, Glass TA, Wityk RJ, Wolfe CDA. A New Method for Predicting Recovery After Stroke. Stroke. 2001;32:2867-73.

35. Howe T, Worrall L, Hickson L. Interviews with people with aphasia: Environmental factors that influence their community participation Aphasiology. 2008;22(10):1-29.

36. Howe T, Worrall L, Hickson L. Observing people with aphasia: Environmental factors that influence their community participation Aphasiology. 2008;22(6):618-43.

37. Brown K, McGahan L, Alkhaledi M, Seah D, Howe T, Worrall L. Environmental factors that influence the community participation of adults with aphasia: The perspective of service industry workers. Aphasiology. 2006;20(7):595-615.

38. Brumfitt S. Psychosocial aspects of aphasia: speech and language therapists' views on professional practice. Disability and Rehabilitation. 2006 Apr 30;28(8):523-34.

39. Whiteneck GG, Gerhart KA, Cusick CP. Identifying environmental factors that influence the outcomes of people with traumatic brain injury. J Head Trauma Rehabil. 2004 May-Jun;19(3):191-204.

40. Jelsma J. Use of the International Classification of Functioning, Disability and health: A literature survey. Journal of Rehabilitation Medicine. 2009;41(1):1-12. 



\section{Chapter 7:}

\section{Facilitating the participation of people with aphasia in research}

Based upon:

Dalemans RJP, Wade D, Van den Heuvel W, De Witte L. Facilitating the participation of people with aphasia in research: a description of strategies. Clinical Rehabilitation 2009;23 948-959. 
Facilitating the participation of people with aphasia in research: a description of strategies

Background: People with aphasia are often excluded from research because of their communication impairments, especially when an investigation into the communication impairment is not the primary goal. In our research concerning social participation of people with aphasia, we wanted to include people with mild, moderate as well as severe aphasia.

Aim: To suggest strategies and techniques for research in people with aphasia based upon experiences in conducting research in this group of people.

Methods: We conducted a qualitative study and a quantitative study in people with aphasia concerning their social participation. In these studies different strategies were developed based upon literature, conversations with people with aphasia and speech and language therapists, to facilitate the inclusion of people with aphasia, even those with severe communication problems. Several strategies were evaluated. The strategies used and our experiences are outlined in this report.

Main contribution: It is possible to conduct research in this group. Several strategies were helpful to make this mission possible: the use of pre-structured diaries, the use of in-depth interviews with attention to non-verbal communication, the use of existing measurements, adjusted for people with aphasia by: using pictograms, placing one question per page, bolding the key concepts in the question, using large font, visualising the answering possibilities in words and in pictures, reducing the question length, and excluding negatives in the question.

Conclusion: Research in people with aphasia is possible when using strategies adjusted to the communicative impairment. 


\section{Introduction}

People with aphasia are often excluded from research (1). One important reason for this is the difficulty of measuring anything when the question is based upon language (2). There is a pattern of recruiting only those individuals who have the competence to express their perspective, or to express verbally with a reflective and clear style (3). Other people with cognitive impairments who have problems in expressing themselves verbally, such as those with traumatic brain injuries, dementia (4) and learning disabilities (5) are also often excluded in research.

Especially people with severe aphasia are excluded from research because of their difficulties in understanding verbal instruction. They are confronted with their language problems in everyday life, making access to public services very difficult (6). People with aphasia are often not included or not described as a separate group in stroke studies concerning participation (7). Consequently, people with aphasia experience many problems that remain unknown. Further, the aphasic stroke population reports that quality of life and psychosocial issues related to their language loss are typically not adequately addressed within the therapeutic process (8). Individuals become marginalised and made invisible by the labels of their conditions or situations when an individual's personal response and perspective are overlooked on the basis of an assumed inability to communicate.

However, some researchers have conducted studies in people with aphasia. Luck and Rose (9) studied the issue of which method adjustments needed to be made in using qualitative research in people with aphasia, and reported that it is necessary to step out of the traditional role of the qualitative interviewer by altering questioning style, offering ideas to participants, and using supportive conversation techniques. Howe et al. (10) audio taped the interviews in their qualitative study and made field notes, used strategies to facilitate the communication of people with aphasia during the interviews like encouraging participants to draw, write or gesture if they had difficulties in talking. Furthermore, they organised meetings with the participants in which the results of the study were discussed (member check meetings) to check the analysis, supported with a verbal and written summary using pictures of the key emerging study results. According to Beukelman (11), people with aphasia prefer personally relevant photographs over non-personal photographs and iconic symbols in message representation. The accuracy for message presentation is higher for personally relevant pictures in the use of alternative and augmentative communication. In contrast, Fujimori et al. (12) found no significant difference between the comprehension of written text, photographs, and illustrations compared with the comprehension of pictograms. Brennan et al. (13) reported that aphasia-friendly formats (simplified vocabulary and syntax, large print, increased white space, and pictures) increase the reading comprehension of people with aphasia. Alilegay et al. (14) found that written health materials obtained from people with aphasia were written at an average grade nine readability level (Flesch Kincaid readability index $(15,16)$ ) and contained low-frequency words, low-imageability words, and complex sentences. Written health materials are not sufficiently modified to suit the reading ability of people with aphasia.

Although there is some information available for doing research in people with aphasia, those people are mostly still excluded from research. We wanted to perform a 
study into participation of people with mild, moderate as well as severe aphasia. In this article we describe the strategies (including some strategies based upon the information from the studies that are described above) used in two studies; and we discuss our experiences with these strategies.

\section{Method}

We conducted two studies in people with aphasia: a qualitative study as well as a quantitative study. The strategies used in both studies will be described here.

\section{Qualitative study}

In the qualitative study (17) the aim was to explore how people with aphasia and their central caregivers perceive their social participation and the factors influencing it.

The only way to capture the perspective of persons with aphasia is to ask the individuals to express themselves. However, when a person has severe aphasia, it is not obvious that he/she can express him/herself, and there are certainly difficulties. In the qualitative study 13 people with aphasia and 12 central caregivers were included. Three different methods were used to collect data: using a pre-structured diary during two weeks, followed by conducting a semi-structured in-depth interview, and a focusgroup interview (after analysing the data gathered through the diaries and the indepth interviews).

We involved the central caregiver as an assistant as well as an informant in filling in the pre-structured diary, and as a translator and informant during the interviews.

Before explaining the use of the pre-structured diary to the participant in the study, the Frenchay Aphasia Screening Test (FAST) (18) was used to measure the communicative abilities of the person with aphasia. The total FAST score (maximum 30) determines overall aphasia severity (1-10: severe, 11-20: moderate, 21-26: mild, 27-30: no aphasia). Based upon the FAST score the interview was adjusted to the communicative capabilities of the participant. For example: if the person with aphasia was not able to read, the interviewer pointed at the pictogram while reading the questions aloud. If the participant was able to read, the interviewer pointed at the written question.

\section{Pre-structured diaries}

The strategies used were:

- Reducing time pressure

- Using a structured outlined lay-out

- Augmentative communication by using pictograms to be placed in the diaries

- Separate space in the diary for the caregiver to express his or her perspective

- Including the caregiver as an assistant for the person with aphasia

- Giving oral and written information concerning the use of the pre-structured diary

People with aphasia often cannot express themselves because of the stress caused by time pressure (19-21). An important advantage of writing a diary was the absence of time pressure. Yet another important obstacle needed to be tackled: people with aphasia often have problems expressing themselves orally as well as in writing. Therefore we used a structured outlined lay-out in the diary so that the person with aphasia 
had a structure that could assist him or her in expressing him/herself (see Figure 1). Since, in some cases, the person was not able at all to write down his/her thoughts, we developed pictograms of important activities of daily living to be put into the diary, as well as pictograms of emotions, health condition, etc. We used a standard pictographic system ('sclera's pictograms'(22)) which uses white silhouettes with little details against a black background.

A separate space was created at the end of each page for the central caregiver. In this space the central caregiver could express his or her perspective on the social participation of the person with aphasia. Further, the central caregiver could assist the person with aphasia in expressing himself or herself by writing down what the person with aphasia said, or by applying the sticker that the person with aphasia pointed out. The central caregiver and the person with aphasia received oral and written instructions regarding the diary (see appendix 1 ). They could ask questions to the researcher at any time, when something was not clear.

The researcher returned after two weeks to collect the diary and to make an appointment for the interview. The researcher encouraged the participants to describe their experiences with regard to writing the diary.

Figure 1: Pre-structured diary

\begin{tabular}{lll} 
Monday & Acitivity & Performance \\
\hline Domestic life & \\
\hline
\end{tabular}

\section{In-depth interviews}

The data collected in the diary formed the basis for the in-depth interview to elicit new experiences and perceptions from the point of view of the person with aphasia. Several persons participated in the in-depth interview: the person with aphasia, a central caregiver, the interviewer and the interview-assistant. Before the interview started, the interviewer explained the role of the interviewer (asking the interview questions), the interview-assistant (monitoring the non-verbal behaviour and audio 
taping the interview), the person with aphasia (expressing his perception of social participation and the involved influencing factors) and the central caregiver (functioning as a translator in the first place and being an informant in the second place).

The interview took place in a quiet environment in the home of the subjects. We used several strategies to promote the involvement of the person with aphasia:

The interviewer checked the communicative abilities of the interviewee based upon the FAST, and reduced the cognitive load of the questions (f.e. ensuring rich environmental context with regard to setting, people, objects, phrasing the question in simple terms, asking one question at a time, reducing the question length) based upon this ability.

The interview was audio taped. This was important in case the person with aphasia was not able to express himself verbally. Further, the interview-assistant monitored the audiotape recording and made records of non-verbal communication and the conversational context, so that the non-verbal communication could also be included in the analysis. We decided not to use a video tape in order to include non-verbal communication, because it could intimidate the person with aphasia and because an interview-assistant can observe situations that might occur beyond the eye of the video recording. Further the interview-assistant checked the trustworthiness by over viewing the interview, by listening very carefully. The interview-assistant asked questions if there seemed to be discrepancies in non-verbal and verbal behaviour, as well as between the utterances of the person with aphasia and their central caregiver.

For each question, the interviewer always addressed the person with aphasia first ensuring time and space to express himself/herself, before asking the perception of the central caregiver.

Questions were made short and simple, and were supported by the use of pictures or photographs which could be used as a prompt and aid to comprehension.

High frequency words were used.

Other forms of communication were encouraged when oral communication was not possible for the interviewee, for example the use of pencil and paper and the use of non-verbal communication.

The interviewer tried to convey and receive ideas in different ways, and checked whether she had understood the person correctly, and checked the understanding of the person with aphasia by looking at non-verbal behaviour as well as by asking, using straightforward language.

When the person with aphasia was losing attention or was showing other signs of fatigue, a short time break was included.

The central caregiver was invited to be present during the interview. The central caregiver had a double role: in the first place he or she was invited to be a 'translator' for the person with aphasia when the interviewer could not understand the person with aphasia fully. After each 'translation', the interviewer addressed the person with aphasia again to check if that was indeed what he/she was trying to say. Furthermore, the central caregiver could express his/her own perception of the social participation of the person with aphasia. 


\section{Focus group interview}

After analysing the data from the diaries and the in-depth interviews, we wanted to check whether the analysis of the collected data really captured what the participants wanted to express. For that purpose, ten of the interviewed people with aphasia and nine central caregivers participated in a focus group interview. To ensure the involvement of the persons with aphasia, the following actions were taken:

1. The participants received a short report of the data analysis to prepare themselves for the focus group interview. The report was aphasia friendly (13): written in simple language, using an outlined lay-out, using font style Verdana, using large font (size 16), a lot of white space between each key point, and using support by pictures and pictograms.

2. The interviewer first presented the main outcomes using a power point presentation (see Figure 2). Then, after a short break, the participants were invited to express their point of view.

Figure 2: example of a slide in power point presentation

\section{Interpersonal: Knowledge}

\section{Facilitating}

- Having knowledge about aphasia

- Knowing how to deal with aphasia

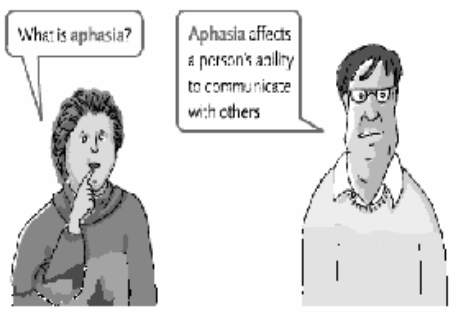

3. During the discussion, central key concepts of the interview were visualised (by means of a power point sheet with the key concepts in writing, as well as expressed with a pictogram).

4. Some conversation rules were pointed out before and during the discussion, such as: listen to each other; check whether you understand what the other person is saying before you react; do not interrupt when another person is speaking; talk slowly.

The interviewer tried to encourage each person with aphasia to express themselves, by addressing them personally. 
Quantitative research in people with aphasia

Before conducting the quantitative study in people with aphasia, a systematic review (2) was conducted to investigate which participation measurements are suitable for use in people with aphasia. Measurement instruments were confirmed as possibly suitable for use in this group when the following strategies are used: simplified language, multimodal presentation of the questions (support by pictograms, drawings etc.), a small set of response choices, a careful ordering of the items, and a short length. The review suggested that questions including a negative or denial, and/or using complex sentences, and/or imposing a large demand upon memory should be avoided.

For the quantitative study, a set of instruments was selected based upon the criteria of the systematic review. The selected measurement instruments needed adjustments before we could use them in people with aphasia. Six speech and language therapists working with people with aphasia as well as researchers in populations with cognitive impairments were consulted in individual conversations.

Further, data from the literature were used to adapt the instruments $(23,24)$ : several studies have found discrepancies between the readability levels compared to the reading skills of the patients who read them (25). The literature generally recommends that a reading grade of 5-6 (Flesch Kincaid readability index) should be used when developing written language for patients whose reading abilities are unknown $(6,26)$.

Based upon these considerations adjustments were made to existing instruments:

- using large font (size 16 points)

- using font style Verdana

- bolding key concepts

- reducing each question to the essence (mean question length ranged from 4.6-11.5 words for the measurement instruments used, after simplification of the questionnaires)

- supporting questions with a specifically designed pictogram

- using an increased amount of white space between the question and the response set

- supporting each response set with pictograms

- using a separate page for each question, so that people were not distracted by other questions

After these adjustments were made, the instruments were tried out in four people with aphasia. Further adjustments (for example a pictogram of a number was supported with dots equal to the number) were made during the interviews. The objective was to make a question as comprehensible as possible for people with aphasia. People with mild, moderate as well as severe aphasia were included in this stage.

Then, based upon this first experience, the instruments were fine tuned and tested in ten new people with aphasia with different degrees of expressive and comprehension problems. They all stated that the instruments were clear.

In the next stage, the adapted instruments were sent to five other speech and language therapists working daily with people with aphasia, and to one researcher in 
people with cognitive impairments, for feedback, using a structured questionnaire (see appendix 2). The instruments were further adapted following their comments and some pictograms were further adjusted, leading to the final version of the instruments. Figure 3 shows an example of an adjusted question.

Questions were administered during an interview. The following strategies were used: Good preparation: the FAST was assessed to gain an impression of the communicative abilities of the person with aphasia

Based upon the data from the FAST, strategies adjusted to the communicative abilities of the person with aphasia were used:

- The interviewer always tried to be aware of non-verbal behaviour

- The interviewer gave plenty of time to answer each question

- After each questionnaire, people with aphasia were asked which strategies were helpful for them to understand the questions.

- The interviewer took impairments like neglect, hearing impairment into account (f.e.by sitting at the right side, asking the person if he fully heard the question).

Figure 3: Example of an adjusted question

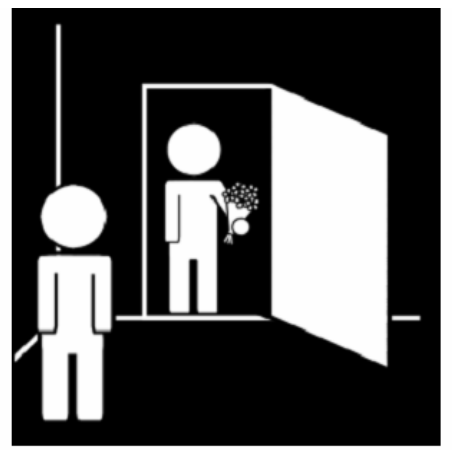

Who usually plans social arrangements?

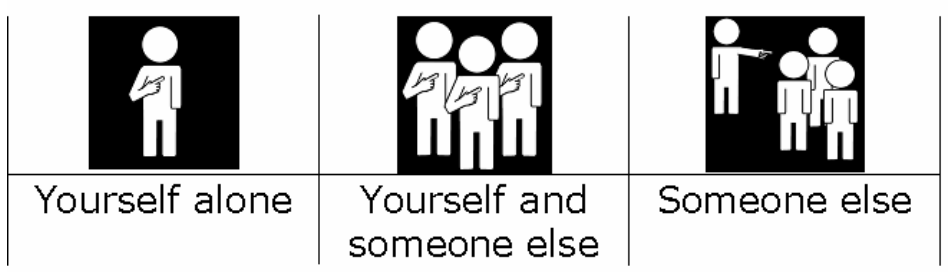




\section{Results}

The strategies used in the qualitative as well as in the quantitative study facilitated people with aphasia to participate in the studies.

\section{Qualitative study}

Using the techniques and strategies described, we found that all the participants even those with quite severe aphasia, could communicate their ideas and concerns. The characteristics of people successfully included are shown in Table 1.

Table 1: Characteristics of people successfully included

\begin{tabular}{|c|c|c|c|c|c|c|c|c|c|c|c|c|}
\hline & $8 / 9$ & age & $\begin{array}{l}\text { time } \\
\text { po(y) }\end{array}$ & rs FAST & z-score & compreh. & expressi & reading & writing & $\begin{array}{l}\text { Marital } \\
\text { status }\end{array}$ & children & $\begin{array}{l}\text { employment pre- } \\
\text { stroke }^{1}\end{array}$ \\
\hline 1. Liv $^{2}$ & 9 & 48 & 2,1 & 12 & $-0,9$ & 3 & 4 & & 3 & 2 married & son & housewife \\
\hline 2. Rita & 9 & 56 & 7,7 & 26 & 1,43 & 8 & 9 & & 5 & 4 married & son, daughter & $\begin{array}{l}\text { Precision production, } \\
\text { craft and repair } \\
\text { occupation E.666 }\end{array}$ \\
\hline 3. Bert & $\delta$ & 49 & 3,6 & 19 & 0,19 & 7 & 7 & & 2 & 2 married & son, daughter & $\begin{array}{l}\text { Professional and } \\
\text { technical occupation, } \\
\text { A 229 }\end{array}$ \\
\hline 4. Mia & 9 & 55 & 5 & 22 & 0,65 & 6 & 9 & & 2 & 2 married & 4 sons & housewife \\
\hline 5. Jo5 & 8 & 57 & 1,4 & 26 & 1,27 & 10 & 8 & & 2 & 2 married & daughter, son & $\begin{array}{l}\text { Transportation and } \\
\text { material moving } \\
\text { occupation G.804 }\end{array}$ \\
\hline 6. Roos & 우 & 45 & 3 & 29 & 1,74 & 10 & 10 & & 4 & 4 married & daughter & $\begin{array}{l}\text { Professional and } \\
\text { technical occupation } \\
\text { A.106 }\end{array}$ \\
\hline 7. Hans & 8 & 58 & 9 & 24 & 0,96 & 9 & 7 & & 3 & 3 married & none & $\begin{array}{l}\text { Service occupation, } \\
\text { except private } \\
\text { household K.434 }\end{array}$ \\
\hline 8. Stan & 8 & 71 & 11 & 12 & $-0,9$ & 6 & 3 & & 0 & 0 married & 3 daughters & retired \\
\hline 9. Roel & 8 & 65 & 3,9 & 22 & 0,65 & 7 & 6 & & 4 & 4 married & 2 sons & $\begin{array}{l}\text { Sales occupation } \\
\text { C. } 256\end{array}$ \\
\hline $\begin{array}{ll}10 . \\
\text { Tom }\end{array}$ & 8 & 55 & 3 & 10 & $-1,21$ & 5 & 2 & & 3 & 0 married & 2 sons & disability pension \\
\hline $\begin{array}{l}11 . \\
\text { Sally }\end{array}$ & q & 69 & 5 & 19 & 0,19 & 4 & 8 & & 5 & 2 married & & housewife \\
\hline 12. Jef & 8 & 66 & 4 & 24 & 0,96 & 7 & 8 & & 4 & 4 married & 3 sons, 1 daughter & $\begin{array}{l}\text { Transportation and } \\
\text { material moving } \\
\text { occupation G.814 }\end{array}$ \\
\hline $\begin{array}{l}13 . \\
\text { Sara }\end{array}$ & 우 & 52 & 8 & 26 & 1,27 & 10 & 8 & & 5 & 3 divorced & 2 sons & $\begin{array}{l}\text { Professional and } \\
\text { technical occupation }\end{array}$ \\
\hline
\end{tabular}

\section{Pre-structured diaries}

People with aphasia focused on the performed activity, and barely described feelings that accompanied a certain activity. Also, the experience of success in performing an activity was described only minimally or not at all.

People expressed themselves using two-three word sentences, or made simple drawings to support their written information. Five people with aphasia did not use the stickers. People with severe writing problems did use stickers to express themselves. Some people used stickers to express the activity as well as the accompanying feeling and the experienced success or failure. The use of stickers made it possible to give some information about a day in the life of a person with a severe communication problem, expressed by the person himself.

Whereas the person with aphasia focused on the performed activity, the central caregiver also described the well-being of the person with aphasia during that particular day. 
One central caregiver wrote a separate diary because he thought his wife would be displeased with his perception.

\section{In-depth interview}

The subjects in this study were very willing to express their experiences, their perceptions and emotions concerning their social participation in life.

Although three persons with aphasia ( 2 persons with FAST score $=12,1$ person with FAST score $=10$ ) experienced many problems in expressing themselves verbally, they succeeded in expressing their perception in different ways, such as by prosody, by gestures, or through mimicking. The interviewer sometimes did use closed questions when people had very severe expression problems, so as to elicit perceptions. When the interviewer misunderstood the person with aphasia, the search to understanding kept going on for about 5 minutes, by asking closed questions. In some occasions it was not possible to found out what the person with aphasia was trying to say, not for the interviewer, nor for the interview-assistant and the central caregiver. In these occasions, there was a time-out for this topic: the topic was picked up again at a later time during the interview, to check if it was possible to found out what the person with aphasia was trying to say earlier. The tension provoked by the miscommunication was taken away and the person with aphasia was able to be more relaxed, facilitating the chance to expose the word, description, gesture or drawing to make clear what he or she was trying to say. In all the interviews, the persons with aphasia expressed that they were happy to get the chance to express their experiences. People with mild aphasia could express themselves very well orally; people with moderate aphasia could bring out their voice with or without support of paper and pencil or gestures. Deep interviews could be performed, and a large body of data could be collected.

For all the participants, there needed to be space for breaks during the interviews, because fatigue was an important barrier. It was important that the interviewer was particularly vigilant to nonverbal signals that indicated discomfort. After a short break (between 15-25 minutes), the person with aphasia was fit again to participate in the interview.

The interviewer needed to be very aware of the different roles of the caregiver at certain times, because the boundaries between those roles were sometimes very thin. For example, when the central caregiver was translating the expression of the person with aphasia, he or she added his/her own point of view without specifying this.

Sometimes the interviewer needed to control the central caregiver to ensure that he or she did not overrule the person with aphasia and impede their ability to express them self. In some cases, the person with aphasia or the central caregiver expressed them self in another way when the other person was out of the room. Although the interviewer always tried to use the different expressions to fully understand the situation, it sometimes remained unclear if one person did fully express them self in the presence of the other.

The interview-assistant sometimes intervened when there appeared to be a discrepancy between the verbal expression and the non-verbal behaviour of the person with aphasia, however this happened rather rarely. Sometimes the interview-assistant asked the question differently when the question seemed not to be answered completely. 


\section{Focus interviews}

Although people with aphasia often found it very difficult to participate in conversations with more than one person, it appeared to be possible to conduct a focus interview with people with aphasia and their central caregivers. Participants encouraged each other to express their experience and point of view. They shared experiences, they gave comments about the collected data, they expressed an interpretation descriptive of their situation, and they gave examples. They really listened to each other, and they gave each other time to express themselves.

\section{Quantitative study}

The main purpose was to gather relevant information from stroke survivors, even those with severe aphasia. In total 128 persons (FAST score < 27) with aphasia were interviewed. The different strategies used to support people with aphasia seemed to be very helpful. Different strategies were used for different people: sometimes the bolded key concept in the question was most helpful, while in other situations (f.e. when the person was not able to read) the pictogram was the most important support. All the participants stated that the pictograms as well as the bolded key concepts were supportive for comprehension of the questions. The person with aphasia never expressed verbally that he could not comprehend the question, however sometimes the facial expression indicated that the question was not understood completely. If this was the case, the interviewer paraphrased the question (f.e. by giving an example of an activity) without changing the content.

One questionnaire used a 6-point scale, and it was found to be too difficult for people with very severe aphasia to handle so much information at the same time. The following adjustment was made to make it possible to asses this questionnaire: The questions needed to be answered in two phases. First a two-point answering set was used: (satisfying versus unsatisfying), then a 3-point scale was used. For example, if the person found that specific situation satisfying in the 2-point scale, the 3-point scale: almost satisfying, satisfying and very satisfying was used.

All the adjusted questionnaires seemed to be feasible for use in people with aphasia, even in people with very severe expression problems.

\section{Discussion}

People with aphasia, even severe aphasia, were successfully included in both qualitative and quantitative research studies using adjusted techniques and strategies. These revolved around reducing the cognitive load as far as possible by means of such techniques as simplifying communication, reducing the content of communication to simple clear concepts, using bold type and clear font in the lay-out of the question, using a clear visual structure, and allowing as much time as needed. Further, it seemed to be important to provide alternative forms of communication, such as, pictograms, pictures, writing, gesture, mime, etc. Also the use of data triangulation in the qualitative study (diary, in-depth interview, focus group interview) was helpful when people had difficulties in understanding or expressing themselves.

Although a structured outlined lay-out was helpful, an important disadvantage of using a pre-structured diary was the possibility of influencing the thoughts of people who 
already had difficulties in expressing themselves. Another important issue is the involvement of the central caregiver as a translator and informant during the study: it might be that the thoughts and expressions of the people with aphasia could be influenced by the presence of the central caregiver. Otherwise, the presence of the central caregiver could give the person with aphasia a feeling of safety, making it easier to express them. The caregiver sometimes had the role of an informant. In the literature (27) proxy respondents demonstrated a significant systematic negative bias in rating their aphasic partners' global quality of life, physical functioning, general or overall health, pain, and vitality. Conversely, proxy respondents rated statistically the same as their aphasic partners on physical fitness, feelings, daily activities, quality of life (COOP), total well-being, autonomy, environmental mastery, and purpose in life, with at least moderate agreement. During the interview the person with aphasia and his central caregiver seemed to agree most of the time. In order to elicit thoughts of people who had problems in expressing their perspective and feelings, it was important to communicate at the level of the communicative abilities of the person with aphasia. Sometimes, we did need to deviate from the usual interview style in qualitative research, occasionally using closed questions, supporting most questions with pictures, photographs or pictograms. By asking closed questions, the perspective of the person with aphasia could be compromised. However, the interviewer always checked whether the answer was influenced by the closed question of the interviewer. Therefore the interview-assistant had an important role as well. The focus group interview was an important part of the triangulation process and made sure that the voice of the people with aphasia was disclosed. By discussing the data analysis with the participants, it was confirmed that the researchers did understand the participants correctly and that the outcome represents the authentic perception of the people with aphasia. In the aphasia literature some information could be found regarding strategies used in qualitative studies, but none could be found with regard to strategies used to adjust questionnaires for people with aphasia in quantitative studies. There are very few instruments that are especially developed for people with aphasia. and there seems to be no consensus in these instruments concerning the use of visual support: some use pictures to support the question $((28),(29))$, others use no visual support (30) except written information.

In our quantitative study the questionnaires were adjusted based upon 1) conversations with speech and language therapists working with people with aphasia, 2) the literature concerning aphasia friendly information and most important the adjustments that were made based upon the experiences in using the questionnaires in people with aphasia, asking them what is really helpful in making the questionnaires comprehensible and accessible. People with severe aphasia often find it easier to understand when the message is given in two input modalities in parallel (f.e. orally and visually) (31).

We are happy to say that in our quantitative study the mission to include people with aphasia successfully in research seemed to be accomplished. The participants in our study, even people with severe aphasia, were able to express their perception using support from pictograms in combination with oral and written information. Therefore we hope that, based upon perceptions of their language problems, people with aphasia will not be excluded from future research studies. 


\section{Clinical message}

Including people with aphasia in stroke studies is possible by using several communication strategies.

Measurements can be adjusted by reducing the cognitive load and providing alternative forms of communication.

The challenge to include people with aphasia in research should be taken up in order to promote accessibility. 


\section{References}

1. Townend E, Brady M, Mc Laughlan M. Exclusion and inclusion criteria for people with aphasia in studies of depression after stroke: a systematic review and future recommendations. Neuroepidemiology. 2007;29(1-2):1-17.

2. Dalemans RJP, de Witte L, Lemmens J, Wade D, van den Heuvel W. Measures for rating social participation in people with aphasia: a systematic review. Clinical Rehabilitation. 2008;22(16):542-55.

3. Paterson B, Scott-Findlay S. Criticial issues in interviewing people with traumatic brain injury. Qualitative Health Research. 2002;12:399-409.

4. Hellström I, Nolan M, Nordenfelt L, Lundh U. Ethical and methodological issues in interviewing persons with dementia. Nursing Ethics. []. 2007;14(5):608-19.

5. Hall E. The entangled geographies of social exclusion/inclusion for people with learning disabilities. Health Place. 2005;11(2):107-15.

6. Worrall L, Rose T, Howe TJ, Mc Kenna K, Hickson L. Developing an evidence-base for accessibility for people with aphasia. Aphasiology. 2007;21(1):124-36.

7. Dalemans RJP, de Witte L, van den Heuvel W, Wade D. A description of social participation in working age people with aphasia: a review of the literature. Aphasiology 2008;22(10):1071-91.

8. Parr S. Psychosocial aspects of aphasia: whose perspectives? Folia phoniatrica et logopaedica : official organ of the International Association of Logopedics and Phoniatrics (IALP). 2001 Sep-Oct;53(5):266-88.

9. Luck A, Rose M. Interviewing people with aphasia: Insights into method adjustments from a pilot study. Aphasiology. 2007;21(2):208-24.

10. Howe TJ, Worrall L, Hickson LMH. Interviews with people with aphasia: Environmental factors that influence their community participation. Aphasiology. 2008;22(10):1092-120.

11. Beukelman D. Reducing the Cognitive/Linguistic Load of Persons with Aphasia and Traumatic Brain Injury Who Rely on AAC. State of the science conference; 2007; Colorado University. RERC-ACT Advancing Cognitive Technologies; 2007.

12. Fujimori M, Ito K, Durst MJ, Hasida K. Experimental evaluation of emotional awareness regarding arrangements and animations of pictograms. Kansei Engineering and Emotion Research (KEER); 2007 10-102007; Ayoma Gakuin University. 2007.

13. Brennan A, Worrall L, Mc Kenna K. The relationship between specific features of aphasia-friendly written material and comprehension of written material for people with aphasia: An exploratory study. Aphasiology. 2005;19(8):693-711

14. Aleligay AA, WorrallL.E., Rose TA. Readability of written health information provided to people with aphasia. Aphasiology. 2008;22(4):383-407.

15. Griffin Erin, McKenna K, Worrall LE. Stroke Education Materials on the World Wide Web: An Evaluation of Their Quality and Suitability Topics in Stroke Rehabilitation. 2004;11(3):29-40.

16. McKenna K, Scott J. Do written education materials that use content and design principles improve older people's knowledge? Occupational Therapy Journal. 2007;54(2):103-12.

17. Dalemans RJP, de Witte L, Wade D, van den Heuvel W. Social participation through the eyes of people with aphasia. International Journal of Language and Communication Disorders. 2009; posted online 20 october 2009.

18. Enderby P, Crow E. Frenchay Aphasia Screening Test: validity and comparability. Disability and Rehabilitation. 1996 May;18(5):238-40.

19. Petheram B. Computers and Aphasia. Psychology Press; 2004.

20. Cardell EA. Comprehension and well-formedness judgement in Broca-aphasia and anomic aphasia University of Queensland; 2006.

21. Lloyd-Jones $\mathrm{t}$, Nettlemil M. Sources of error in picture naming under time pressure Memory and Cognition. 2007(june 1).

22. Serrien B. Sclera picto`s 2006 [updated 2006 26-06-2008; cited]; Available from: http://www.sclera.be/index.php. 
23. Ho K, Weiss S, Garrett K, Lloyd L. The Effect of Remnant and Pictographic Books on the Communicative Interaction of Individuals with Global Aphasia. Augmentative \& Alternative Communication. 2005;21(3):218-32.

24. Dietz AR. Reading comprehension by people with chronic aphasia: A comparison of three levels of visuographic contextual support. Nebraska: University of Nebraska; 2007.

25. Mc Kenna K, Tooth L. Client Education: A partnership Approach for Health Practitioners. UNSWPress; 2006.

26. Brennan A, Worrall L, McKenna K. The relationship between specific features of aphasia-friendly written material and comprehension of written material for people with aphasia: An exploratory study Aphasiology. 2005;19(8):693-711

27. Cruice M, Worrall L, Hickson L, Murison R. Measuring quality of life: Comparing family members' and friends' ratings with those of their aphasic partners Aphasiology. 2005;19(2):111-29.

28. Engell B, Hutter B-O, Wilmes K, Huber W. Quality of Life in Aphasia: Validation of a pictorial self-rating procedure. Aphasiology. 2003;17(4):383-96.

29. The Communication Disability Profile [database on the Internet]. Connect Press. [cited. Available from: http://www.ukconnect.org/research_217.aspx.

30. Hilari K, Byng S, Lamping DL, Smith SC. Stroke and Aphasia Quality of Life Scale-39 (SAQOL-39): evaluation of acceptability, reliability, and validity. Stroke. 2003 Aug;34(8):1944-50.

31. van de Sandt-Koenderman MW. Crossroads in Aphasia Rehabilitation:High-tec AAC and Aphasia, widening horizons? Rotterdam: Rotterdam Erasmus University 2007. 
$\Rightarrow$ You and your partner (or relative or close friend) could best plan a fixed moment in the evening to keep up the diary.

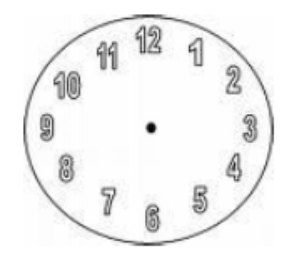

$\Rightarrow$ The diary is divided in different life domains.

$\Rightarrow$ The aim is to report performed activities per life domain.

$\Rightarrow$ If you did not perform activities in a certain life domain, you can report that as well.

$\Rightarrow$ Please, report the things that facilitated you in performing an activity.

$\Rightarrow$ Please, report the barriers in performing an activity.

$\Rightarrow$ You can use stickers if writing is difficult.

$\Rightarrow$ The stickers are attached at the end of the diary.

$\Rightarrow$ If you cannot find a sticker that represents your thoughts, please try to express your thoughts otherwise (f.e. make a drawing)

$\Rightarrow$ You may ask assistance from your partner (close relative or friend) if it is difficult to fill in the diary yourself.

$\Rightarrow$ For you, as a partner (close relative or friend) there is space/day to write down your remarks concerning the experiences of the partner's day.

$\Rightarrow$ It will take about $\mathbf{2 0}$ minutes per day to keep up the diary. 
Appendix 2: structured questionnaire: adjustments to the instrument for use in people with aphasia

Measurement instrument:

Participant:

Date:

Duration of assessment?

Number of items suitable?

Use of bolded key concepts helpful?

Use of pictograms:

- Are they supportive?

- Are they clear?

Is the formulation of the items clear?

The answering set;

- Are the answering possibilities clear?

- Are the answering possibilities suitable?

Total 
Chapter 8:

General discussion 


\subsection{Introduction}

This thesis reports the results of our research project which aimed to investigate the social participation of people with aphasia and its related factors.

We performed several studies to answer the following questions:

- What is already known about the social participation of people with aphasia?

- How can we measure social participation in people with aphasia?

- How do people with aphasia perceive their social participation?

- How do people with aphasia participate and which factors are related to social participation in this population?

This chapter concludes the thesis in three parts. Firstly, the main findings are summarized in section 8.2.. Secondly, we present a comparison of our results with those from the recent literature with some methodological and clinical reflections (section 8.3.). Finally, the challenges arising from this research are outlined.

\subsection{Main findings of the study}

Research into the topic of this thesis has been sparse, with few studies investigating any aspect of social participation in this population. Our research demonstrates the possibility for completing complex research into the wishes and experiences of people with aphasia, a population well able to express their views.

This section summarizes the main findings from each study, followed by a general discussion of these findings.

\subsubsection{What was already known about the social participation of people with aphasia} (before 2005)?

In this thesis, we defined social participation as the performance of people in actual activities in social life domains through interaction with others in the context in which they live. Four social life domains are included in this definition: (1) domestic life, (2) interpersonal life (including formal relationships, informal social relationships, family relationships, and intimate relationships); (3) education (informal, vocational training and higher education) and employment (remunerative and non-remunerative, excluding domestic work); (4) community, civic and social life, including religion, politics, recreation and leisure (hobbies, socializing, sports, arts and culture).

Our systematic literature review (1960-2005)revealed scattered and fragmented information about social participation in people with aphasia (1). No firm conclusions could be made concerning the social participation of this population, due to the inconsistent use of conceptual frameworks and mostly small sample sizes used in the reviewed studies. In addition, there appeared to be a lack of good instruments measuring different aspects of social participation. No study compared people with aphasia with equally disabled people without aphasia.

Although data should be interpreted with caution, the following trends on social participation of people with aphasia were brought to light in all the reviewed studies: Participation in social life domains diminished; There was a decrease in participation in 
domestic life; altered interpersonal interactions and relationships after aphasia onset, with shifts in contacts from friends to professionals, and shifts in roles as partner, family member, parent, friend, and citizen.

\subsubsection{How can we measure social participation in people with aphasia?}

The high frequency of self-made questionnaires used in research concerning people with aphasia was notable. One important reason for the use of self-made questionnaires may be the difficulty in finding appropriate measurement instruments for use in people with aphasia.

We found twelve validated instruments measuring aspects of participation in the literature (1960-2005) and we reviewed their feasibility for use in people with aphasia. Only two of those instruments were identified as potentially suitable for use in people with aphasia: the Community Integration Questionnaire $(2,3)$ and the Nottingham Extended Activities of Daily Living (4). Although the Community Integration Questionnaire (CIQ) was confirmed as most suitable by speech and language pathologists, some adjustments were required for use in this population, such as the availability of a multimodal presentation of the items.

In order to stay as close as possible to the comprehension and expression of the person with aphasia, it might be better to use open or semi-structured interview protocols. The person with aphasia can use the strategies that are most helpful to him and the interviewer can check more easily if he has understood the person with aphasia correctly, by paraphrasing, verbal and non-verbal feedback. However, conducting open or semi-structured interviews is very time intensive. We investigated the use of structured interview formats in this population. All participants with aphasia in our crosssectional study were able to complete the adjusted Community Integration Questionnaire (CIQ) in an interview format. We have shown that the CIQ can be adapted for use by people with aphasia up to a severe level, producing reliable and valid data. The use of the $\mathrm{CIQ}$ adjusted for people with aphasia allows most people with aphasia to participate in research.

\subsubsection{How do people perceive their social participation?}

Our qualitative study exposed alternative perspectives on social participation. In the way people with aphasia talked about their social participation, they seemed to be referring to something else. They spoke in terms of engagement, involvement, having a feeling of belonging. It became clear that they did not necessarily want to do more, but that they wanted their interactions to be more satisfying. People with aphasia perceived the quality of the performance in social activities as more important than the quantity. They found it essential to experience engagement in social activities. They stated that doing things, being active and participating in social life domains was often very difficult, and did not automatically lead to engagement and the feeling of belonging.

We uncovered important individual differences in the participation of people with aphasia in social activities, but social participation was largely absent. Most people with aphasia reported feelings of isolation and exclusion, but some people with aphasia succeeded in feeling engaged in social activities. 


\subsubsection{How do people with aphasia participate?}

Our investigation of 150 people with aphasia with the Community Integration Questionnaire revealed diminished social participation (5), confirming the findings of our systematic literature review. Most people in this population did not participate in remunerative work, in an educational program, or in voluntary work. Domestic activities such as taking care of personal finances, shopping for groceries, were mostly performed by someone else or with help from someone else. Most people with aphasia were no longer taking care of their children anymore because they had already left home. Although people with aphasia participated less, most people left their house almost every day. The majority of the participants reported that they had a good friend they could trust and stated that they performed leisure activities together with friends and family.

\subsubsection{Which factors influence social participation in people with aphasia?}

Engagement in social participation was influenced by personal, social and environmental factors. People with aphasia in our qualitative study reported motivation, physical and psychological condition and communication skills as influencing personal factors. The social factors reported were the role of the central caregiver and the characteristics of the communication partner(s), namely willingness, skills and knowledge. The environmental factors identified were the quietness and familiarity of the place in which the person with aphasia lived and moved. A motivated person with aphasia has a better chance to achieve engagement when living in a quiet accessible environment with a stimulating caregiver and surrounded by willing people with knowledge and skills to adapt to the communicative possibilities of the person with aphasia.

The factors perceived by people with aphasia in our qualitative study were not confirmed in our quantitative study. The quantitative study identified other factors important in predicting social participation, namely age, gender, functional performance in activities of daily living and severity of aphasia. This explained $37 \%$ of the total variance in social participation of people with aphasia. More participation was correlated with younger age, female gender, good functional performance and minimal aphasia. It is an important finding that aphasia severity as a single factor has a strong relationship to social participation. 


\subsection{Social participation in people with aphasia: where do we stand?}

The main findings of this thesis are discussed first in relation to recent literature and policy, before describing some reflections.

In 2001 the WHO presented the ICF (6), a classification system with four main constructs: Health condition, Body functions and structures, Activity/Participation and Contextual Factors. Activity is defined as the execution of a task or an action by an individual and participation is defined as involvement in a life situation. Recently, the social participation of people with aphasia has received increasing attention. Since 2005 (the limit of our review) many studies have been published on this subject, using the ICF as a conceptual framework (7-11). The outcomes of these studies confirm the results of our studies: People with aphasia experience difficulties in their social participation due to their communicative problems, resulting in a diminished social network with a loss of friends and colleagues and diminished participation in activities in society.

The difficulties with regard to the conceptualization of participation remains (1214) but discussions lead to the development of new instruments based upon the ICF to capture social participation in people with communication impairments (15-19) using strategies comparable to those in our study.

Many studies have been published with regard to environmental factors. Research and policy development relating to environmental changes however, has focused on people with physical disabilities and the physical environment (20). The importance of identifying barriers to and facilitators for participation in society of people with aphasia has been recognized, but further investigation in this area is needed. Research highlighted lack of awareness and accessibility problems as major environmental barriers for people with aphasia $(21,22)$ for example they experience barriers in the use of public transport due to their communication problems, like problems in understanding time schedules (23). Some strategies reported in this study might help to make it possible for people with aphasia to participate in society; the willingness, the knowledge and the skills of people in the environment to communicate with a person with aphasia, besides strategies to make the written information more aphasia-friendly. Other recent studies also reported similar strategies (24-28). As in this study, however, also other studies reported the difficulty in capturing the perceived environmental problems due to a considerable diversity among people with aphasia about their perceptions of the barriers and facilitators to social participation in the community(29).

In the literature more attention is given to the impact of technology on social participation in this population (30-33) as an important environmental factor, yet this remains a rather neglected area of attention in rehabilitation. In our study none of the participants made use of technology to support their communication.

Whereas many studies have been published with regard to environmental factors, personal factors are difficult to grasp. Personal factors are the most controversial and difficult part of the ICF. The WHO did not develop a classification system for personal factors because there was no consensus and too much international variation at the time of publication. Further development of this component however, was identified as a goal for the future. Personal factors are those attributes within the person that are 
not caused by the health or disabling condition (6). Demographic information such as age and gender can be captured easily and relates to social participation, however, personality traits (such as overall behavior patterns, personality, individual psychological assets) remain incoherent in the literature and are difficult to capture in one measurement(34). Personality traits identified in our qualitative study were not captured in our quantitative study, despite the obvious impact (34).

Recently, unprecedented changes have occurred in the way treatment for aphasia is viewed and reimbursed, due to internal and external pressures. Internal pressures include the growing interest in treatments that produce meaningful outcomes in life leading to enhanced participation. Externally, pressures come from disability rights activists campaigning for change in philosophy and treatment, and consumers frustrated by unmet needs and unfulfilled goals. The Life Participation Approach for Aphasia Project Group (LPPA) proposed a philosophy of service delivery that meets the needs of people affected by aphasia in achieving their immediate and longer term life goals (35-37). It focuses on re-engagement in life, beginning with initial assessment and intervention, and continuing, after hospital discharge, until the consumer no longer elects to use communication support. This thesis contributes to the knowledge about the social participation of people with aphasia and its influencing factors.

\subsubsection{Methodological reflections}

This study raises a number of methodological issues, some specifically related to research with people with difficulties in communicating and others specifically related to the difficulty defining and measuring the construct of participation.

In our systematic review we found that participation is often vaguely defined. In most studies, a clear conceptual framework was missing. The variety of definitions made comparisons very difficult. In 2001 the WHO presented the ICF (International Classification of Functioning, Disability and Health), however, the concept of participation as defined in the ICF is not used as a medical subheading in the electronic databases. This complicated the search strategy. It was difficult to find the correct key words to identify the relevant literature concerning social participation in people with aphasia. In order to find as many relevant publications as possible, we used a wide search strategy. Further, we studied all publications selected by three researchers, using outlined selection criteria. We are therefore reasonably confident that we did not exclude many relevant articles concerning this domain.

Also with regard to the review concerning instruments for measuring social participation in people with aphasia, the complexity of the concept of social participation making the boundaries of the concept vague - may have led to missing some social participation measurements. However, by using the search terms participation, quality of life, activities, and other concepts referring to aspects of social participation, we have limited the possibility of missing a social participation measure. By making the definition of social participation more concrete and by using selection criteria, we have eliminated instruments that do not meet the selection criteria. The list of possibly suitable instruments for use in people with aphasia was very small, even smaller than the number of instruments that already have been used in the reviewed studies about the social participation of people with aphasia (1960-2005). It might be that the re- 
searchers in those studies made use of instruments, that were judged as not suitable in this study, because there were no other instruments available.

We have shown that the Community Integration Questionnaire (CIQ) can be used in people with aphasia up to a severe level with minor adaptations, and that the data collected are both reliable and valid. There is a good similarity between the factor analysis in this study and that in the study of Sander (1999) (38). The internal consistency of the CIQ total was good and was comparable to that in the study of Willer et al, 1994 (39). The test-retest reliability of the CIQ adjusted for people with aphasia was excellent, but because the number of participants was rather small, further testing in a larger population is indicated. The Community Integration Questionnaire adjusted for people with aphasia appears to have psychometric properties comparable with other populations.

Little was known about the way people with aphasia perceive their social participation. Therefore we conducted a qualitative study using several strategies to ensure trustworthiness of the results and analyses. Younger and older persons with varied communicative possibilities, varied mobility abilities and a wide range stroke post onset were included. Although data saturation was obtained, the research group remained rather small, making prudence necessary regarding the overall conclusions. Numerous strategies to stimulate the person with aphasia to express himself were attempted: the non-verbal communication (an important source of information, particularly for those unable to express themselves with words) was registered in each interview, and the use of alternative communication was stimulated. We interviewed the person with aphasia and the central caregiver together. In this setting, participants were encouraged to use the ideas of each other as cues to more fully elicit their own views. By interviewing the person with aphasia and the central caregiver together, we did not use the central caregiver as a proxy. There is much debate concerning the use of proxies and some studies found discrepancies between the outcome of proxies and people with aphasia $(40,41)$. In our study the central caregiver had a role as translator and informant, mostly encouraging the person with aphasia to express himself.

Different strategies such as a prestructured- diary and interview, were used to get a full view of the perceived participation and its influencing factors. The results were then validated by all the participants in a focus group interview.

The results of our quantitative study are consistent with other studies, which have shown that social participation in people with aphasia is diminished $(1,8,11,42,43)$, but our study was more extensive with more people included and people with a wider range of severity of aphasia.

A number of factors were identified related to social participation: age, gender, functional performance in ADL and severity of aphasia. These findings agree with the results of other stroke studies including patients with aphasia $(44,45)$. There might be some other important variables influencing social participation that were not measured. In our measurement set, we tried to capture all the variables possibly related to social participation as perceived by people with aphasia (identified through our qualitative study) and as described in the reviewed literature $(26,27,46,47)$ in terms of personal factors and environmental factors. However, it is possible that individual variation in the factors influencing social participation is so large that no group study will identify them. 


\subsubsection{Conceptual reflections}

For rehabilitation and disability research, participation is a crucial construct that has been placed centre stage by the International Classification of Functioning, Disability and Health. The ICF has been criticized for its lack of conceptual clarity in defining and explaining participation(13). Its definition of participation as involvement in a life situation imparts little specificity about what type of involvement is meant or which life situations are included. This leads to conceptual and operational confusion, making it complex to measure participation.

Participation is a relational concept that can only be assessed by taking into consideration other factors beyond simply the capabilities and limitations of an individual. Role expectation, along with the social setting and environment in which the roles are to be performed, should be considered. In this thesis we define participation as the performance of people in actual activities in social life domains through interaction with others in the context in which they live. This definition implies that participation is performance at the societal level, tending to be more complex and broadly encompassing several activities. Still, it seems another dimension remains unidentified when using this definition. People not only want to 'perform'; they also want to experience their performance as meaningful. This implies that the actual performance of activities should not be the only key indicator, but also the fulfilment of personal goals and societal roles in a context in which they are recognized and respected by others.

Fougeyrollas (48) introduces the concept of life habits, defined as the regular activity or social role valued by the individual or his/her socio-cultural context according to his/her characteristics. In this definition the value of activities for the individual is included. Perenboom and Chorus (49) defined participation as the involvement in life situations which includes being autonomous to some extent or being able to control ones own life, even if one is not actually doing things himself.

Participation is a complex and broad concept that refers to performance at the societal level. Therefore, a focus on participation requires adherence to a model of disability that includes social functioning. 


\subsection{Social participation in people with aphasia: where should we go?}

One important finding of this thesis is the confirmation that aphasia impacts on social participation. People with aphasia have a diminished social participation. Even long after the aphasia onset, the effects of aphasia on social participation permeate through all people closely associated with the injury. Moreover, people with aphasia often feel isolated and excluded. According to Whiteneck et al. 2007(13) people with disability can, at least in theory, fully participate in society with the right assistive devices, personal assistance, polices and environment. However, there is an enormous gap between what is possible in theory and what people with aphasia experience every day. It is time to translate constructive thoughts into constructive actions. To make this possible the gap between theory and reality must be filled. This is one of the many challenges that follow from this thesis: some will be discussed in the next section.

\subsubsection{Challenges in rehabilitation of people with aphasia}

Our findings suggest that actions should be taken to develop service delivery that stimulates re-engagement in life, and that meets the needs of people affected by aphasia in achieving their immediate and long term life goals:

- Participation oriented strategies and tools for speech and language pathologists to encourage them to use a life participation approach:

- Speech and language pathologists should shift their working field from the clinical setting into the natural context of the person with aphasia. This implies that they should take the challenge to broaden the traditional role of therapist into the roles of advisor, supporter, encourager, facilitator.

- Speech and language pathologists should not separate language from the communicative context. It is therefore important to train language in a way that is meaningful to the person. Adjusted tools should be developed and implemented. In this way it is possible to build a bridge for re-engagement in life. By reducing limitations in functional performance as well as by promoting communication, people with aphasia could gain greater social participation.

- Speech and language pathologists should take on the challenge to advocate for aphasia-friendly environments with policy makers, public services, and health care institutes, facilitating access to the community for people with aphasia.

- The personal life concerns of the person with aphasia and those confronted with the consequences of aphasia should be central to decision making in care. Working in mutual respectful partnership creates opportunities for people with aphasia to share decisions about their therapy.

- People in the direct environment should be involved more intensively to facilitate the immediate and long term life goals of people with aphasia. They should be supported in their daily care and in their daily communication with the person with aphasia. Strategies must be identified in connection with the direct environment to promote interaction in such a way that everybody feels respected and recognized. 


\subsubsection{Challenges for policy makers}

The United Nations charter stakes that every person is equally entitled to receive treatment (50). Regulations for equal treatment should be translated into constructive actions to counter the communicative problems that people with aphasia experience everyday:

- Policy makers should engage in promoting aphasia awareness in society, making the voices of people with aphasia heard, making the invisible impairment more visible for the public, so people in society can understand and act upon the consequences of aphasia. 'Communication ramps' need to become as accepted as 'wheelchair ramps'.

- Policy makers should be responsible for promoting accessibility for people with communication impairments. This population needs to be supported by public services and health services, in order to receive all the information necessary to make participation possible. This can be facilitated through the provision of accessible versions of written information (for example stroke and aphasia booklets, adjusted train tables, menu cards, phone instructions, information brochures,...).

- Recovery from aphasia is a process that may continue for many years. Unfortunately, most people with aphasia find that their ability to access rehabilitation for their communication disability (through health insurance coverage or in other ways) runs out before therapy is no longer useful. It is often frustrating for the patient and their family as they try to continue the recovery process with very limited professional support. Insurance companies should be aware of the long term problems and should search for solutions together with policy makers and speech and language pathologists to address this problem.

- Policy makers should advocate for voluntary work infrastructures, and promote stroke and aphasia support groups bridging the gap between rehabilitation and social participation of people with aphasia.

\subsubsection{Challenges in research}

Future research into social participation of people with aphasia and its influencing factors is necessary to fill the blank spots. In gathering data from people with aphasia and facilitating inclusion in society, researchers should not hesitate and take on the challenge to include this population in studies on social participation:

- It is important that researchers are aware that research in people with aphasia is possible. People with aphasia, even severe aphasia, can be successfully included in both qualitative and quantitative research studies (51). Several strategies are helpful to meet this challenge. These revolve around reducing the cognitive load as far as possible by means of techniques including: simplifying communication, reducing the content of communication to simple clear concepts, using bold type and clear font in the lay-out of the question, using a clear visual structure in words and pictures, reducing the question length, excluding negatives in the question and allowing as much time as needed. Further, it is important to provide alternative forms of communication, such as, pictograms, pictures, writing, gesture, and mime.The use of data triangulation in qualitative studies (the use of pre-structured diaries, the use of in-depth interviews with attention to non-verbal communication and focus 
group interview) can also be helpful when people have difficulties understanding or expressing themselves.

- Research into social participation should be guided by a clear conceptual framework and well-defined concepts: researchers should take the challenge to further clarify the complex concept of participation as used from the ICF.

- Adequate measuring instruments should be adjusted for use in people with aphasia and further investigations in psychometric properties for this population conducted.

- Another important challenge is the investigation of personal and environmental factors. The relationship between personal and environmental factors and social participation needs more study with adequate instruments to capture those factors important for people with communicative problems. Research into the real-life effects of looking at these factors might be complex to design and measure, but is a necessary task in order to determine the effectiveness of intervention. 


\section{References}

1. Dalemans RJP, de Witte L, van den Heuvel W, Wade D. A description of social participation in working age people with aphasia: a review of the literature. Aphasiology 2008;22(10):1071-91.

2. Willer B, Ottenbacher $\mathrm{KJ}$, Coad ML. The community integration questionnaire. A comparative examination. American Journal of Physical and Medical Rehabilitation. 1994 Apr;73(2):103-11.

3. Willer B, Rosenthal M, Kreutzer JS, Gordon W, Rempel R. Assessment of the community integration following rehabilitation for traumatic brain injury. Journal of Head Trauma and Rehabilitation. 1993;8(2):75-87.

4. Lincoln NB, Gladman JR. The Extended Activities of Daily Living scale: a further validation. Disability and Rehabilitation. 1992 Jan-Mar;14(1):41-3.

5. Dalemans RJP, de Witte LP, Beurskens S, Van den Heuvel WJ, Wade DT. Insight into the social participation of stroke survivors with aphasia. submitted in Stroke. 2009.

6. WHO. ICF international homepage. 2001 [updated 2001; cited]; Available from: http://www.who.int/classifications/icf/site/icftemplate.cfm?myurl=introduction.html\%20\&mytitle=Intr oduction.

7. Natterlund BS. A new life with aphasia: everyday activities and social support. Scandinavian Journal of Occupational Therapy. 2009 Mar 16:1-13.

8. Davidson B, Howe T, Worrall L, Hickson L, Togher L. Social participation for older people with aphasia: the impact of communication disability on friendships. Topics in Stroke Rehabilitation. 2008 JulAug;15(4):325-40.

9. Hilari K, Northcott S. Social support in people with chronic aphasia. Aphasiology. 2006;20(1):17-36.

10. Parr S. Living with severe aphasia: tracking social exclusion. Aphasiology. 2007;21(198-123).

11. Worrall L, Hickson LMH. Quantifying aphasia people`s social lives in the context of non-aphasic peers. Aphasiology. 2006;20(12):1210-25.

12. Daniel K, Wolfe C, D.A.,, Busch M, McKevitt C. What Are the Social Consequences of Stroke for WorkingAged Adults?:A Systematic Review Stroke. 2009.

13. Whiteneck G, Dijkers M. Measuring difficult to measure constructs:participation and environmental factors. Clinical trials in rehabilitation research: balancing rigor and relevance; 2007 3-7-2007; Washington DC. 2007.

14. Participation Theme Working Report. Conceptualizing and measuring participation: A collaboration of: St.. John`s Rehabilitation Hospital, The Toronto Rehabilitation Institute, University Health Network, University of Toronto; 2005 Contract No.: Document Number|.

15. Murphy J, Tester S, Hubbard G, Downs M, MacDonald C. Enabling frail older people with a communication difficulty to express their views: the use of Talking Mats as an interview tool. Health Soc Care Community. 2005 Mar;13(2):95-107.

16. Kagan A, Simmons Mackie N, Rowland A, Huijbregts M, Shumway E, Mc Ewen S, et al. Counting what counts: A framework for capturing real-life outcomes of aphasia intervention. Aphasiology. 2008;22(3):258-80.

17. Eadie TL, Yorkston KM, KLasner ER, Dudgeon BJ, Deitz JC, Baylor CR, et al. Measuring Communicative Participation: a review of Self-Report Instruments in Speech-Language Pathology. American Journal of Speech-Language Pathology. 2006 november 2006;15:307-20.

18. Ross A, Winslow I, Marchant P, Brumfitt S. Evaluation of communication, life participation and psychological well-being in chronic aphasia: The influence of group intervention Aphasiology. 2006;20(5):42748.

19. Lloyd V, Gatherer A, Kalsy S. Conducting qualitative interview research wit people with expressive language difficulties. Qualitative Health Research. 2006;16(10):1386-404.

20. Brown K, McGahan L, Alkhaledi M, Seah D, Howe T, Worrall L. Environmental factors that influence the community participation of adults with aphasia: The perspective of service industry workers. Aphasiology. 2006;20(7):595-615.

21. Maviş I. Perspectives on public awareness of stroke and aphasia among Turkish patients in a neurology unit. Clinical Linguistics \& Phonetics. 2007;21(1):55-70. 
22. Simmons Mackie N, Kagan A, O'Neill C, Huijbregts M, Willems J. Communicative acces and decision making for people with aphasia: implementing sustainable health care systems change. Aphasiology. 2007;21(1):39-66.

23. Ashton C, Noor AA, Barwood C, French R, Savina E, Worrall L. Communicatively accesible public transport for people with aphasia: a pilot study. Aphasiology. 2008;22(3):305-20.

24. Simmons-Mackie N, Damico JS. Acces and social inclusion in aphasia: interactional principles and applications. Aphasiology. 2007;21(1):81-97.

25. Aleligay AA, WorrallL.E., Rose TA. Readability of written health information provided to people with aphasia. Aphasiology. 2008;22(4):383-407.

26. Howe T, Worrall L, Hickson L. Observing people with aphasia: Environmental factors that influence their community participation Aphasiology. 2008;22(6):618-43.

27. Howe T, Worrall L, Hickson L. Interviews with people with aphasia: Environmental factors that influence their community participation Aphasiology. 2008;22(10):1-29.

28. Mason I. Developing and implementing aphasia-friendly stroke information for patients, families and carers. Nursing Times. 2006;102(47):32-3.

29. Worrall L, Rose T, Howe TJ, Mc Kenna K, Hickson L. Developing an evidence-base for accessibility for people with aphasia. Aphasiology. 2007;21(1):124-36.

30. Golashesky C. Technology applications at the Adler aphasia center. Top Stroke Rehabil. 2008 NovDec;15(6):580-5.

31. Greig CA, Harper R, Hirst T, Howe T, Davidson B. Barriers and facilitators to mobile phone use for people with aphasia. Topics in stroke rehabilitation 2008;15(4):307-24.

32. van de Sandt-Koenderman MW. Crossroads in Aphasia Rehabilitation:High-tec AAC and Aphasia, widening horizons? Rotterdam: Rotterdam Erasmus University 2007.

33. Lasker JP, Garrett K. Using the Multimodal Communication Screening Test for Persons with Aphasia (MCST-A) to guide the selection of alternative communication strategies for people with aphasia. Aphasiology. 2006;20(2/3/4):217-32.

34. Threats TT. Acces for persons with neurogenic communication disorders: Influences of Personal and Environmental Factors of the ICF. Aphasiology. 2007;21(1):67-80.

35. Kimbarow ML. Integrating Life Participation Approaches to Aphasia Treatment With Adult Learning Theory: A Synergistic Approach. Topics in Language Disorders. 2007;27(4):318-23.

36. Chapey R, Duchan J, F., Elman R, J., Garcia L, J., Kagan A, Lyon J, et al. Life Participation Approach for people with Aphasia: A Statement of Values for the Future. American Speech-Language-Hearing Association; 2009 [updated 2009 2009; cited 1997]; Available from.

37. Shadden BB, Hagstrom F. The Role of Narrative in the Life Participation Approach to Aphasia. Topics in Language Disorders. 2007;27(4):324-38.

38. Sander AM, Fuchs KL, High WM, Jr., Hall KM, Kreutzer JS, Rosenthal M. The Community Integration Questionnaire revisited: an assessment of factor structure and validity. Archives of Physical Medicine and Rehabilitation. 1999 Oct;80(10):1303-8.

39. Willer B, Ottenbacher KJ, Coad ML. The Community Integration Questionnaire: a comparitive examination. American Journal of Physical and Medical Rehabilitation. 1994 73:103-11.

40. Cruice M, Worrall L, Hickson L, Murison R. Measuring quality of life: Comparing family members' and friends' ratings with those of their aphasic partners Aphasiology. 2005;19(2):111-29.

41. Hilari K, Owen S, Farrelly SJ. Proxy and self-report agreement on the Stroke and Aphasia Quality of Life Scale-39. Journal of neurology, neurosurgery, and psychiatry. 2007;78:1072-5.

42. Code C. The quantity of life for people with chronic aphasia. Neuropsychological Rehabilitation. 2003;13(3):379-90.

43. Black-Schaffer RM, Osberg JS. Return to work after stroke: development of a predicitive model. Archives Physical and Medical Rehabilitation. 1990;71:285-90.

44. Tilling K, Sterne JAC, Rudd AG, Glass TA, Wityk RJ, Wolfe CDA. A New Method for Predicting Recovery After Stroke. Stroke. 2001;32:2867-73.

45. Schepers VP, Visser-Meily AM, Ketelaar M, Lindeman E. Prediction of social activity 1 year poststroke. Archives Physical Medicine and Rehabilitation. 2005 Jul;86(7):1472-6. 
46. Brown K, Mc Gahan L, Alkhaledi M, Seah D, Howe T, Worrall L. Environmental factors that influence the community participation of adults with aphasia: The perspective of service industry workers Aphasiology. 2006;20 (7):595-615.

47. Brumfitt S. Psychosocial aspects of aphasia: speech and language therapists' views on professional practice. Disability and Rehabilitation. 2006 Apr 30;28(8):523-34.

48. Fougeyrollas P, Noreau L, Bergeron H, Cloutier R, Dion SA, St.Michel G. Social consequences of long-term impairments and disabilities: Conceptual approaches and assessment of handicap. International Journal of Rehabilitation Research. 1998;21:127-41.

49. Perenboom RJ, Chorus AM. Measuring participation according to the International Classification of Functioning, Disability and Health (ICF). Disability and Rehabilitation. 2003 Jun 3-17;25(11-12):577-87.

50. Ministerie van Volksgezondheid Welzijn en Sport. Equal treatment in practice: vision and measures for people with disabilities, make it happen! In: Ministry of Health WaS, editor.; 2004. p. 16.

51. Dalemans RJP, Wade D, Van den Heuvel W, De Witte L. Facilitating the participation of people with aphasia in research: a description of strategies. Clinical Rehabilitation. 2009;23 948-59. 
Summary / samenvatting 


\section{Summary}

This dissertation describes a research project concerning the social participation of people with aphasia. After a period of rehabilitation, most people return to their home were they are confronted with a social and physical environment, unadjusted to the consequences of aphasia.

Mostly they do not succeed in picking up their life as before the stroke. People with aphasia experience a changed social participation. In this dissertation social participation is defined as the actual performance of activities in social life domains in interaction with others in the context in which they live. The following social life domains are included in this definition: domestic life, interpersonal life, employment and education, community, civic and social life.

This dissertation describes five studies: 1) a systematic literature research to investigate what is known in the literature (1960-2005) about participation in people with aphasia after stroke to assess the quality of these studies, 2) a study to identify and describe measures of social participation that may be specifically useful when measuring participation in people with aphasia, 3) a psychometric study with regard to the Community Integration Questionnaire, adjusted for people with aphasia, 4) a qualitative study to explore how people with aphasia perceive participation in society and to investigate influencing factors, 5) a quantitative study to describe how people with aphasia participate socially, and to investigate the factors which are related to social participation.

In the first chapter, the background of this dissertation is delineated: aphasia as a consequence of stroke is presented in the acute phase, the rehabilitation phase and the chronic phase. This dissertation focuses on the social participation of people with aphasia in the chronic phase. At the end of this chapter, the objectives and research questions are outlined. The aim of this dissertation is to gain insight in the social participation of people with aphasia and the factors that facilitate and impede the social participation of this population.

In chapter two our systematic literature review concerning the social participation of people with aphasia is described. This study was conducted to review the information in the scientific literature (1960-2005) concerning the social participation of people with aphasia and to assess the methodological quality of these studies. This study revealed that little is known about the social participation of people with aphasia. Further, the quality of the reviewed studies was rather low. Often a vague or no conceptual framework was used and the use of self-made questionnaires was common, making comparison between the different studies difficult. Furthermore, the study samples were mostly small and the use of control groups to get insight in the specific impact of aphasia was lacking. Overall, the studies showed that the social participation of people with aphasia was diminished, with loss of social relations, work and leisure activities.

Chapter three presents the results of our study concerning measurement instruments possibly suitable to assess social participation in people with aphasia. Several strategies were used: the literature was reviewed and criteria lists were developed to assess the suitability of the instruments in this population. Those lists were con- 
structed based on the literature and conversations with experts. Next, the measurement instruments were scored on their suitability first by three investigators, then by six speech and language therapists working daily with people with aphasia. From the twelve selected measurement instruments, two were found suitable. The Community Integration Questionnaire was scored as most suitable to measure social participation in people with aphasia.

Based on the findings in chapter three, the Community Integration Questionnaire was slightly adjusted for use in people with aphasia. Thereafter, the psychometric properties of the adjusted version were investigated in a cross-sectional study in 150 people. The feasibility, the internal consistency, the factor-analyses and the convergent validity were assessed. The test-retest reliability was examined by assessing twenty people with different grades of aphasia (minimal to severe) twice by two different interviewers within a period of two weeks. This is presented in chapter four. The results showed that the adjusted Community Integration Questionnaire is a reliable and valid instrument for use in people with aphasia.

To gain insight in how people with aphasia experience their social participation and to report the factors people with aphasia perceive as facilitating or obstructing, we conducted a qualitative study. This study is described in chapter five and reveals that people with aphasia consider the number of social activities and the character of these activities not to be as important as the perceived engagement in the social activities. People with aphasia feel isolated but want to feel engaged. They feel burdensome to others and wish to function in an ordinary way. It is difficult for them to extract information from conversations, but they want to know what is going on. Often they are not able to work, but they want to contribute to society in an active way. People with aphasia find it important to feel engaged and respected in relation to others, but often they feel stigmatized. Personal, social and environmental factors facilitating or hindering their social participation are reported. A motivated person living together with a stimulating partner in a quiet environment surrounded by willing people, who have knowledge and skills to adapt to the communicative possibilities of the person with aphasia, has a better chance to achieve engagement.

Chapter six describes the central part of this dissertation: a quantitative study in 150 people with aphasia to gain insight in the social participation and related factors in this population. This study reveals a great variation in the social participation of people with aphasia, with some people hardly leaving the house and other people living an active social life. However, social participation is diminished in all people with aphasia. Domestic life, social life and productive life is limited: $62 \%$ of the participants were retired, not working and doing no voluntary work. Aphasia has a unique impact on social participation, next to other factors like functional performance in everyday living, gender and age. Young female persons with minimal aphasia and a good functional performance have a better chance for a satisfying level of social participation.

Chapter seven describes a number of strategies and techniques that might be useful when conducting research in people with aphasia, including the use of prestructured diaries; the use of in-depth interviews with attention for the non-verbal communication; the use of existing measurement instruments adjusted for people with aphasia by: 
- The use of pictograms

- Placing one question per page

- Bolding the key concepts in the question

- Using style Verdana, size 14

- Visualizing the answering set with words and images

- Reducing the question length

- Avoiding negatives in the question

Those insights were obtained by our experience during our research studies in this population. It seems to be possible to do research in this population. People with aphasia are often excluded from research because of their communicative impairments. By using the above described strategies and techniques, this exclusion can be avoided.

In the last chapter, chapter eight, the main findings of the studies are presented, followed by a discussion and some methodological and conceptual reflections. The chapter closes with a number of challenges for policy health care providers, policy makers and researchers. The most important conclusion is that people with aphasia participate less, that aphasia has a unique impact on the social participation and that people with aphasia consider the number and character of the activities to be less important than the experienced engagement in their social participation. They report personal (motivation, physic and psychological condition and communication skills), social ( the role of the central caregiver and the characteristics of the communication partner: willingness, skills and knowledge) and environmental factors ( a quiet and accessible environment) facilitating or obstructing their level of engagement in social participation. Another important conclusion refers to the possibility of doing research in this population, providing that adjusted techniques are used.

By searching the literature systematically with regard to social participation in this population and by using qualitative and quantitative methods, the social participation of people with aphasia was investigated widely and in depth. So, fundamental insights were gained into the social participation of people with aphasia. Based on these insights, this dissertation concludes with a number of challenges for health care providers, policy makers and researchers. For health care providers the challenge was formulated to organize care in such a way that rejoining life and the needs of people with aphasia and their direct environment are central in care, based on a mutual relation of respect. Participation approaches and instruments needs to be developed to stimulate speech and language therapists to use a participation approach, never disconnecting language from the communicative context. This involves that speech and language therapists need to broaden their view with attention for the lifed experience of the person and his loved ones within a natural setting. To make this possible, speech and language therapists will need to contract other roles beside the role of therapist, namely the role as advisor, coach, facilitator. Further, speech and language therapists should take the challenge to negotiate with policy makers, services and health care institutes concerning the importance of an accessible and aphasia-friendly environment.

Policy makers should engage to create an aphasia friendly society in which aids for communication support are as common as mobility ramps. They should take their 
responsibility in facilitating the accessibility for this population in society and public and health services.

Negotiation with health insurances should take place to make long term consequences of aphasia transparent.

For researchers the challenge was formulated to include people with aphasia in research to gain more insight in living with aphasia. To make this possible existing instruments should be adjusted for people with aphasia and tested on their psychometric properties. Based on further research, the concept participation should be further clarified, making comparison between different studies easier. Another important challenge for researchers is to investigate personal and environmental factors using adjusted instruments to gain insight into the factors that are important for this population. 


\section{Samenvatting}

Dit proefschrift beschrijft een onderzoek naar de sociale participatie van mensen met afasie. Na een periode van revalidatie keren deze mensen vaak terug naar huis. Daar worden zij geconfronteerd met een sociale en fysieke omgeving die doorgaans niet is afgestemd op de gevolgen van afasie. Terugkeren naar een leven zoals voorheen is meestal niet mogelijk. Mensen met afasie ervaren een veranderde sociale participatie. In dit proefschrift wordt sociale participatie gedefinieerd als de uitvoering van activiteiten binnen sociale levensdomeinen in interactie met anderen, binnen de context waarin men leeft. De volgende vier sociale levensdomeinen worden onderscheiden in deze definitie: huishoudelijk leven, interpersoonlijke interacties en relaties, werk en onderwijs en burgerlijk, sociaal en cultureel leven.

In dit proefschrift worden vijf studies beschreven: (1) een systematische literatuurstudie naar wat er in de wetenschappelijke literatuur bekend is over sociale participatie van mensen met afasie (1960-2005), (2) een studie naar meetinstrumenten die geschikt zijn om sociale participatie bij mensen met afasie in kaart te brengen, (3) een psychometrische studie met betrekking tot de Community Integration Questionnaire, aangepast voor mensen met afasie, (4) een kwalitatieve studie om inzicht te krijgen in hoe mensen met afasie zelf hun sociale participatie ervaren en welke factoren zij als bevorderend dan wel belemmerend ervaren, (5) een kwantitatieve studie om de sociale participatie van mensen met afasie in kaart te brengen en zicht te krijgen op de factoren die hieraan gerelateerd zijn.

In het eerste hoofdstuk wordt de achtergrond van dit proefschrift geschetst: afasie als gevolg van een beroerte wordt nader omschreven binnen de acute fase, de revalidatie fase en de chronische fase. Dit proefschrift richt zich op de sociale participatie van mensen met afasie in de chronische fase. Aan het einde van dit hoofdstuk worden de doelstellingen en de onderzoeksvragen van dit proefschrift beschreven. Het doel van dit proefschrift is inzicht te verwerven in de sociale participatie van mensen met afasie en de factoren die de sociale participatie van deze mensen belemmeren dan wel bevorderen.

In hoofdstuk twee wordt onze systematische literatuurstudie met betrekking tot de sociale participatie van mensen met afasie beschreven. Deze studie werd uitgevoerd om zicht te krijgen op informatie in de wetenschappelijke literatuur (1960-2005) met betrekking tot sociale participatie van mensen met afasie en om de methodologische kwaliteit van deze studies te onderzoeken. Deze systematische literatuurstudie brengt aan het licht dat de informatie over sociale participatie van mensen met afasie beperkt is. Bovendien is de kwaliteit van de gereviewde studies niet altijd even goed. Vaak wordt er een vaag of geen conceptueel kader gehanteerd waardoor vergelijking tussen de studies moeilijk is. Er wordt vaak gebruik gemaakt van zelfgemaakte vragenlijsten, waardoor vergelijking tussen de verschillende studies eveneens bemoeilijkt wordt. Bovendien is de onderzoeksgroep doorgaans erg klein en wordt er geen gebruik gemaakt van een controlegroep om de specifieke impact van afasie in beeld te brengen. Over het algemeen komt uit de betrokken studies naar voren dat de sociale parti- 
cipatie van mensen met afasie beperkt is, met verlies van sociale relaties, werk en vrije tijdsbesteding.

Hoofdstuk drie presenteert de resultaten van onze studie naar meetinstrumenten die geschikt zijn om sociale participatie bij mensen met afasie in kaart te brengen. Hierbij werden verschillende methoden gehanteerd: de literatuur werd onderzocht en criterialijsten werden opgesteld om de bruikbaarheid van de meetinstrumenten na te gaan. Deze criterialijsten werden opgesteld op basis van literatuur en gesprekken met experts. Vervolgens werden de meetinstrumenten gescoord op hun bruikbaarheid voor mensen met afasie, eerst door drie onderzoekers en vervolgens door zes logopedisten die dagelijks werken met mensen met afasie. Van de twaalf meetinstrumenten die geselecteerd werden op basis van de literatuur, werden er twee meetinstrumenten bruikbaar bevonden. De Community Integration Questionnaire werd beoordeeld als meest bruikbaar om de sociale participatie van mensen met afasie in kaart te brengen.

Op basis van de bevindingen uit hoofdstuk drie werd de Community Integration Questionnaire enigszins aangepast voor gebruik bij mensen met afasie. Vervolgens werden de psychometrische eigenschappen van de aangepaste versie onderzocht aan de hand van een cross-sectionele studie bij 150 mensen. De hanteerbaarheid, de interne consistentie, de factor-analyse en de convergente validiteit werden onderzocht. De test-hertest betrouwbaarheid werd nagegaan door 20 mensen met verschillende ernst van afasie (minimaal tot ernstig) tweemaal te testen door twee verschillende interviewers, binnen een periode van twee weken. Dit wordt besproken in hoofdstuk 4. Uit de resultaten van dit onderzoek komt naar voor dat de aangepaste versie van de Community Integration Questionnaire een valide en betrouwbaar meetinstrument is voor gebruik bij mensen met afasie.

Om zicht te krijgen op hoe mensen met afasie zelf hun sociale participatie ervaren en om de factoren die zij als belemmerend dan wel bevorderend ervaren in hun sociale participatie in beeld te brengen, deden wij een kwalitatieve studie. Deze studie wordt in hoofdstuk vijf beschreven en maakt duidelijk dat mensen met afasie het aantal en de aard van de sociale activiteiten niet zo belangrijk vinden als de ervaren betrokkenheid in de sociale activiteiten. Mensen met afasie voelen zich vaak geïsoleerd. Ze ervaren zichzelf als een last voor anderen en zouden het liefst op een gewone manier kunnen functioneren. Het is voor hen vaak moeilijk om informatie uit gesprekken te halen, maar ze willen wel graag op de hoogte zijn van wat er besproken wordt. Vaak zijn ze niet in staat weer te gaan werken, maar ze willen wel een actieve bijdrage leveren aan de maatschappij. Mensen met afasie vinden het belangrijk dat ze zich betrokken en gerespecteerd voelen in relatie tot anderen, maar voelen zich vaak gestigmatiseerd. Persoonlijke, sociale en omgevingsfactoren die hun niveau van betrokkenheid in de sociale activiteiten kunnen belemmeren dan wel bevorderen, worden gerapporteerd. Een gemotiveerd persoon die samenleeft met een stimulerende partner in een rustige toegankelijke omgeving met bereidwillige mensen in de buurt, die kennis en vaardigheden hebben om zich aan te passen aan de communicatieve mogelijkheden van de persoon met afasie, heeft een betere kans om zich geëngageerd te voelen in zijn sociale participatie.

Hoofdstuk zes presenteert het centrale deel van dit proefschrift: een kwantitatieve studie bij 150 mensen om de sociale participatie van mensen met afasie en daaraan gerelateerde factoren inzichtelijk te maken. Uit deze studie komt naar voren dat er 
veel variatie bestaat in de sociale participatie van mensen met afasie, waarbij sommige mensen nauwelijks hun huis verlaten en andere mensen een actief sociaal leven leiden. De sociale participatie is echter bij alle mensen met afasie verminderd. Zowel het huishoudelijke leven, het sociale leven als het productieve leven is beperkt: $62 \%$ van de deelnemers is met pensioen of werkt niet en doet geen vrijwilligerswerk. Afasie heeft een unieke invloed op de sociale participatie, naast andere factoren zoals het uitvoeren van activiteiten in het alledaagse leven, geslacht en leeftijd. Jonge vrouwen met een minimale afasie en een goede functionaliteit hebben meer kans op een gewenst niveau van sociaal participeren.

Hoofdstuk zeven beschrijft een aantal strategieën en technieken die zinvol kunnen zijn bij het betrekkenen van mensen met afasie in onderzoek. Dit zijn het gebruik van voorgestructureerde dagboeken, het gebruik van diepte-interviews met aandacht voor de non-verbale communicatie, het gebruik van bestaande meetinstrumenten aangepast voor mensen met afasie door:

- het gebruik van pictogrammen,

- het plaatsen van 1 vraag per pagina,

- het accentueren van de sleutelwoorden in de vraag,

- het gebruik van de letterstijl Verdana en lettergrootte 14,

- het visualiseren van de antwoordmogelijkheden in woorden en beelden,

- het reduceren van de lengte van de vraag en

- het vermijden van ontkenningen in de vraag.

Deze inzichten werden verworven door onze ervaring tijdens het doen van onderzoek in deze populatie. Het blijkt goed mogelijk om onderzoek te doen in deze groep. Mensen met afasie worden vaak uitgesloten van onderzoek omwille van hun communicatieve beperkingen. Door de beschreven technieken en strategieën te gebruiken kan dit voorkomen worden.

In het laatste hoofdstuk, hoofdstuk acht, worden de belangrijkste bevindingen van de studies weergegeven, gevolgd door een discussie van deze bevindingen en een aantal methodologische en conceptuele overwegingen. Het hoofdstuk sluit af met een aantal uitdagingen en aanbevelingen voor zorgverleners, beleidmakers en onderzoekers.

De belangrijkste conclusie is dat mensen met afasie minder sociaal participeren, dat afasie een unieke invloed heeft op sociale participatie en dat mensen met afasie de aard van de activiteiten en het aantal activiteiten minder van belang vinden dan het ervaren niveau van betrokkenheid binnen de sociale participatie. Zij rapporteren persoonlijke (m.n. motivatie, fysieke en psychische conditie en communicatievaardigheden), sociale (m.n. de rol van de mantelzorger en de eigenschappen van de communicatiepartner: bereidheid, vaardigheid en kennis) en omgevingsfactoren (een rustige en toegankelijke omgeving) die hun niveau van betrokkenheid in sociale participatie kunnen bevorderen dan wel belemmeren. Een andere belangrijke conclusie van dit proefschrift is dat onderzoek in deze populatie mogelijk is, mits aangepaste technieken gebruikt worden.

Door de literatuur met betrekking tot de sociale participatie in deze groep systematisch te onderzoeken en door gebruik te maken van kwalitatieve en kwantitatieve onderzoeksmethodes, werd sociale participatie zowel in de breedte als in de diepte 
onderzocht. Op deze manier werden onderbouwde inzichten verworven in de sociale participatie van mensen met afasie.

Op basis van deze inzichten besluit dit proefschrift met een aantal belangrijke uitdagingen voor logopedisten en andere hulpverleners, voor beleidmakers en voor verder onderzoek.

Voor beroepsbeoefenaars werd de uitdaging geformuleerd om de zorg zo in te richten dat de terugkeer naar het leven en de behoeften van mensen met afasie en hun directe omgeving centraal staan in een relatie van wederzijds respect. Participatiegerichte strategieën en instrumenten dienen ontwikkeld te worden om logopedisten te stimuleren een participatiegerichte benadering te hanteren waarbij taal nooit wordt losgekoppeld van de communicatieve context. Dit betekent dat logopedisten hun klinische kijk moeten verruimen met aandacht voor de leefwereld van de persoon en zijn dierbaren binnen de natuurlijke setting. Om dit mogelijk te maken zullen logopedisten naast de rol van therapeut ook de rol van adviseur, coach, facilitator moeten aangaan. Logopedisten zouden verder de uitdaging moeten aangaan om te onderhandelen met beleidsmakers, publieke diensten en gezondheidsinstellingen over het belang van toegankelijke en afasievriendelijke omgevingen binnen de maatschappij.

Beleidsmakers zouden zich moeten engageren om een afasiebewuste maatschappij te creëren waarin hulpmiddelen voor het ondersteunen van communicatie even normaal zijn als rolstoelhellingen. Zij zouden hun verantwoordelijkheid moeten nemen in het bevorderen van toegankelijkheid voor deze populatie in de maatschappij, in publieke en gezondheidsdiensten.

Onderhandelingen met zorgverzekeraars zouden plaats moeten vinden om de langdurige gevolgen van afasie inzichtelijk te maken en de daaraan gekoppelde behoeften aan zorg op maat.

Voor onderzoekers werd de uitdaging geformuleerd om mensen met afasie te betrekken in onderzoek om zo meer zicht te krijgen op leven met afasie. Om dit mogelijk te maken moeten bestaande meetinstrumenten aangepast worden voor mensen met afasie en moeten deze getest worden op hun psychometrische eigenschappen. Het concept participatie zou op basis van onderzoek verder verhelderd moeten worden waardoor vergelijking tussen verschillende studies beter mogelijk wordt. Een andere belangrijke uitdaging voor onderzoekers is het onderzoeken van persoonlijke en omgevingsfactoren met behulp van adequate meetinstrumenten met als doel die factoren inzichtelijk te maken die voor mensen met afasie van belang zijn. 

APPENDIX:

Community Integration

Questionnaire adjusted for people with aphasia 
Gemeenschap Integratie Vragenlijst

\section{Community Integration Questionnaire}

Vertaald en aangepast voor mensen met afasie, 2007

(C) R.J.P. Dalemans

Naam: Deelnemersnummer:

Opleiding: Geslacht:

Burgerlijke staat:

Beroep:

Adres:

Geboortedatum:

Onderzoeksdatum:

Leeftijd:

Werd de vragenlijst ingevuld door een naaste? Ja: Nee:

Relatie van de naaste tot de respondent:

Score:

Score Huishoudelijke Integratie:

Score Sociale Integratie:

Score productiviteit:

Totale score: 
1.

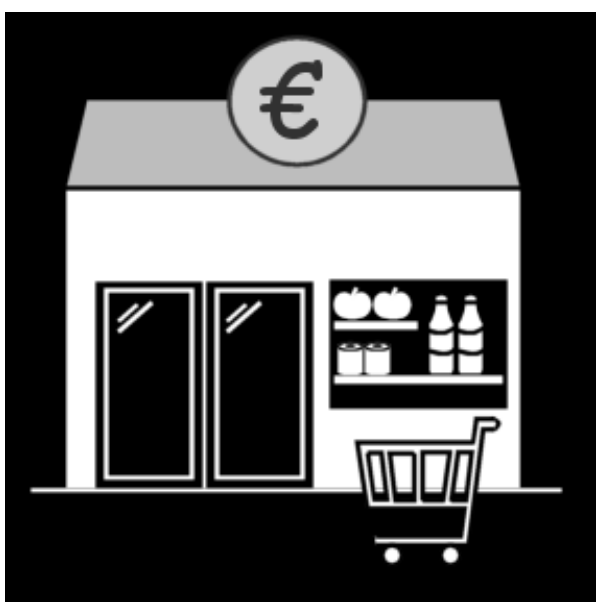

Wie doet gewoonlijk de boodschappen?

\begin{tabular}{|c|c|c|}
\hline$U$ & $\begin{array}{c}\text { u en iemand } \\
\text { anders }\end{array}$ \\
\hline$U$ alleen & Iemand anders \\
\hline
\end{tabular}


APPENDIX

2.

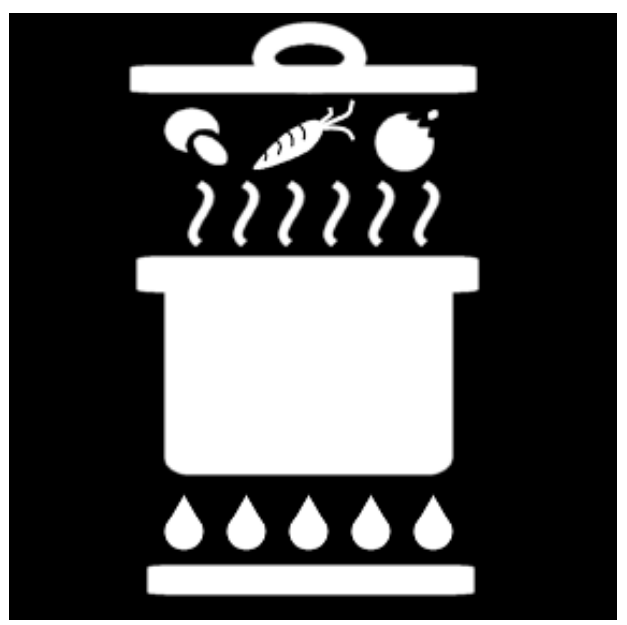

Wie kookt er gewoonlijk?

\begin{tabular}{|c|c|c|}
\hline U alleen & $\begin{array}{c}\text { u en iemand } \\
\text { anders }\end{array}$ \\
\hline 1
\end{tabular}


3.

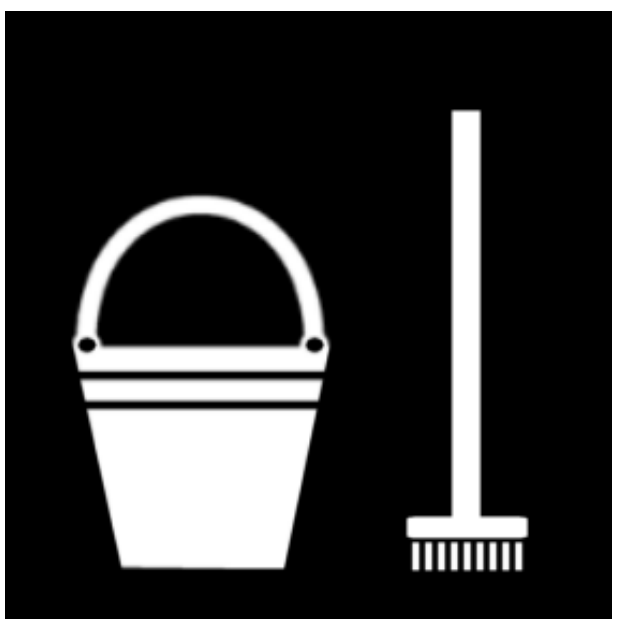

Wie doet gewoonlijk het huishouden?

\begin{tabular}{|c|c|c|}
\hline U alleen & $\begin{array}{c}\text { u en iemand } \\
\text { anders }\end{array}$ \\
\hline
\end{tabular}


APPENDIX

4.

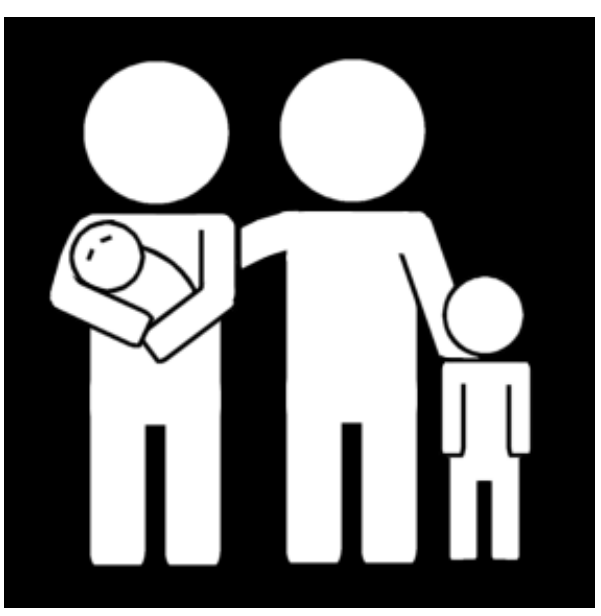

Wie zorgt er gewoonlijk voor de kinderen?

\begin{tabular}{|c|c|c|c|}
\hline$U$ alleen & $\begin{array}{c}\text { u en } \\
\text { iemand } \\
\text { anders }\end{array}$ & $\begin{array}{c}\text { Iemand } \\
\text { anders }\end{array}$ & $\begin{array}{c}\text { Niet van } \\
\text { toepassing/ } \\
\text { In huis } \\
\text { geen } \\
\text { kinderen } \\
\text { onder } 17 \\
\text { jaar }\end{array}$ \\
& \\
&
\end{tabular}


5.

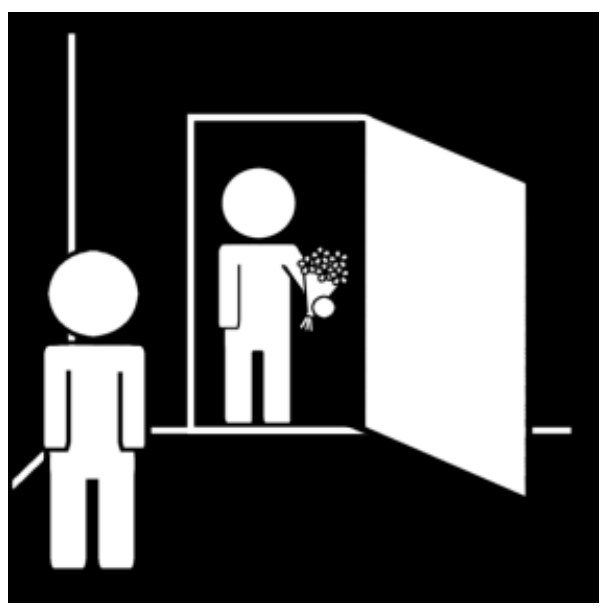

Wie zorgt er gewoonlijk voor de sociale contacten?

\begin{tabular}{|c|c|c|}
\hline & \\
\hline U alleen & $\begin{array}{c}\text { u en iemand } \\
\text { anders }\end{array}$ & Iemand anders \\
\hline
\end{tabular}


APPENDIX

6.

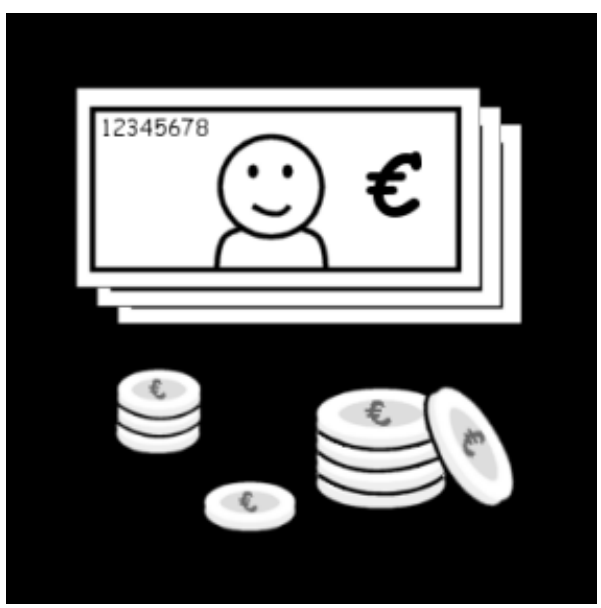

Wie zorgt er gewoonlijk voor de persoonlijke financiën?

\begin{tabular}{|c|c|c|}
\hline & $\begin{array}{c}\text { u en iemand } \\
\text { anders }\end{array}$ \\
\hline U alleen & Iemand anders \\
\hline
\end{tabular}


7.

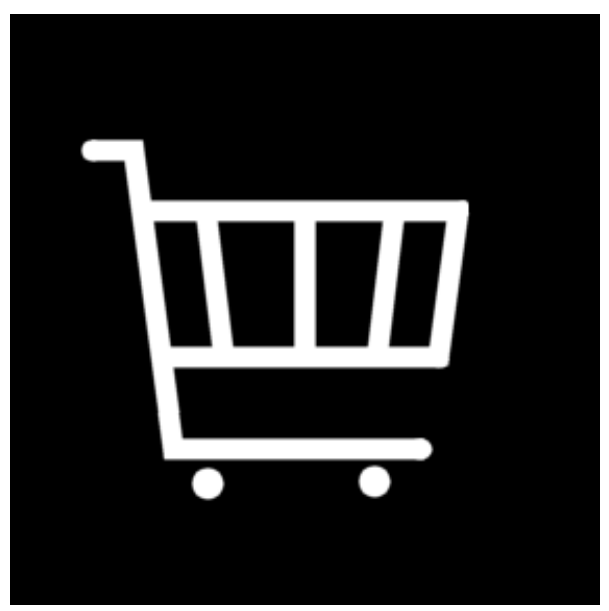

Hoe vaak per maand gaat u winkelen?

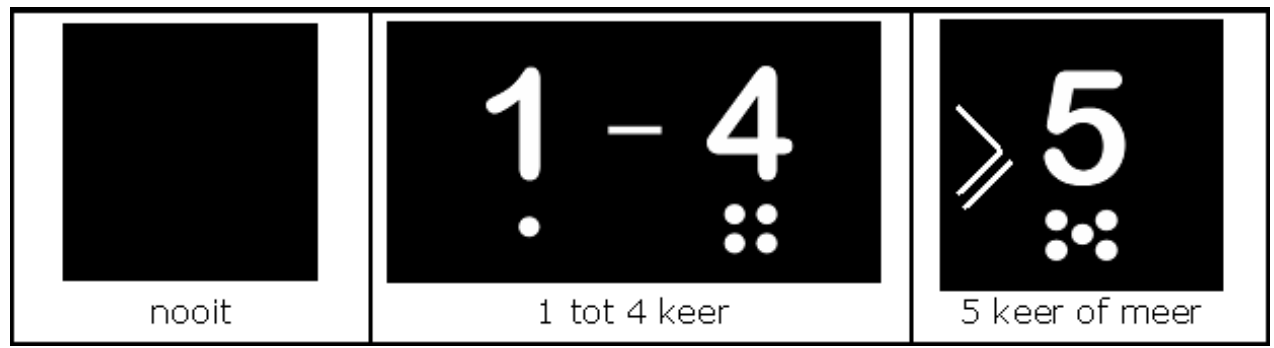


APPENDIX

8.
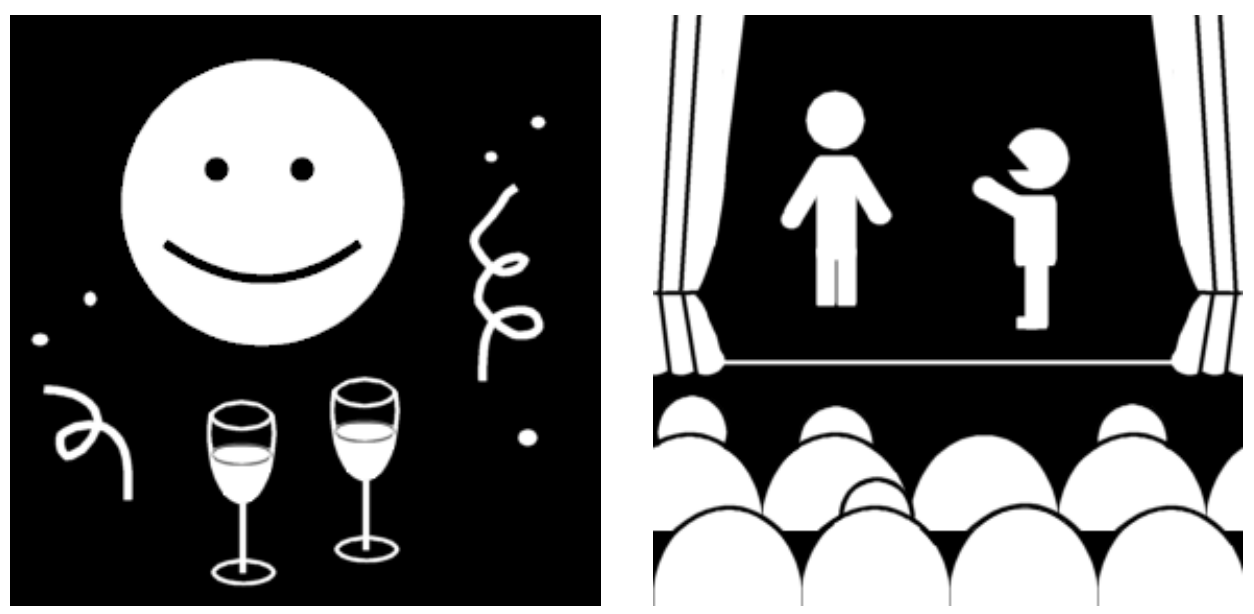

Hoe vaak per maand neemt $u$ deel aan vrije tijd activiteiten?

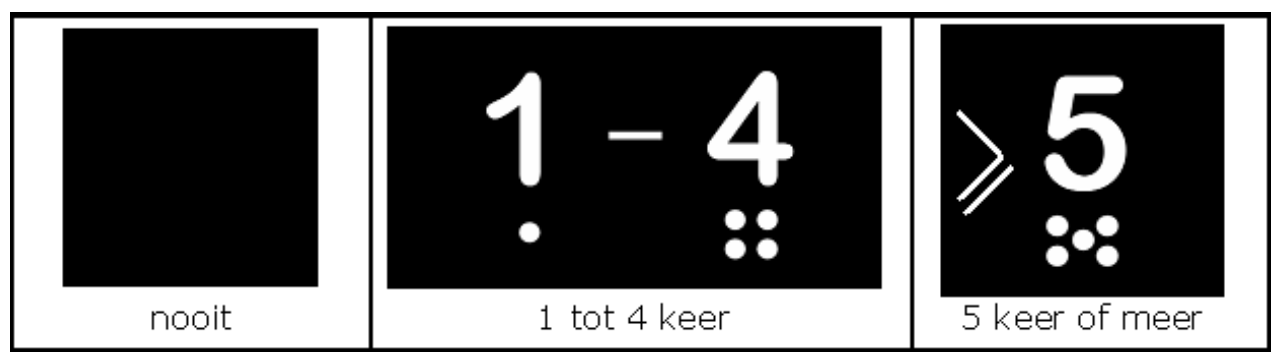


9.

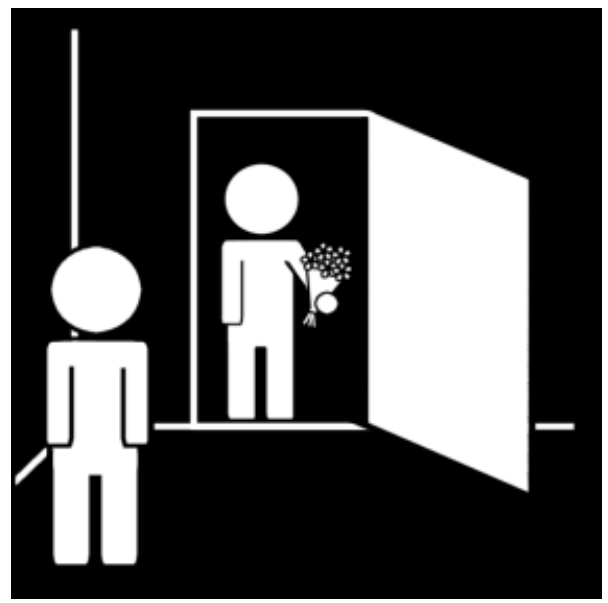

Hoe vaak per maand bezoekt u vrienden of familie?

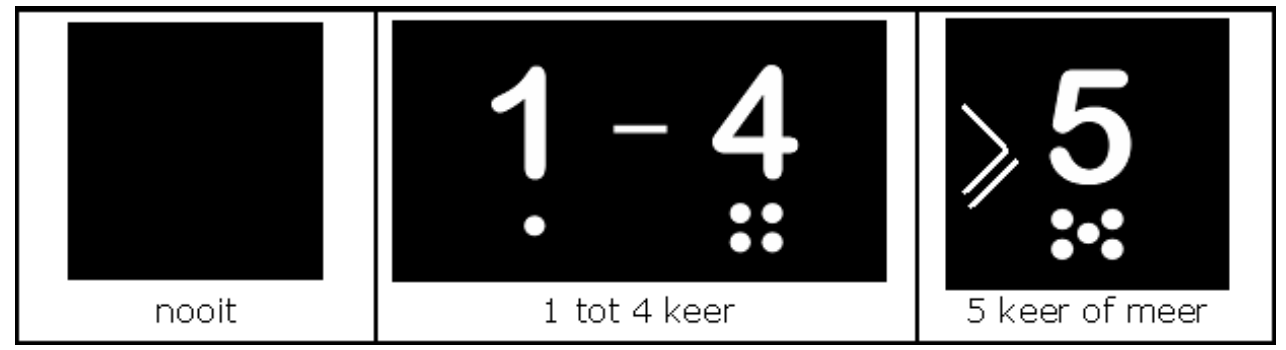


10.
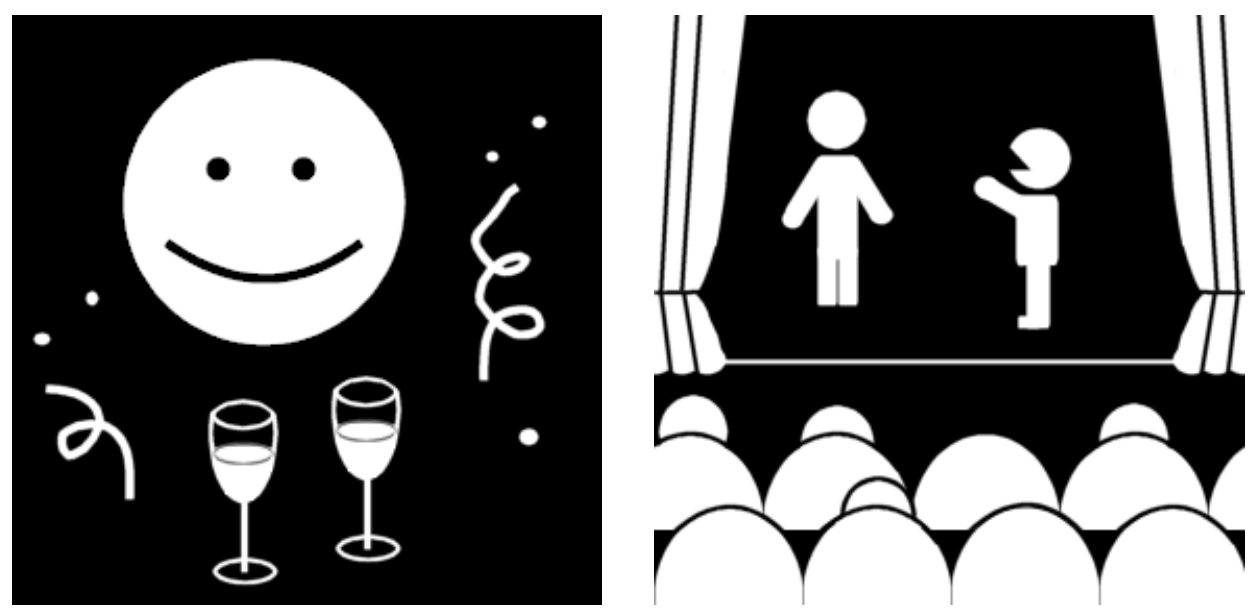

Doet $u$ vrije tijd activiteiten alleen of met anderen?

\begin{tabular}{|l|l|l|l|l|}
\hline Meestal & $\begin{array}{l}\text { Meestal met } \\
\text { vrienden } \\
\text { die een } \\
\text { hersenletsel } \\
\text { hebben }\end{array}$ & $\begin{array}{l}\text { Meestal met } \\
\text { familieleden }\end{array}$ & $\begin{array}{l}\text { Meestal met } \\
\text { vrienden } \\
\text { zonder } \\
\text { hersenletsel }\end{array}$ & $\begin{array}{l}\text { In } \\
\text { combinatie } \\
\text { met } \\
\text { vrienden } \\
\text { en } \\
\text { familie }\end{array}$ \\
\hline
\end{tabular}


11.

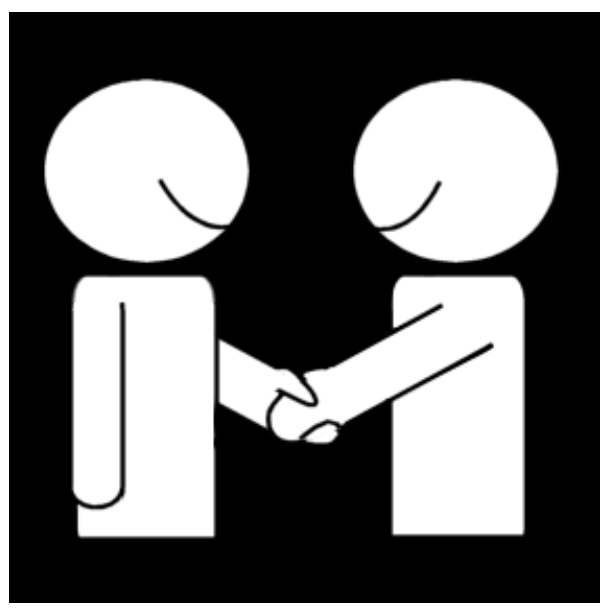

Heeft $u$ een goede vriend die $u$ in vertrouwen neemt?

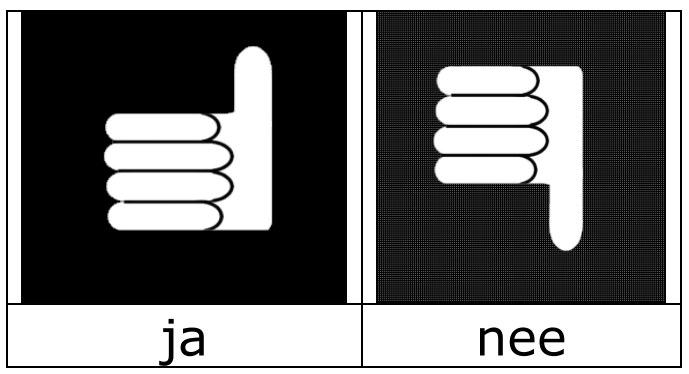




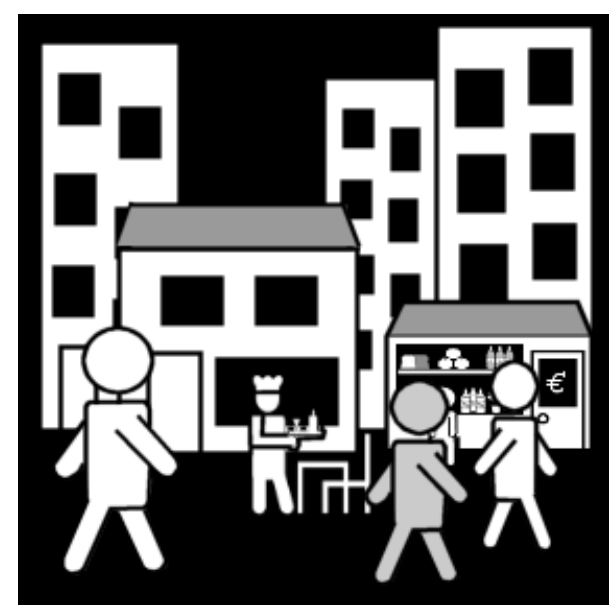

Hoe vaak gaat u uw huis uit?

\begin{tabular}{|c|c|c|}
\hline \begin{tabular}{|c|c|}
\hline Zelden of \\
nooit
\end{tabular} & Bijna iedere & Bijna iedere \\
\hline week & dag \\
\hline
\end{tabular}


13.
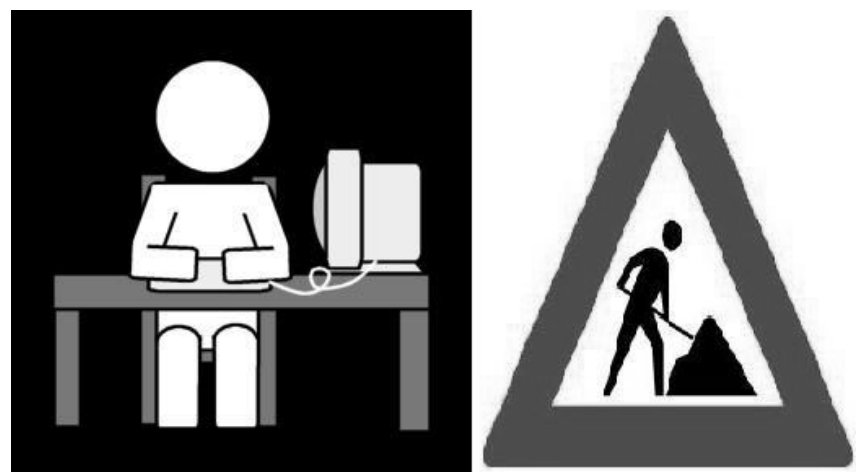

\section{Wat beschrijft het best uw huidige werksituatie?}

\begin{tabular}{|c|c|c|c|c|}
\hline & & $<20$ & $>20$ & \\
\hline $\begin{array}{c}\text { Geen werk, niet op } \\
\text { zoek }\end{array}$ & $\begin{array}{l}\text { Geen werk, maar } \\
\text { actief op zoek }\end{array}$ & $\begin{array}{l}\text { Deeltijd } \\
\text { (minder } \\
\text { dan } 20 \\
\text { u/week) }\end{array}$ & $\begin{array}{c}\text { voltijd } \\
\text { (meer } \\
\text { dan } 20 \\
\text { u/week) }\end{array}$ & $\begin{array}{c}\text { Niet van } \\
\text { toepassing, } \\
\text { met pension } \\
\text { of VUT }\end{array}$ \\
\hline
\end{tabular}


14.

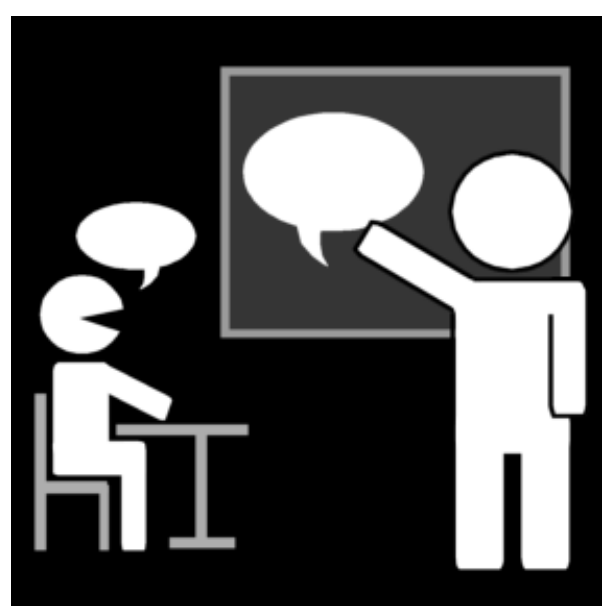

Wat beschrijft het best uw huidige opleidingssituatie?

\begin{tabular}{|c|c|c|}
\hline & $<20$ & $>20$ \\
\hline $\begin{array}{l}\text { Geen school } \\
\text { of opleiding }\end{array}$ & $\begin{array}{c}\text { Deeltijd } \\
\text { (minder dan } \\
\text { of gelijk aan } \\
20 \text { u/week) }\end{array}$ & $\begin{array}{c}\text { Voltijd (meer } \\
\text { dan 20 } \\
\text { u/week) }\end{array}$ \\
\hline
\end{tabular}


15.

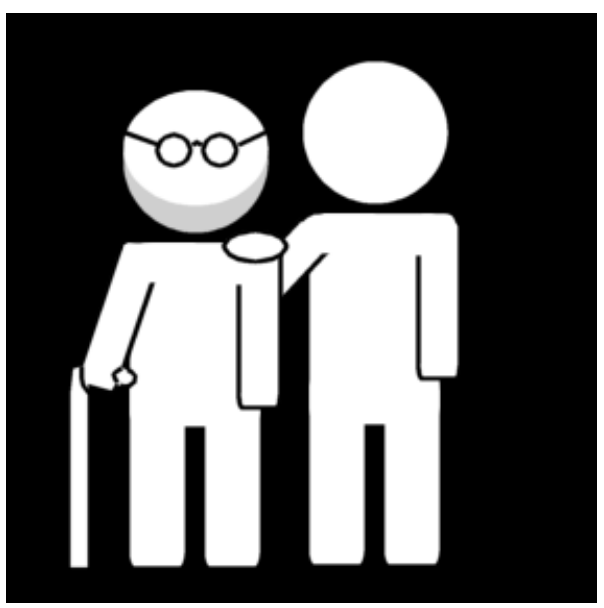

Hoe vaak heeft $u$ de afgelopen maand deelgenomen aan vrijwilligerswerk?

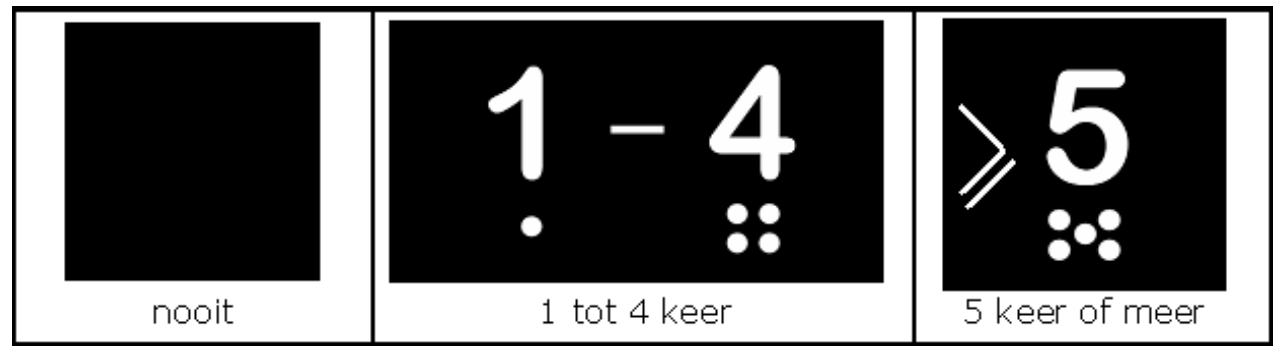

(C) Nederlandse vertaling en aanpassing voor mensen met afasie door Ruth J.P Dalemans 



\section{Dankwoord}

How long before I get in?

Before it starts, before I begin?

How long before you decide?

Before I know what it feels like?

Where to, where do I go?

If you never try, then you'll never know.

How long do I have to climb,

Up on the side of this mountain of mine?

Look up, I look up at night,

Planets are moving at the speed of light.

Climb up, up in the trees,

every chance that you get,

is a chance you seize.

Uit: "Speed Of Sound" (Coldplay, X\&Y album 2005) 
Laat ik beginnen bij het begin... op de eerste plaats wil ik mijn ouders bedanken, zij hebben mij immers mijn leven geschonken. Een warm stimulerend nest heeft mij gemakt tot wie ik nu ben. lemand die voortdurend wil leren en nieuwe uitdagingen wil aangaan. Vele mensen op mijn levenspad hebben hun steentje bijgedragen om tot de beslissing te komen te promoveren. Mijn docenten aan de opleiding logopedie in Antwerpen die mij de passie voor logopedie hebben bijgebracht. Renee Reijnders, mijn stagebeleidster, die mij op een motiverende manier vertrouwend op mijn mogelijkheden, gecoacht heeft in mijn omgang met en begeleiding van mensen met afasie. Daar is mijn nieuwsgierigheid voor deze complexe problematiek aangewakkerd, een vlammetje dat nooit meer gedoofd is. Tijdens mijn studie aan de universiteit in Leuven heeft Prof. Erik Manders mij de passie voor onderzoek bijgebracht door zijn enthousiaste begeleiding tijdens het schrijven van mijn master thesis. Deze passie voor onderzoek is alleen maar sterker geworden tijdens mijn carrière binnen de Hogeschool Zuyd. Deze omgeving biedt voor zijn medewerkers zoveel kansen om zich persoonlijk te ontwikkelen. Kansen die je wel zelf moet willen grijpen. Ik wil Johan Lambert, voormalig directeur van de opleiding Logopedie bedanken om mij aan te sporen te solliciteren voor een positie binnen de kenniskring Autonomie en Participatie. Binnen deze onderzoeksomgeving werd mij door Prof. Luc de Witte de kans geboden aan een promotietraject te beginnen. Bedankt Luc dat je vertrouwde in mijn mogelijkheden om zo'n traject aan te gaan. Bedankt Trui ten Kampe, toenmalig directeur van de opleiding Logopedie dat jij vond dat ik deze kans met twee handen moest grijpen en dat je bovendien mee tijd voor mij creëerde om deze kans waar te maken. Bedankt Sandra Beurskens en Peter Hilderink dat jij de voortzetting van dit traject hebt ondersteunt sinds de dag dat je de vaandel van Luc c.q. Trui hebt overgenomen. Ook bedankt voor jullie aanmoedigende gesprek op het moment dat ik het even zwaar had. Het heeft even geduurd vooraleer ik de stap durfde te zetten om aan dit traject te beginnen, maar in deze wil ik vooral mijn man Bart Paumen bedanken dat hij mij ondersteunde en aanmoedigde om deze uitdaging aan te gaan. De stap was gezet, een begin van een avontuurlijke route op weg naar zelfstandig onderzoek leren doen, maar ook een route waarin ik heel veel lieve en inspirerende mensen heb mogen ontmoeten. Bedankt Yolande Keulers voor al de afspraken die je voor mij geregeld hebt, bedankt Nancy Vrouenraets voor het aanleveren van geadresseerde briefomslagen, bedankt Stefanie Cornips voor het verdelen van de bedankbrieven aan de deelnemers, bedankt Hub Reijders voor het aanpassen van mijn docentenrooster aan mijn beperkte beschikbaarheid. Bedankt Annette Graat, mijn niet te missen maatje binnen het studielandschap, je bent met zoveel enthousiasme voor mij aan de slag gegaan om mij te ondersteunen in mijn zoektocht naar geschikte literatuur, ook de andere mensen binnen het studielandschap wil ik in deze bedanken. Ook Jeroen ten Have voor zijn geweldige uiteenzetting over het gebruik van Endnote, een tool die mij heel wat werk bespaart heeft bij het maken van mijn referenties. Als ik weer eens een of ander probleem had bij het formatteren van mijn literatuurlijst, kon ik op de gekste tijden bij jou terecht. Bedankt Jessie Lemmens dat je samen met mij en Luc de duizenden titels hebt gescoord voor de twee reviews die we hebben uitgevoerd. Bedankt Tineke Schoot, Ramon Daniels, Suzy Braun en Jessie Lemmens voor de gezellige aio-soep, het waren er niet zoveel, maar altijd inspirerend! Ook binnen de hogeschool werd tijdens mijn promotietraject de promovendiklas opgericht. Een goed initiatief waarin mensen met 
gelijkaardige vragen, worstelingen, uitdagingen met elkaar in overleg kunnen treden en van elkaars ervaring kunnen leren. Bedankt Jos Willems om altijd aanwezig te willen zijn met je welgemeende interesse in het wel en wee van ons allemaal! Bedankt aan alle leden van de kenniskring autonomie en participatie van mensen met een chronische aandoening voor jullie zinvolle feedback op onderzoeksdesigns en jullie belangstellende vragen over de voortgang. Bedankt Petra Franssen dat je samen met mij de kwalitatieve studie hebt uitgevoerd, het hebben van een inhoudelijke gesprekspartner in deze aangrijpende materie was zeker nodig. Bedankt dat je deze uitdaging met mij bent willen aangaan. Ook bedankt oma Tita dat je van op een afstand onze worsteling met de data hebt mee gevolgd en af en toe vanuit een frisse blik met nieuwe inzichten kwam terwijl jij voor mij de strijk deed waar ik op dat moment zelf niet aan toe kwam! Bedankt lieve ouders en schoonouders voor de opvang van onze kinderen en ondersteuning in het huishouden. Wat zouden we toch zonder jullie moeten beginnen! Bedankt Hannah Biener, Kristina Boshof, Laura Hirtz, Daniela Hermann, Bregje van der Heijden en Desiree voor jullie bijdragen aan de datacollectie van het kwantitatief onderzoek. Jullie zijn allemaal heel gedreven studenten en hebben mij goed geholpen! Bedankt Sofie Ubben, Marga Hofman, Carine Crijns, Marie-Jeanne te Meij en al de andere logopedisten binnen het werkveld die mij met jullie professionele kijk hebben geholpen bij het vorm geven van de lay-out van de meetinstrumenten en bij het vinden van geschikte kandidaten voor mijn onderzoek. Bedankt Sander voor je oproep binnen de opleiding ergotherapie om dataverzamelaars te vinden voor mijn kwantitatief onderzoek! Bedankt Rob de Ruyter voor je enthousiasme waarmee je meegezocht hebt naar geschikte kandidaten voor mijn onderzoek en voor je bijdrage bij de dataverzameling voor de test-hertest van de CIQ. Bedankt aan alle mantelzorgers en mensen met afasie die hebben willen deelnemen aan dit onderzoek, dankzij jullie bijdragen is dit onderzoek mogelijk geworden. De openheid waarmee jullie mij een blik hebben gegund op jullie persoonlijke leven is echt bijzonder. Ik waardeer dat enorm! Bijzondere dank gaat ook uit naar Mat Brans die mij van in het begin van mijn promotietraject heeft aangemoedigd, meegedacht en actief heeft gezocht naar geschikte kandidaten. Jouw bereidheid om mee te werken aan dit project was bijzonder groot, bedankt dat jij vanaf het begin geloofd hebt in dit traject! Bedankt Marieke Spreeuwenberg voor je snelle ondersteuning in mijn laatste statistische analyses, het gemak waarmee jij kan goochelen met getallen is bewonderenswaardig! Ook Emily Steel wil ik van harte bedanken voor je gedegen hulp bij het vinden van de juiste woorden en juiste zinstructuren in het Engels. Bedankt Jet Lancee voor je voortdurende interesse in mijn promotietraject en je bemoedigende woorden. Bedankt Thomas Gunther voor je daadkracht op het gebied van onderzoek, je vormt voor mij een voorbeeld op het gebied van onderzoek doen binnen logopedie, je enthousiasme werkt aanstekelijk. Ook je tips en bereidwilligheid tot hulp voor mijn statistische analyses verdient een dank je wel. Lieve Suzy, lieve Michelle, lieve Jessie, jullie zijn mijn drie ‘Charlie`s Angles`. Mijn drie ‘partners in crime'. Jullie maakten dit traject naast leerrijk ook gezellig! Samen praten over onderzoek, samen onderzoeksdagen bijwonen, samen presenteren op congressen, samen artikels schrijven, het schept een bijzondere band! Dank je wel! Bedankt Sandra en Luc dat jullie nu ook na mijn promotietraject mij de ruimte geven om nieuwe uitdagende onderzoeksprojecten vorm te geven. 
Beste Luc, heel erg bedankt voor je geloof in mij, voor je steun, je wijze woorden, je scherpe inzichten, je inspirerende discussies, je uitdagende uitspraken, je aanwezigheid voor mij ondanks je overvolle agenda. Bedankt ook voor de gezellige momenten samen met je lieve vrouw en toffe kinderen. Beste Wim, bedankt voor je frisse kijk, je concrete feedback, je snelle respons. Dear Derick, thank you for your encouraging words, your remarks and your belief in me and this project. Lieve slimme mannen, bedankt voor jullie wijsheid en jullie begeleiding. Ik had het niet anders kunnen wensen!

Mijn allerliefste Bart, mijn rots in de branding, mijn gaspedaal en rempedaal tegelijkertijd, bedankt voor je onvoorwaardelijke steun. Dankzij jou kon ik na een stresvolle dag steeds toch tot rust komen in mijn veilige thuishaven.

Mijn allerliefste kindjes, jullie zijn het haast niet anders gewoon dan een mama te hebben die werkt, bedankt dat jullie mij elke dag op nieuw terugbrengen naar de alledaagse realiteit, naar de kleine dingen die het leven de moeite waard maken. Jullie zijn voor eeuwig in mijn hart gesloten!

Ook voor al die anderen die meeleefden en hebben meegewerkt, maar niet zijn genoemd in dit dankwoord, dank je wel! 


\section{Curriculum Vitae}

Ruth Dalemans was born on July, the 3th , 1974 in Maaseik, Belgium. She finished secondary school at the 'Vrije Humaniora St-Ursula' in Maaseik. After secondary school she moved to Antwerp where she studied Speech and language pathology, graduating with a Bachelor degree 'Magna Cum Laude` at the 'Katholieke Vlaamse Hogeschool ' in 1995. Afterwards, she went to Leuven. There, she studied at the Faculty of Medicine, she graduated in 1998 with a master of Science 'Cum Laude` in Speech and Language Pathology and Audiology at the 'Katholieke Universiteit Leuven'. She wrote her thesis: 'Language changes in people with Alzheimer disease: a longitudinal study'. Beside her study, she worked part-time as speech language therapist in a practice and in the hospital Mc Nol in Maaseik. After she graduated in Leuven, she worked shortly as a preventive speech and language therapist in Hasselt at LDSST. In September 1998 she married to Bart Paumen, and their sons were born in 2001 and 2004. Since December 1998 she started working as a lecturer at the Zuyd University, Heerlen, in the department of Speech and Language Pathology. She was mostly involved with supervising bachelor projects, co-ordination tasks and giving lecturers on aphasia, methodology, participation. In December 1999, she received her teaching endorsement for higher education in Tilburg. Since 2002 she has been a member of the Centre of Expertise on Autonomy and Participation. In 2005 she started with her PH.D study. In 2008 and 2009, she participated in the Project Measurement Instruments for people with Neurological Communication Impairments, implementing the use of measurement instruments in practices, nursing homes and rehabilitation centre's, and giving a pilto-study to speech and language therapists. She is currently working as lecturer and as member of the core team of the department Speech and Language Pathology, member of the SRO. Further, she is a member of the Research Centre on Autonomy and Participation and member of the Research Centre Technology in Care, where she is participating in a project application in cooperation with Sensis. 